UNIVERSIDADE DE SÃO PAULO

INSTITUTO DE ASTRONOMIA, GEOFÍSICA E CIÊNCIAS ATMOSFÉRICAS

GYRLENE APARECIDA MENDES DA SILVA

Evolução dos eventos EI Niños em fases distintas da Oscilação Decadal do Pacífico: impactos no Jato de Baixos Níveis a Leste dos Andes e nos ciclones extratropicais da América do Sul

São Paulo 
GYRLENE APARECIDA MENDES DA SILVA

Evolução dos eventos El Niños em fases distintas da Oscilação Decadal do Pacífico: impactos no Jato de Baixos Níveis a Leste dos Andes e nos ciclones extratropicais da América do Sul

Tese apresentada ao Instituto de Astronomia, Geofísica e Ciências Atmosféricas da Universidade de São Paulo para a obtenção do título de Doutora em Ciências.

Programa: Meteorologia

Orientador: Prof. Dr. Tércio Ambrizzi

São Paulo 


\section{ERRATA}

\section{Página $4,1^{\circ}$ parágrafo}

A referência para Kousky e Kayano (1994) é "KOUSKY, V.E., M. T. KAYANO, 1994: Principal modes of outgoing longwave radiation and $250-\mathrm{mb}$ circulation for the South American sector. $J$. Climate, 7, 1131-1143."

\section{Página $12,2^{\circ}$ parágrafo}

Na sentença "Nos anos de LN...", substituí-se a palavra "inversão" por "enfraquecimento".

\section{Página 21, Tabela 2, linha 1 coluna 2}

O domínio correto da forçante é $20^{\circ} \mathrm{S}-20^{\circ} \mathrm{N} ; 120^{\circ} \mathrm{E}-75^{\circ} \mathrm{W}$ e as aTSMs foram calculadas para os eventos EN de 1950-1999.

\section{Página $32,1^{\circ}$ parágrafo}

Substitui-se Servain (1991) por Servain (1998).

\section{Páginas iii e 55, Figura 16}

A legenda correta é "Figura 16 - Idem a Figura 14, mas para o vento em 850 hPa e PNMM. Isolinhas a cada $1 \mathrm{hPa}$ começando por $0.5 \mathrm{hPa}$ e vetor vento em $\mathrm{m} . \mathrm{s}^{-1}$."

\section{Página $60,3^{\circ}$ parágrafo}

Substitui-se a sentença "No Capítulo 2,..." por "No Capítulo $3, \ldots$...

Página 62, último parágrafo

Substitui-se Kayano (2005) por Andreoli e Kayano (2005).

\section{Página 65}

Na Figura 20a, a leste do Nordeste brasileiro há predomínio de anomalias de $\psi(200 \mathrm{hPa})>0$

Na Figura 20b, sobre os trópicos há predomínio de anomalias $\psi(200 \mathrm{hPa})>0$ e $\omega(500 \mathrm{hPa})>0$

\section{Página $67,6^{\circ}$ referência}

A referência correta é "BEU, C. M. L; AMBRIZZI, T. Variabilidade Interanual e Intersazonal da Freqüência de Ciclones no Hemisfério Sul. Rev. Bras. Meteor., v. 21, n. 1, p. 44-55, 2005”.

\section{Página $67,9^{\circ}$ referência}

Substitui-se a referência "BOVILLE, B.; GENT, P. The NCAR Climate System Model, Version One. Journal of

Climate, v. 11, p.1115-1130, 1998" por "BOVILLE, B. A.; RASCH, P. J.; HACK, J. J.; McCAA J. R. Representation of clouds and precipitation processes in the Community Atmosphere Model version 3 (CAM3). J. Climate, v. 19, p. 2184-2198, 2006". 
Aos que não desistem diante dos obstáculos da vida, pois conseguem transformá-los em constante aprendizado. 


\section{AGRADECIMENTOS}

A Deus, por estar sempre me guiando!

Agradeço apoio dos meus pais e familiares, em especial a minha amada Mãe Zaira por seus ensinamentos. Ao Luciano Prado por sua dedicação, companheirismo e paciência e aos seus pais por todo carinho recebido.

Aos conselhos, orientações e demonstração de confiança do professor Tércio. A todos os professores do IAG que fizeram parte do meu processo de formação acadêmica: Adilson Gandu, Alice Grimm, Augusto Pereira, Leila Carvalho, Maria Assunção, Pedro Dias, Ricardo de Camargo, Rosmeri Rocha, Tércio Ambrizzi, Terezinha Xavier.

A todos os membros do Grupo de Estudos Climáticos (GrEC) e do Grupo de Estudos em Multi-escalas (GEM) pela dedicação nas reuniões climáticas, e ao Laboratório Master pelo uso dos computadores quando foi necessário.

Não acredito em coincidências nesta vida, penso que tudo tem um motivo pra ser, estar, acontecer. Você Anita minha irmã é um desses motivos, sou eternamente grata por você e sua família fazerem parte da minha vida.

Meus sinceros agradecimentos a todos que de alguma forma estiveram presentes durante meu período na pós-graduação do IAG: Alexandre Auê, Alexandre Pezza, Alexsandro Jacob, Aline Anderson, Amauri Dantas, América Murguía, Ana Duran, Ana Elizabethe, Andréa Taschetto, Augusto Barbosa, Aurenice Castro, Carlos Raupp, Cássia Beu, Cinthia Avellar, Clara Iwabe, Cléa Roger, Edna Pinto, Eliane Larroza, Enver Ramirez, Fabiana Weykamp, Gabriel Pontes, Gabriela Muller, Graziele Omena, Guilherme Martins, Helber Gomes, Helena Balbino, Jezabel Fernandes, Joana Deconto, João Rafael, José Felipe, Kleber Ataíde, Leuda Oliver, Luis Gimeno, Marcelo Pinheiro, Marcelo Schneidder, Márcio Gledson, Maria Cristina, Mario Quadro, Megan Bella, Meiry Sakamoto, Michel Muza, Michelle Reboita, Mozar Salvador, Nilton Manuel, Olívia Nunes, Raquel Nieto, Raquel Silva, Renata Tedeshi, Ricardo Hallak, Rogério Bruno, Taciana Toledo, Thaís Scherrer, Santiago Cuadra, Sidney Abreu, Silvia Zilli, Simone Ferraz.

Aos que compõem as secretarias: Bethe, Ana, Sônia, Rose, Marcel, André, Virgínia; e aos analistas de informática, Luciana, Samuel, Sebastião e Fagner... obrigada por todo apoio. Às meninas "do café", Cida e Eugênia, obrigada!

Agradeço aos membros da banca por terem aceitado o convite.

Agradeço imensamente ao suporte financeiro da FAPESP e auxílios recebidos da CAPES e CNPQ. 


\section{RESUMO}

GYRLENE, A. M. DA SILVA. Evolução dos eventos El Niños em fases distintas da Oscilação Decadal do Pacífico: impactos no Jato de Baixos Níveis a Leste dos Andes e nos ciclones extratropicais da América do Sul. 2009. 76 f + apêndice. Tese (Doutorado) - Departamento de Ciências Atmosféricas, Universidade de São Paulo.

Neste trabalho foi investigado o impacto da evolução dos eventos El Niño (EN) de acordo com as fases distintas da Oscilação Decadal do Pacífico (positiva, ODP(+) e negativa, ODP(-)) nas mudanças no transporte de umidade sobre o Sudeste da América do Sul (SEAS) durante o verão austral de 1950-1999. A resposta da variabilidade do Jato de Baixos Níveis a leste do Andes (JBN) e de algumas propriedades dos ciclones extratropicais sobre o cone sul do continente as modificações na circulação associadas aos eventos mencionados acima foi analisada. Foi mostrado que existem poucas mudanças significativas no regime de precipitação sobre a América do Sul ao se considerar a influência dos anos neutros do Pacífico Equatorial durante a ODP(+) quando comparado com os anos da ODP(). Entretanto, os eventos $\mathrm{EN}$ da $\mathrm{ODP}(+)$ indicam diferenças no padrão de anômalo de ondas em altos níveis em resposta as diferentes anomalias de Temperatura de Superfície do Mar (TSM) dos oceanos Pacífico e Atlântico Equatorial quando comparado com os eventos da ODP(-). Como conseqüência foram observadas anomalias positivas de precipitação no SEAS associadas à intensificação do fluxo convergente de umidade em baixos níveis oriundo do Atlântico Equatorial e região Amazônica para esta região durante os eventos EN da ODP(+). Todavia, os eventos da ODP(-) apresentaram anomalias positivas de precipitação apenas ao sul do SEAS e negativas ao norte desta como resposta ao movimento descendente e divergência anômala sobre o centro-leste do Brasil seguido de enfraquecimento do fluxo de umidade transportado pelos ventos alísios em direção aos subtrópicos. Os experimentos numéricos com Community Atmosphere Model versão 3.0 serviram para ajudar na interpretação das análises observacionais onde foi sugerido que o fenômeno EN é mais importante para forçar as anomalias climáticas de verão do continente do que o modo de ODP. A maior freqüência de casos de JBN detectados com o critério 1 de Bonner durante anos de EN da ODP(+) em relação a ODP(-) foi proporcional à quantidade de eventos selecionados em cada categoria. Em geral, os casos de JBN anômalo se deslocaram desde a Amazônia até o Sul do Brasil e Nordeste da Argentina, mas foi na ODP(-) que o sistema foi mais intenso apesar de apresentar menor potencial para o transporte de umidade para o SEAS quando comparado com os casos da ODP $(+)$. Através do esquema numérico de Murray e Simmonds foi observado que, coerentemente com a intensificação do fluxo convergente de ar quente e úmido dos trópicos para o SEAS, os eventos EN da $\mathrm{ODP}(+)$ apresentaram ciclones extratropicais mais freqüentes e com pressões centrais mais baixas sobre o extremo Sul do Brasil, Uruguai, Nordeste da Argentina e vizinhanças do Atlântico Sudoeste em comparação com os eventos da ODP(-).

Palavras-chave: El Niño, Oscilação Decadal do Pacífico, fluxo de umidade, América do Sul, Jato de Baixos Níveis a leste dos Andes, ciclones extratropicais 


\section{ABSTRACT}

GYRLENE, A. M. DA SILVA. El Niño events and their evolution in different phases of the Pacific Decadal Oscillation: impacts on the Low Level Jet east of the Andes and extratropical cyclones on the South America. 2009. $76 p+$ appendix. PhD Thesis - Department of Atmospheric Sciences, University of São Paulo.

This work investigates the impact of the El Niño (EN) events and their evolution according to the PDO phases (warm, $\mathrm{PDO}(+)$ and cold, $\mathrm{PDO}(-)$ ) focusing on the moisture transport exchanges from the north to the Southeast of the South America (SESA) during the austral summer period of 1950-1999. The variability of the Low Level Jet east of the Andes (LLJ) and some properties of extratropical cyclones over the southern cone of the continent in response to the modifications in the atmosphere circulation due to above mentioned events is analyzed. It is shown that on the South America continent there are not any significant changes in precipitation distribution during the neutral years in the Equatorial Pacific for $\mathrm{PDO}(+)$ when compared to the years of PDO(-). However, the EN events during $\mathrm{PDO}(+)$ indicate some differences in the anomalous wave pattern at high levels due to the variability of the Sea Surface Temperature (SST) anomalies on the Equatorial Pacific and Atlantic oceans when compared with the events for PDO(-). This implies in positive precipitation anomalies over the SESA which is associated to the enhancement of convergent moisture flux in this region. However, the events for PDO(-) showed positive precipitation anomalies only over the southern part of the SEAS and negative to the north which is associated to the downward motion and anomalous divergence over the centraleastern Brazil. This pattern may have contributed for weakening the moisture flux transported by the trade winds towards the subtropics. Numerical experiments with the Community Atmosphere Model version 3.0 also helped on the interpretation of the observational analysis where was suggested that EN events are more important to force the climate anomalies in the summer season over the continent than the PDO mode. The frequency of LLJ cases detected with the Bonner criterion 1 during the years of EN for PDO(+) is bigger than for PDO(-). The spatial position pattern for both categories of the anomalous LLJ is from the Amazon to Southern Brazil and Northeastern Argentina. During the PDO(-) the jet is more intense, however it seems to transport less moisture towards the SEAS region when compared to the PDO $(+)$ cases. The extratropical cyclones tracked through a numerical scheme showed higher frequency and lower central pressures on the extreme of Southern Brazil, Uruguay, Northeastern Argentina and around the Southwest Atlantic during the EN events of $\mathrm{PDO}(+)$ when compared to the events of $\mathrm{PDO}(-)$. This is in agreement with the largest flux convergence of warm and humid air from the tropics to these areas.

Keywords: El Niño, Pacific Decadal Oscillation, moisture flux, South America, Low Level Jet east of the Andes, extratropical cyclones 




\section{SUMÁRIO}

Lista de Figuras

Lista de Tabelas $\quad$ v

\section{CAPÍTULO 1}

Introdução e Objetivos 1

1.1) Variabilidade da precipitação de verão na América do Sul e as forçantes interanual e interdecadal do oceano Pacífico

1.2) Precipitação de verão sobre o Sudeste da América do Sul (SEAS) e sistemas meteorológicos associados

1.3) Influências dos modos ENOS e ODP na variabilidade do JBN

1.4) Influência dos modos ENOS e ODP na variabilidade dos ciclones extratropicais da América do Sul

1.5) Motivação e Objetivos

\section{CAPÍTULO 2}

Dados e Metodologia

a) Dados $r$

b) Metodologia $\quad 20$

b.1) Estudo observacional e numérico para DJF 20

b.2) Estudo observacional: JBN e propriedade dos ciclones extratropicais 22

2.1) Fluxo de umidade integrado verticalmente e divergente associado $\quad 23$

2.2) Teste de significância estatística (teste T-Student)

2.3) O Modelo de Circulação Geral Atmosférico CAM3 25

2.4) Algoritmo para detecção de ciclones extratropicais $\quad \mathbf{2 8}$

\section{CAPÍTULO 3}

3.1) Circulações de verão sobre a América do Sul durante os anos neutros do Pacífico Equatorial em fases distintas da ODP

3.2) Estudo observacional da evolução dos eventos EN em fases distintas da ODP: impactos no verão austral da América do Sul

\section{CAPÍTULO 4}

Estudo numérico da evolução dos eventos EN em fases distintas da ODP: impactos na circulação de verão da América do Sul

\section{CAPÍTULO 5}

5.1) Estudo observacional da evolução dos eventos EN em fases distintas da ODP: impactos nos casos de JBN durante o verão austral

5.2) Estudo observacional da evolução dos eventos EN em fases distintas da ODP: impactos nas propriedades dos ciclones extratropicais

\section{CAPÍTULO 6}

Conclusões

Sugestões para trabalhos futuros 


\section{Lista de Figuras}

Figura 1 - Médias da precipitação acumulada e do fluxo de umidade integrado verticalmente para (a) DJF e (b) JJA. Fonte: Vera et al. (2006).

Figura 2 - Padrões típicos de verão austral das anomalias de TSM (colorido), PNMM (contorno) e stress do vento (vetores) durante a $\operatorname{ODP}(+)$ e ODP(-). Fonte: Mantua et al. (1997)

Figura 3 - Taxa de precipitação média do CMAP $\left(\mathrm{mm}^{\mathrm{dia}}{ }^{-1}\right)$ durante DJF para o SEAS. Fonte: Berbery e Barros (2002). 9

Figura 4 - Distribuição anual da freqüência ciclogenética para o período de 1979-1988. Fonte: Gan e Rao (1991)......

Figura 5 - Diagrama conceitual dos mecanismos físicos que podem modular a variabilidade espacial e temporal do JBN durante o verão austral de anos de (a) EN e (b) LN. As setas amarelas e pretas representam os ventos alísios e circulação do JBN, respectivamente, ambos mais intensos (setas mais escuras) em (a) do que em (b). As letras $\mathrm{H}$ (seta vermelha) e $\mathrm{L}$ (seta azul) representam altas e baixas pressões em $850 \mathrm{hPa}$. Em (b) a seta pontilhada preta indica fluxo de sul associado a $\mathrm{H}$ e L em $850 \mathrm{hPa}$ sobre médias latitudes. A linha laranja mostra o JST em $200 \mathrm{hPa}$ onde a cor mais escura em (a) indica que o sistema é mais intenso do que em (b). As nuvens representam a região de precipitação associada ao JBN. Fonte: Silva et al. (2009).

Figura 6 - Localização das regiões de análise das circulações atmosféricas sobre a América do Sul. As linhas entre $15^{\circ} \mathrm{S}$ e $40^{\circ} \mathrm{S}$ em azul delimitam o SEAS e entre $30^{\circ} \mathrm{S}-$ $90^{\circ} \mathrm{S}$ e $90^{\circ} \mathrm{W}-30^{\circ} \mathrm{W}$ em verde delimitam a região onde as propriedades dos ciclones extratropicais foram calculadas.

Figura 7 - Composições médias observadas durante anos neutros ocorridos na ODP(+): (a) taxa de precipitação; (b) componente zonalmente assimétrica de $\psi(200 \mathrm{hPa})$; (c) $\omega(500 \mathrm{hPa})$ e (d) fluxo de umidade integrado e divergente associado entre 1000-850 $\mathrm{hPa}$. Contornos a cada $2 \mathrm{~mm} \cdot$ dia $^{-1}, 4 \times 10^{6} \mathrm{~m}^{2} \cdot \mathrm{s}^{-1}$ começando por $2 \times 10^{6}, 2 \mathrm{hPas} \mathrm{s}^{-1}, 3 \mathrm{~g} \cdot \mathrm{m}^{-2} \cdot \mathrm{s}^{-1}$ começando por $1 \mathrm{~g} \cdot \mathrm{m}^{-2} \cdot \mathrm{s}^{-1}$. Valores positivos (negativos) estão em linhas contínuas (pontilhadas/tracejadas). Vetores de fluxo $\left(\mathrm{g} \cdot \mathrm{m}^{-1} \cdot \mathrm{s}^{-1}\right)$ plotados e áreas sombreadas indicam valores estatisticamente significativos ao nível de $90 \%$.

Figura 8 - Diferenças entre as composições médias observadas durante anos neutros ocorridos na $\mathrm{ODP}(+)$ menos os da $\operatorname{ODP}(-)$ : (a) taxa de precipitação; (b) TSM; (c) componente zonalmente assimétrica de $\psi(200 \mathrm{hPa})$; (d) $\omega(500 \mathrm{hPa})$ e (e) fluxo de umidade integrado e divergente associado entre 1000-850 hPa. Contornos a cada 1 $\mathrm{mm} \cdot \mathrm{dia}^{-1}$ começando com $0.5 \mathrm{~mm} \cdot \mathrm{dia}^{-1}, 0.4^{\circ} \mathrm{C}, 4 \times 10^{6} \mathrm{~m} 2 . \mathrm{s}^{-1}$ começando por $2 \times 10^{6} \mathrm{~m}^{2} . \mathrm{s}^{-}$ ${ }^{1}, 2 \mathrm{hPas}^{-1}$ começando por $1 \mathrm{hPas}{ }^{-1}, 0.2 \mathrm{~g} \cdot \mathrm{m}^{-2} \cdot \mathrm{s}^{-1}$. Valores positivos (negativos) estão em linhas contínuas (pontilhadas/tracejadas). Vetores de fluxo $\left(\mathrm{g} \cdot \mathrm{m}^{-2} \cdot \mathrm{s}^{-1}\right)$ plotados e áreas sombreadas indicam valores estatisticamente significativos ao nível de $90 \%$. 
Figura 9 - Composições de anomalias observadas para os eventos EN ocorridos na ODP(+): (a) taxa de precipitação, (b) TSM. Idem para as letras (c) e (d), mas para os eventos ocorridos na ODP(-). Contornos a cada $0.5 \mathrm{~mm} \cdot \mathrm{dia}^{-1}$ começando com $1 \mathrm{~mm} \cdot \mathrm{dia}^{-1}$, $0.4^{\circ} \mathrm{C}$. Valores positivos (negativos) estão em linhas contínuas (pontilhadas). Valores estatisticamente significativos ao nível de $90 \%$ estão sombreados.

Figura 10 - Composições de anomalias observadas para os eventos EN ocorridos na ODP(+): (a) componente zonalmente assimétrica de $\psi(200 \mathrm{hPa}) ;(\mathrm{b}) \omega(500 \mathrm{hPa})$ e (c) fluxo de umidade integrado e divergente associado entre 1000-850 hPa. Idem para as letras (d), (e) e (f), mas para os eventos ocorridos na ODP(-). Contornos a cada $4 \times 10^{6}$ $\mathrm{m}^{2} \cdot \mathrm{s}^{-1}$ começando por $2 \times 10^{6} \mathrm{~m}^{2} \cdot \mathrm{s}^{-1}, 1 \mathrm{hPas}{ }^{-1}, 1 \mathrm{~g} \cdot \mathrm{m}^{-2} \cdot \mathrm{s}^{-1}$. Valores positivos (negativos) estão em linhas contínuas (pontilhadas/tracejadas). Vetores de fluxo $\left(\mathrm{g} \cdot \mathrm{m}^{-2} \cdot \mathrm{s}^{-1}\right.$ ) plotados e áreas sombreadas indicam valores estatisticamente significativos ao nível de $90 \%$.

Figura 11 - Ensemble médio do experimento EN_ODP(+): (a) taxa de precipitação, (b) componente zonalmente assimétrica de $\psi(200 \mathrm{hPa})$; (c) $\omega(500 \mathrm{hPa})$ e (d) fluxo de umidade integrado e divergente associado entre 1000-850 hPa. Contornos a cada 2 $\mathrm{mm} \cdot \mathrm{dia}^{-1}, 4 \times 10^{6} \mathrm{~m}^{2} \cdot \mathrm{s}^{-1}$ começando por $2 \times 10^{6} \mathrm{~m}^{2} \cdot \mathrm{s}^{-1}, 2 \mathrm{hPas}{ }^{-1}, 3 \mathrm{~g} \cdot \mathrm{m}^{-2} \cdot \mathrm{s}^{-1}$. Valores positivos (negativos) estão em linhas contínuas (pontilhadas/tracejadas). Vetores de fluxo $\left(\mathrm{g} \cdot \mathrm{m}^{-1} \cdot \mathrm{s}^{-1}\right)$ plotados e áreas sombreadas indicam valores estatisticamente significativos ao nível de $90 \%$.

Figura 12 - Diferença entre o ensemble médio do experimento EN_ODP(+) e a composição média observada durante eventos EN na ODP(+). Seqüência das letras (a) (d) idem a Figura 11. Idem para as letras (e)-(g), mas para a diferença entre o ensemble médio do experimento EN_ODP(-) e a composição média observada durante eventos EN na ODP(-). Contornos a cada $1 \mathrm{~mm} \cdot \mathrm{dia}^{-1}$ começando por $0.5 \mathrm{~mm} \cdot \mathrm{dia}^{-1}, 4 \times 10^{6} \mathrm{~m}^{2} \cdot \mathrm{s}^{-1}$ começando por $2 \times 10^{6} \mathrm{~m}^{2} \cdot \mathrm{s}^{-1}, 2 \mathrm{hPas}^{-1}$ começando por $1,3 \mathrm{~g} \cdot \mathrm{m}^{-2} \cdot \mathrm{s}^{-1}$ começando com 1 $\mathrm{g} \cdot \mathrm{m}^{-2} \cdot \mathrm{s}^{-1}$. Valores positivos (negativos) estão em linhas contínuas (pontilhadas/tracejadas). Vetores de fluxo $\left(\mathrm{g} \cdot \mathrm{m}^{-1} . \mathrm{s}^{-1}\right.$ ) plotados e áreas sombreadas indicam valores estatisticamente significativos ao nível de $90 \%$

Figura 13 - Composições de anomalias do conteúdo de água precipitável durante o Dia 0 da atividade máxima dos casos de JBN detectados em anos de EN na: (a) ODP(+); (b) ODP(-). Isolinhas a cada $2 \mathrm{~kg} \cdot \mathrm{m}^{-2}$, começando com $0.5 \mathrm{~kg} \cdot \mathrm{m}^{-2}$. Anomalias estatisticamente significativas ao nível de $95 \%$ estão sombreadas.

Figura 14 - Composições de anomalias da componente zonalmente assimétrica da $\Psi$ (200 hPa) durante o: (a) Dia -1; (b) Dia 0 e (c) Dia +1 da máxima atividade dos casos de JBN detectados em anos de EN na ODP(+). Idem para as letras (d) a (f), mas durante a ODP(-). Isolinhas a cada $2 \times 10^{-6} \mathrm{~m}^{2} \cdot \mathrm{s}^{-1}$. Valores positivos (negativos) estão em linhas contínuas (pontilhadas/tracejadas). Anomalias estatisticamente significativas ao nível de $95 \%$ estão sombreadas.

Figura 15 - Idem a Figura 14, mas para $\omega(500 \mathrm{hPa})$. Isolinhas a cada $2 \mathrm{hPa} . \mathrm{s}^{-1}$, iniciando em 1 hPa.s ${ }^{-1}$.

Figura 16 - Idem a Figura 14, mas para o fluxo de umidade integrado verticalmente e divergente associado entre $1000-850 \mathrm{hPa}$. Isolinhas a cada $3 \mathrm{~g} \cdot \mathrm{m}^{-2} \cdot \mathrm{s}^{-1}$ começando por 1 g. $\mathrm{m}^{-2} \cdot \mathrm{s}^{-1}$, e vetor vento em $\mathrm{m} \cdot \mathrm{s}^{-1}$. 
Figura 17 - Idem a Figura 13, mas para o perfil vertical do vento (v) em Santa Cruz. Isolinhas a cada $1 \mathrm{~m} \cdot \mathrm{s}^{-1}$....

Figura 18 - Médias de (a) Densidade Ciclogenética (b) Pressão Central dos ciclones extratropicais detectados durante o verão austral de anos de neutros no Pacífico Equatorial usando o algoritmo de MS. Apenas sistemas com tempo de vida superior a 24 $\mathrm{h}$ foram considerados. Contorno de intervalo a cada 1 ciclones/ $\left({ }^{\circ} \text {. lat }\right)^{2} ; 5 \mathrm{hPa}$.

Figura 19 - Anomalias de (a) Densidade Ciclogenética (b) Pressão Central dos ciclones extratropicais detectados durante o verão austral de anos de $\mathrm{EN}$ da $\mathrm{ODP}(+)$ usando o algoritmo de MS. Idem para (c) e (d), mas para a ODP(-). Apenas sistemas com tempo de vida superior a $24 \mathrm{~h}$ foram considerados. Contorno de intervalo a cada 0.5 ciclones $/\left({ }^{\circ} \text {. lat }\right)^{2}$ e $0.75 \mathrm{hPa}$.

Figura 20 - Diagramas conceituais das anomalias observadas na ocorrência de eventos EN durante a (a) ODP(+) e (b) ODP(-). A seta verde indica o escoamento associado ao transporte meridional de umidade dos trópicos para os subtrópicos. As cores mais escuras em (a) indicam anomalias mais intensas do que em (b) 65 


\section{Lista de Tabelas}

Tabela 1 - Seleção dos eventos extremos de EN e anos neutros durante as fases fria e quente da ODP.

Tabela 2 - Descrição dos experimentos numéricos, onde aTSM significa anomalia de TSM; neu_ODP(+) e neu_ODP(-) significam anos neutros ocorridos na fase quente e fria da ODP, respectivamente.

Tabela 3 - Dias e horários dos casos de JBN detectados durante o verão austral de anos de EN selecionados da ODP(+).

Tabela 4 - Idem a Tabela 3, mas para os anos de EN da ODP(-). 



\section{CAPÍTULO 1}

\section{Introdução e Objetivos}

O ciclo sazonal de precipitação sobre grande parte do continente sul americano mostra aspectos típicos de um clima monçônico, com grandes contrastes entre o inverno e o verão. Segundo Jones e Carvalho (2002) a reversão sazonal dos ventos em baixos níveis, observada quando a média anual é removida, determina as fases de início e fim do Sistema de Monção da América do Sul (SMAS) que é descrita em Zhou e Lau (1998). Na primavera (Setembro a Novembro) ocorre o início da estação chuvosa caracterizada por um regime de precipitação mais convectiva devido ao forte aquecimento da superfície pela radiação, ocorrendo sobre a maior parte central da América do Sul desde o equador até $20^{\circ} \mathrm{S}$, exceto sobre o leste da bacia Amazônica e Nordeste do Brasil. Em baixos níveis em torno de $20^{\circ} \mathrm{S}$, uma baixa térmica denominada de Baixa do Chaco $(B C)$ começa a se desenvolver devido ao forte aquecimento da superfície continental. Em altos níveis a liberação de calor latente devido à convecção profunda e calor sensível no platô boliviano originam o processo de formação da Alta da Bolívia $(A B)$ sobre a região entre $8^{\circ} S$ e $62^{\circ} \mathrm{W}$ (Schwerdtfeger, 1961). A formação da $A B$ também pode ser atribuída a forçante dinâmica em que a fonte de calor transiente sobre a Amazônia gera ondas de equatoriais de Rossby (Silva Dias et al., 1987; Gandu e Geisler, 1991; Figueroa et al., 1995). A leste desta circulação sobre o oceano Atlântico e proximidades da costa leste do Nordeste começa a formação do cavado semi-estacionário em altos níveis que posteriormente no verão (Dezembro a Fevereiro) adquire uma circulação mais fechada sendo denominado de Vórtice Ciclônico de Altos Níveis (VCAN) (Uvo, 1989). É no verão que ocorre a fase madura SMAS (Figura 1a) em que a zona de aquecimento migra para os subtrópicos onde ocorrem os máximos de precipitação desde o sul da Amazônia até o Sudeste do Brasil e vizinhanças do Atlântico, caracterizando a estação chuvosa destas regiões. A banda de convecção associada é conhecida como Zona de Convergência do Atlântico Sul (ZCAS), região de alta variabilidade convectiva em intensidade, localização e persistência (Kousky e 
Cavalcanti, 1988; Carvalho et al., 2004). Em altos níveis a circulação anticiclônica relacionada à $A B$ mostra-se bem mais definida nesta época entre $15^{\circ} \mathrm{S}, 65^{\circ} \mathrm{W}$ e a circulação ciclônica da BC se torna mais fechada. Ocorre também a intensificação dos alísios de nordeste que tendem a serem defletidos no interior do continente adquirindo uma componente de noroeste onde são canalizados em direção a BC e subtrópicos. Quando esse escoamento atinge velocidades supergestróficas é denominado de Jato de Baixos Níveis a leste do Andes (JBN) sendo responsável pelo transporte de umidade do Atlântico Equatorial e Bacia Amazônica até o Sudeste/Sul do Brasil, Paraguai, Uruguai e Argentina (Cavalcanti et al., 2002; Marengo et al., 2004). A convergência de umidade devido ao JBN também pode sofrer influência da Alta Subtropical do Atlântico Sul (ASAS) que fica localizada em torno de $30^{\circ} \mathrm{S}$ no oceano Atlântico durante o verão (Kodama, 1993). O ramo oeste da ASAS juntamente com o bloqueio dos sistemas frontais sobre o interior do continente devido a atuação do VCAN contribuem para a convergência de umidade na região da ZCAS. No verão, entre $5^{\circ} \mathrm{N}$ e $8^{\circ} \mathrm{N}$ sobre o continente e o oceano Atlântico também é observada uma banda de nebulosidade associada à Zona de Convergência Intertropical (ZCIT) que contribui com parte da precipitação observada nesta região (Citeau et al., 1988; Uvo, 1989).

A fase de decaimento do SMAS começa no início do outono, estação entre os meses de Março a Maio, com redução do aquecimento sobre o continente e diminuição dos contrastes térmicos entre continente e oceano. Isto contribui para o enfraquecimento das circulações de $A B$, VCAN e redução do fornecimento de umidade pelos alísios para a região da ZCAS. O máximo de precipitação migra gradualmente em direção ao equador onde ocorre o início da estação chuvosa do leste do Nordeste brasileiro cuja maior parte da convecção está associada à ZCIT e que nesta época do ano começa a se deslocar em direção mais ao sul. No inverno (Figura 1b), entre os meses de Junho a Agosto os máximos de precipitação ocorrem nas porções norte do equador e no sudeste dos subtrópicos. Esta fase é acompanhada pela atuação de um jato de oeste na alta troposfera posicionado em médias latitudes entre $35^{\circ}-40^{\circ} \mathrm{S}$ e que é denominado de Jato Subtropical (JST). Este contribui para o bloqueio dos sistemas frontais no sudeste dos subtrópicos contribuindo para os totais de chuva observados na região. 

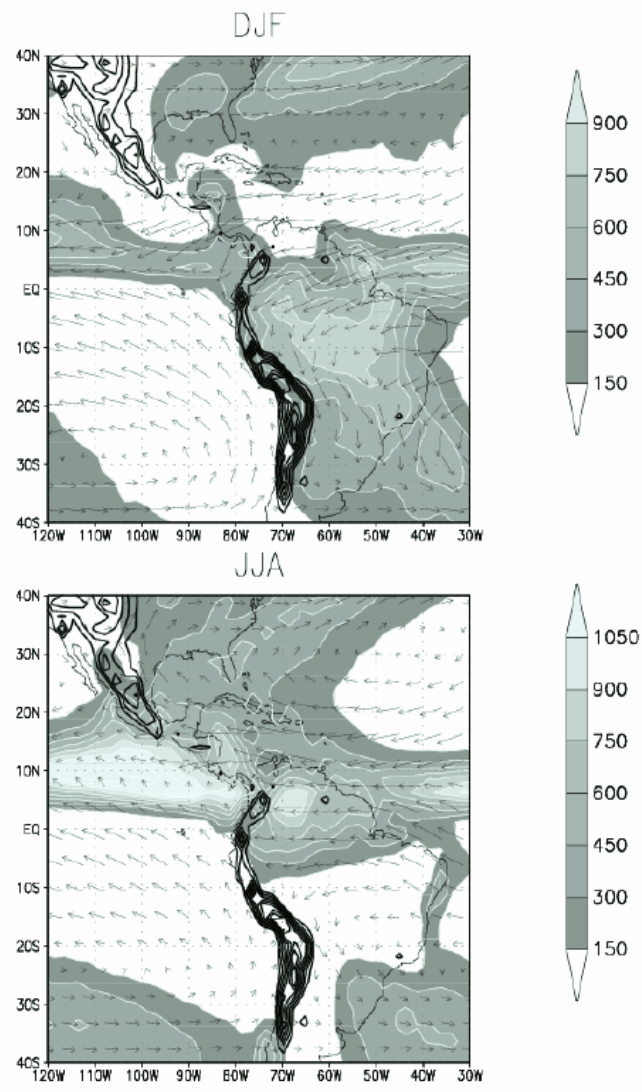

Figura 1 - Médias da precipitação acumulada e do fluxo de umidade integrado verticalmente para (a) DJF e (b) JJA. Fonte: Vera et al. (2006)

\section{1) Variabilidade da precipitação de verão na América do Sul e as forçantes interanual e interdecadal do oceano Pacífico}

As características médias descritas acima mostram variabilidade em diversas escalas de tempo. O enfoque aqui será dado às escalas interanual e interdecadal relacionadas às forçantes de Temperatura de Superfície do Mar (TSM) da bacia do oceano Pacífico uma vez que esta ocupa $1 / 3$ da superfície do globo terrestre, contribuindo para estabelecer um sinal detectável no clima global.

Em escala interanual temos o ENOS como primeiro modo de influência dominante da variabilidade das chuvas de verão do continente (Dettinger et al., 2001; Zhou e Lau, 2001; Nogués-Peagle, 2002) que é resultado da interação entre oceano e a atmosfera tendo uma oscilação irregular em freqüência e amplitude com períodos de 3 a 8 anos. A resposta atmosférica à forçante de calor simétrica em 
relação ao equador com escoamento zonal nos baixos níveis em direção à fonte consiste em ondas de Kelvin a leste e Rossby a oeste desta (Gill, 1980; Magaña e Ambrizzi, 2005). Holton (2004) e Raupp (2002) discutem os principais aspectos destas ondas, onde nas ondas de Kelvin a resposta da circulação atmosférica ao aquecimento convectivo tropical tem estrutura baroclínica e é linearmente forçada pelo aquecimento convectivo no equador. Estas ficam confinadas ao longo do equador, onde a componente meridional do vento é nula e propagam-se rapidamente para leste sem mudar a forma. A resposta da circulação atmosférica nas ondas de Rossby tem estrutura barotrópica, ou seja, as perturbações no escoamento horizontal estão em fase ao longo de toda a troposfera, e é não linear. A dispersão de energia é lenta e há uma estrutura aproximadamente geostrófica entre os campos do vento e massa. O trem de ondas de Rossby esta relacionado à variabilidade climática extratropical (Hoskins e Ambrizzi, 1993; Ambrizzi et. al., 1995) por estabelecer padrões de teleconexões em diversas escalas temporais. Sobre a América do Sul destaca-se o modo Pacífico-América do Sul (em inglês, PacificSouth American, PSA1 e PSA2 descritos por Kidson (1999) e Mo (2000)). O modo PSA1 está associado à escala interanual do ENOS, enquanto que o PSA2 está relacionado à sua componente quasi-bienal. Em termos de impactos canônicos, chuvas acima do normal são observadas sobre o Sul do Brasil, Norte de Argentina, Uruguai e Chile durante anos de EN, pois o padrão PSA contribui para a intensificação do Jato Subtropical (JST) e conseqüente bloqueio dos sistemas frontais sobre estas regiões (Rao e Hada, 1990). Os anos de La Niña (LN) são marcados por chuva acima do normal no Nordeste brasileiro devido ao deslocamento da célula de Walker (Kousky e Kayano, 1994; Trenberth, 1997) nesta época. A influência dos episódios ENOS ainda não é totalmente bem entendida, em parte devido à variabilidade inter episódios dos padrões anômalos de circulação observados. Ou seja, a variabilidade entre os episódios com diferentes intensidades e posicionamento do máximo de aquecimento, resulta em totais pluviométricos não homogêneos sobre várias partes do globo.

Dettinger et al. (2001) discutem que a variabilidade interdecadal do regime de chuvas sobre os trópicos da América do Sul está correlacionada com a Oscilação Decadal do Pacífico (ODP). A ODP é representada pelo primeiro modo de Funções Ortogonais Empíricas das anomalias mensais de TSM ao norte de $20^{\circ} \mathrm{N}$ no oceano Pacífico desde 1900 e que exibe oscilações no período aproximado de 50 anos. Sua 
assinatura foi comparada com o padrão associado ao ciclo do ENOS (Mantua et at., 1997; Zhang et al., 1997; Mestas-Nuñez e Enfield, 2001) em que os padrões de TSM, Pressão ao Nível do Mar (PNMM) e stress do vento de superfície no Pacífico estão aproximadamente simétricos em torno do equador porém menos confinados equatorialmente no Pacífico Leste. A Figura 2, extraída de Mantua et al. ilustra as fases fria e quente da ODP, onde na fase quente (warm phase) as anomalias de TSM tendem a ser anômalamente frias na região central do Pacífico Norte e aprofundamento da Baixa das Aleutas coincidente com águas mais quentes sobre a costa oeste das Américas. A fase fria (cool phase) caracteriza-se por um padrão aproximadamente inverso. Adicionalmente, dois ciclos bem definidos foram estimados: ODP fria de 1890-1924 e novamente 1947-1976, e ODP quente dominando de 1925-1946 e de 1977 até fins da década de 1990. Do começo do ano 2000 até 2009 o índice vem apresentando um comportamento oscilatório não mostrando uma fase bem definida. A partir deste momento serão usadas as siglas ODP(-) e ODP(+) como referência as fases fria e quente da ODP, respectivamente.

Os estudos de Mantua et al. e Mestas-Nuñez e Enfield têm mostrado que durante a ODP(-) houve um aumento na freqüência de eventos $L N$ e desde meados da década de 70 até o final da década de 90 os episódios EN tem sido mais intensos e freqüentes, porém, existe uma incerteza considerável a respeito dos mecanismos que forçam a ODP. Zhang et al. (1997) através das técnicas de regressão linear e Componentes Principais separaram a variação interanual de TSM relacionada ao ENOS de outras variações interanuais e decadais e concluíram que ODP ocorre em resposta a um duradouro padrão de ENOS, denominado de ENSO-like. Os resultados concordam com alguns estudos que indicam que as teleconexões atmosféricas do Pacífico Equatorial podem influenciar as TSM do Pacífico Norte através da variabilidade nos fluxos de superfície em escalas decadais (Graham et al., 1994; Deser et al., 2004) ou pela forçante interanual relacionada às ondas de Rossby no Pacífico Norte (Newman et al., 2003; Schneider e Cornuelle, 2005). Estes últimos sugerem que a ODP não seria um modo dinâmico, mas surgiria em resposta à superposição de flutuações de TSM com diferentes origens dinâmicas, como o modo ENOS e o modo Pacífico-América do Norte. 


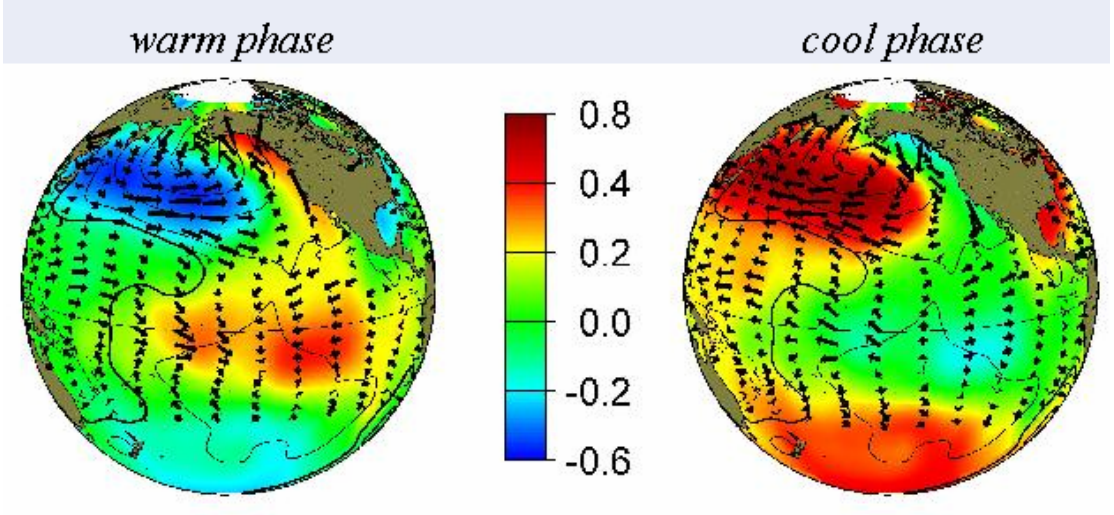

Figura 2 - Padrões típicos de verão austral das anomalias de TSM (colorido), PNMM (contorno) e stress do vento (vetores) durante a ODP(+) e ODP(-). Fonte: Mantua et al. (1997)

A ODP tem recebido considerável atenção por ser altamente correlacionada com as anomalias de circulação da América do Norte tendo em vista o posicionamento da baixa das Aleutas (Kiladis e Diaz, 1989; Gershunov e Barnett, 1998) e com as anomalias nos ecossistemas do Pacífico (Mantua et al., 1997). Flutuações na monção asiática também sofrem influência da oscilação (Krishnamurthy e Goswami, 2000; Kim e Lau, 2001; Krishnan e Sugi, 2003). O impacto da OPD nas teleconexões relacionadas ao ENOS foi verificado por Gershunov e Barnett que relatam que as similaridades entre ENOS e ODP na resposta climática podem exercer efeitos combinados na distribuição das anomalias de precipitação em algumas regiões do globo, agindo com anomalias fortes e bem definidas (fracas e ruidosas) devido ao efeito construtivo (destrutivo) quando eles estão em mesma fase (fases opostas). Mestas-Nuñez e Enfield verificaram, porém, que as fases quente e fria da ODP apresentam comportamentos opostos na circulação atmosférica sobre os trópicos de ambos os hemisférios, podendo resultar em variações na intensidade e previsão das anomalias relacionadas ao ENOS.

Para o Hemisfério Sul, Wang (1995) verificou que na ODP(-) os meses de Novembro e Dezembro, marcados pelo estágio inicial do desenvolvimento dos eventos EN, são acompanhados de uma circulação ciclônica anômala em baixos níveis sobre o leste da Austrália seguida de enfraquecimento dos alísios no sudeste do Pacífico. Então, o aquecimento iniciaria primeiramente ao longo da costa sul americana e então se propagaria para oeste. Para os eventos ocorridos na $\operatorname{ODP}(+)$, 
a circulação em baixos níveis foi caracterizada por um ciclone anômalo sobre o mar das Filipinas e intensificação dos alísios no Pacífico Sudeste. Neste caso o aquecimento ao longo da costa da América do Sul ocorreria depois do aquecimento no centro do Pacífico Equatorial. Garreaud e Battisti (1999) estenderam o estudo de Zhang et al. para uma área global entre $60^{\circ} \mathrm{N}$ e $60^{\circ} \mathrm{S}$ e verificaram que a variabilidade interdecadal do Hemisfério Sul é dominada por um número de onda 3 zonal em torno de $60^{\circ} \mathrm{S}$. Robertson e Mechoso (2000) documentaram um aumento da precipitação e escoamento dos rios sobre o sudeste da América do Sul e sudeste da Amazônia, e decréscimo das chuvas no norte da Amazônia (Marengo, 2004) depois de 1976/77 consistente com a mudança de fase da ODP. Entretanto isto não pode ser exclusivamente atribuído à variabilidade da ODP, pois os El Niños tornaram-se mais freqüentes e intensos nas décadas de 80 e 90 (Ambrizzi et al, 2004) comparado com décadas anteriores.

Dettinger et al. usando a mesma metodologia de Zhang et al. utilizaram dois índices, um representativo do ENOS e outro da ODP para verificar o impacto interhemisférico destes modos nas Américas, e tiveram conclusões semelhantes aos de Gershunov e Barnett. Ou seja, quando os índices tinham os mesmos sinais (sinais opostos) os coeficientes de regressão linear entre eles e as variáveis de precipitação e temperatura eram mais (menos) intensos. Sobre a América do Sul foram detectadas condições de chuva acima do normal acompanhadas da fase negativa do ENOS e positiva da ODP nos subtrópicos, e condições de chuva abaixo da normal na maior parte tropical e cone sul deste continente seguida de aquecimento nas temperaturas.

Os estudos observacionais de Andreoli e Kayano (2005), Garcia e Kayano (2006) e Kayano e Andreoli (2007) também tiveram conclusões semelhantes aos de Dettinger et al.. Em particular, Andreoli e Kayano verificaram que o sinal do EN na precipitação da América do Sul durante os meses de Janeiro e Fevereiro é mais pronunciado na $\operatorname{ODP}(+)$ do que na $\operatorname{ODP}(-)$. Kayano e Andreoli analisando os padrões anômalos de chuva sobre a América do Sul para as condições de EN e LN selecionados de acordo com as fases da ODP durante três bimestres de novembro a abril verificaram que as diferenças na intensidade das teleconexões do ENOS agem construtivamente (destrutivamente) quando ENOS e ODP estão na mesma fase (fases opostas). 


\section{2) Precipitação de verão sobre o Sudeste da América do Sul (SEAS) e sistemas meteorológicos associados}

Apesar dos maiores valores climatológicos de precipitação ocorrerem no verão sobre o Brasil Central, também podem ser observado um segundo máximo sobre o Sudeste da América do Sul (SEAS), região delimitada entre $15^{\circ} \mathrm{S}$ e $40^{\circ} \mathrm{S}$ e que inclui a região da Bacia do Prata. A Figura 3 extraída de Berbery e Barros (2002) mostra valores aproximados de $9 \mathrm{~mm} \cdot \mathrm{dia}^{-1}$ na parte mais norte e de $5 \mathrm{~mm} \cdot \mathrm{dia}^{-1}$ sobre a parte central da Bacia do Prata. Isto é em parte devido à influência do JBN que foi identificado durante as décadas de 1980 e 1990 nos estudos de casos de Inzunza e Berri (1980) e Sugahara et al. (1994) baseados em observações de radiossodagem sobre a América do Sul. Através das reanálises do NCEP/NCAR e simulação de 10 anos com um Modelo de Circulação Geral Atmosférico (MCGA), Cavalcanti et al. (2002) analisaram a situação de grande escala associada ao JBN e observaram que o sistema, pode ocorrer em todas as estações do ano, mas é durante o verão que o transporte de umidade associado ao jato parece ser mais intenso (Saulo et al., 2000; Silva Dias, 2000; Marengo et al., 2004). Nestes últimos podem ser encontradas discussões sobre o ciclo diurno do JBN onde o máximo do perfil do vento pode ser afetado pelo calor latente no Brasil Central e pela presença da camada de inversão térmica. Alguns estudos discutem a relação entre o JBN e a ZCAS em diversas escalas de tempo e sugerem que quando o fluxo de umidade em direção ao sudeste do Brasil via JBN é mais (menos) intenso, a ZCAS mostra-se mais (menos) ativa sobre a região (Sugahara et al., 1994; Liebmann et al., 1999; Herdies et al., 2002; Liebmann et al., 2004; Marengo et al., 2004,). 


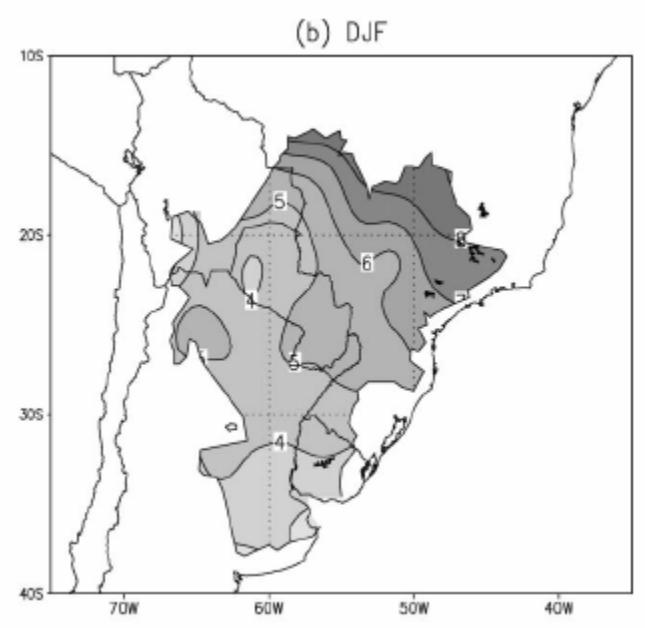

Figura 3 - Taxa de precipitação média do $\operatorname{CMAP}\left(\mathrm{mm}^{\mathrm{dia}}{ }^{-1}\right)$ durante DJF para o SEAS. Fonte: Berbery e Barros (2002)

A maior disponibilidade de umidade fornecida pelo JBN para a Bacia do Prata pode favorecer o aumento da instabilidade convectiva e conseqüentemente maior desenvolvimento de ciclones extratropicais próximo ao continente entre $15^{\circ} \mathrm{S}$ e $60^{\circ} \mathrm{S}$ (Gan e Rao 1994a; Jusevicius, 1999; Vera et al., 2002; Weykamp, 2006; Mendes et al., 2007). Os ciclones extratropicais são sistemas de tempo com movimento circulatório associados a áreas de baixa pressão na superfície (Petterssen, 1956) e são responsáveis pelo transporte de calor, vapor d'água e momento na atmosfera em direção aos pólos (Peixoto e Oort, 1992) desempenhando papel importante no controle do clima nos subtrópicos.

No Hemisfério Sul estas depressões tendem a se formar e intensificar nas latitudes médias do Pacífico Sul, pois esta região é caracterizada por intensos contrastes norte-sul de temperatura, onde atuam as ondas baroclínicas. Os ciclones extratropicais sofrem então um deslocamento para leste ou sudeste, alcançando o continente sul americano em sua fase madura e posterior decaimento (Jones e Simmonds, 1993; Sinclair, 1995). Outros fatores são também importantes para gênese e manutenção destes sistemas, tais como distribuição a instabilidade hidrodinâmica e o efeito orográfico associado à instabilidade baroclínica. Neste último, a conservação de vorticidade potencial do escoamento de oeste sobre as montanhas induz a formação de um cavado na média e alta troposfera a leste dos Andes (Bluestein, 1992) que contribui para a formação dos ciclones em superfície 
sobre a América do Sul. Relatos comuns entre os estudos de Gan (1992) e Mendes et al. mostram que os cavados em médios e altos níveis estão presentes em todos os casos analisados de ciclogênese na América do Sul e o escoamento de ar quente e úmido para o sul do continente contribuiu para intensificar a zona baroclínica entre $30^{\circ}-40^{\circ} \mathrm{S}$.

Estudos apontam que o oceano Atlântico Sudoeste nas proximidades do continente atua como outra área ciclogenética devido a influência de alguns dos seguintes fatores: gradiente produzido pela confluência das correntes BrasilMalvinas ou anomalias positivas de TSM (Necco 1982b; Dal Piva, 2001; Reboita et al., 2007b); gradiente entre a temperatura de superfície continente-oceano (Saraiva, 1996); e impacto dos fluxos de calor sensível e latente que pode contribuir para a fase inicial da formação do ciclone ou para o seu aprofundamento (Mendes et al., 2007) e na sua fase de maturação no caso do Atlântico Sul (Reboita et al., 2009).

Alguns estudos relatam a relação entre o escoamento do JBN e os ciclones extratropicais onde características comuns nos estudos indicam que a região ao redor de $30^{\circ} \mathrm{S} ; 65^{\circ}-75^{\circ} \mathrm{W}$ durante o verão é propícia para o desenvolvimento de ciclones (Gan, 1992; Sinclair, 1995; Mendes et al., 1997). Basicamente devido a dois mecanismos: o de origem térmica devido a BC e a instabilidade hidrodinâmica. Neste último os Andes tenderiam a canalizar o ar quente e úmido de origem tropical para as latitudes médias na fase inicial da ciclogênese. Já durante o inverno os ciclones formados na região do Rio da Prata estariam associados ao acoplamento com os sistemas baroclínicos. Recentemente, Mendes et al. utilizando mínimos de PNMM elaboraram uma climatologia de ciclones para o período de 1948 a 2003 para os casos ocorridos entre $0^{\circ}-120^{\circ} \mathrm{W} ; 70^{\circ} \mathrm{S}-0^{\circ}$. Os autores identificaram uma maior freqüência no inverno (35 casos) e menor no verão (28 casos) e desde um dia antes dos episódios de ciclogêneses o transporte de umidade para o Norte da Argentina via JBN já se mostrava intensificado, contribuindo para o desenvolvimento dos sistemas forçando uma circulação ciclônica a sotavento dos Andes.

Gan e Rao (1991) analisaram 14.600 cartas sinóticas e elaboraram uma climatologia de ciclones entre janeiro de 1979 a dezembro de 1988, na região entre $15^{\circ}-50^{\circ} \mathrm{S}, 30^{\circ}-90^{\circ} \mathrm{W}$. Foram identificadas duas regiões ciclogenéticas: uma sobre o Golfo de São Matias $\left(42.5^{\circ} \mathrm{S}\right.$ e $\left.62.5^{\circ} \mathrm{W}\right)$, com máximos no verão relacionado à instabilidade baroclínica dos ventos de oeste em altos níveis; e outra sobre o Uruguai $\left(31.5^{\circ} \mathrm{S}\right.$ e $\left.55^{\circ} \mathrm{W}\right)$, com máximos no inverno devido ao efeito dos Andes 
através da interação dos distúrbios transientes com o cavado estacionário de origem orográfica associado à instabilidade baroclínica dos ventos de oeste (Figura 4).

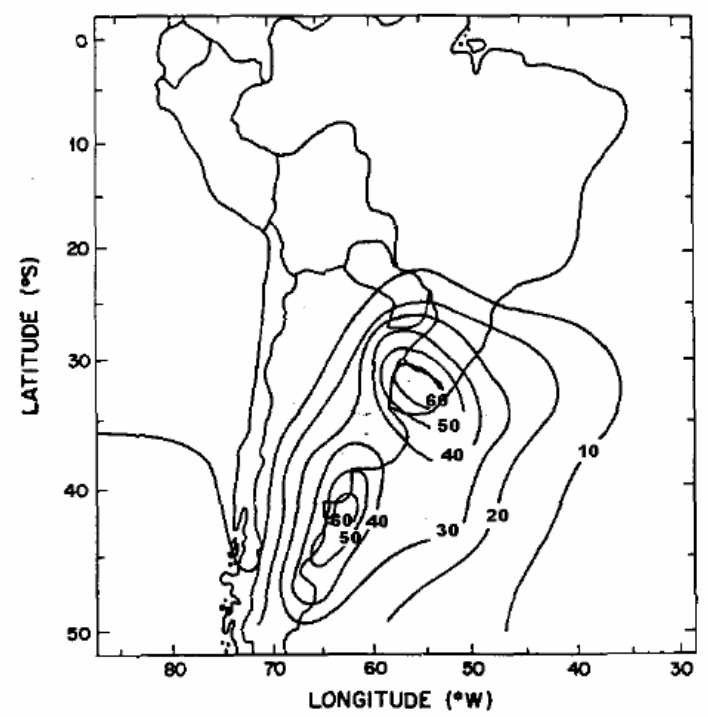

Figura 4 - Distribuição anual da freqüência ciclogenética para o período de 19791988. Fonte: Gan e Rao (1991).

\section{3) Influências dos modos ENOS e ODP na variabilidade do JBN}

Estudos de caso de Lau e Zhou (2003) mostraram no evento EN de 1997/98 ocorreram intensos episódios de JBN que adentraram mais ao sul em relação a sua posição climatológica e estiveram associados à intensificação de ventos de oeste em altos níveis sobre o subtrópicos. Marengo et al. (2004) e Nieto Ferreira et al. (2003) verificaram casos de JBN mais intensos e freqüentes durante o evento EN de 1997/98 quando comparado com o evento de LN de 1999/2000. Através de uma análise estatística Marengo et al. verificaram que $20 \%$ da variabilidade do JBN pode ser explicada pelas anomalias de TSM do oceano Pacífico Tropical; sobre o Atlântico as correlações foram bem fracas. Entretanto uma análise dinâmica não havia sido explorada, o que serviu de incentivo para o estudo de Silva (2005) onde foi investigado o impacto dos eventos inter ENOS (fortes e fracos) ocorridos de 19812003 na variabilidade do JBN. De maneira geral, a autora verificou que o JBN é sensível a mudanças no estado básico atmosférico como as que ocorrem devido à 
variabilidade inter ENOS, onde durante o estágio de maturidade da fase quente do ENOS os episódios de JBN ocorreram em uma freqüência de normal a acima da normal climatológica, enquanto que na fase fria o fenômeno ocorreu com freqüência de normal à abaixo da média. Parte desta análise pode ser encontrada em Silva e Ambrizzi (2006) que contém dois estudos de casos relativos ao comportamento episódios de JBN detectados em dois El Niños de intensidades diferentes. No evento de 1997/98, classificado como forte, um anticiclone anômalo em baixos níveis predominou sobre a parte central do Brasil acelerando o escoamento de norte-sul a leste dos Andes e deslocando-o em direção ao Sul do Brasil e Norte da Argentina. Entretanto, durante o evento de EN fraco de 2002/03 os casos de JBN foram menos intensos e deslocados na direção mais ao sudeste do Brasil.

Procurando complementar os estudos de Silva (2005) e Silva e Ambrizzi (2006) foi investigado no início da Tese de Doutorado o impacto canônico dos eventos ENOS na modulação do JBN. O período de estudo foi de 1977-2004 o que permitiu a análise de campos de precipitação diários durante os dias de atuação de JBN. Os resultados que podem ser encontrados em Silva et al. (2009) (artigo incluso no Anexo 1) estão esquematizados na Figura 5 sugerindo que os casos de JBN detectados tanto em anos de EN como em anos de LN canônicos estão associados com chuvas acima da média sobre o SEAS, porém mais intensas durante anos de LN. Durante anos de EN o aumento na freqüência do jato esteve associado à intensificação do JST em torno de $30^{\circ} \mathrm{S}$ e anomalias positivas de PNMM sobre o oeste do Atlântico e região central da América do Sul. Isto contribui com a intensificação dos ventos alísios sobre o norte do continente que foram canalizados a leste dos Andes em direção ao SEAS onde anomalias negativas de PNMM foram encontradas. Nos anos de LN os casos foram mais fracos e menos freqüentes quando comparados com aqueles identificados nos anos de EN onde $O$ enfraquecimento do JST e as anomalias negativas de PNMM sobre os trópicos contribuíram para a inversão dos ventos alísios de nordeste. Além disso, o balanço geostrófico devido à circulação de alta de bloqueio anômalo sobre o sudeste do Pacífico e um intenso ciclone transiente sobre o cone sul do continente contribuíram para um fluxo anômalo de sul em direção ao interior do continente. Estas características juntas parecem ter favorecido a interação sobre a Bacia do Prata do ar tropical transportado pelo JBN e o ar frio extratropical de sul aumentando a condição de instabilidade condicional sobre a região, explicando assim parte das 
chuvas mais intensas sobre a região do SEAS nos casos de JBN em anos de LN em relação aos anos de EN. As anomalias diárias de circulação durante os dias de atuação do JBN foram bem semelhantes às composições sazonais o que reforça a hipótese da variabilidade do JBN ser influenciada pelo modo ENOS.

Em termos de variabilidade decadal, Marengo et al. (2004) detectaram um aumento na freqüência de casos de JBN a partir de meados da década de 70, associado à mudança de fase da ODP, entretanto uma análise dinâmica mais detalhada não foi realizada.

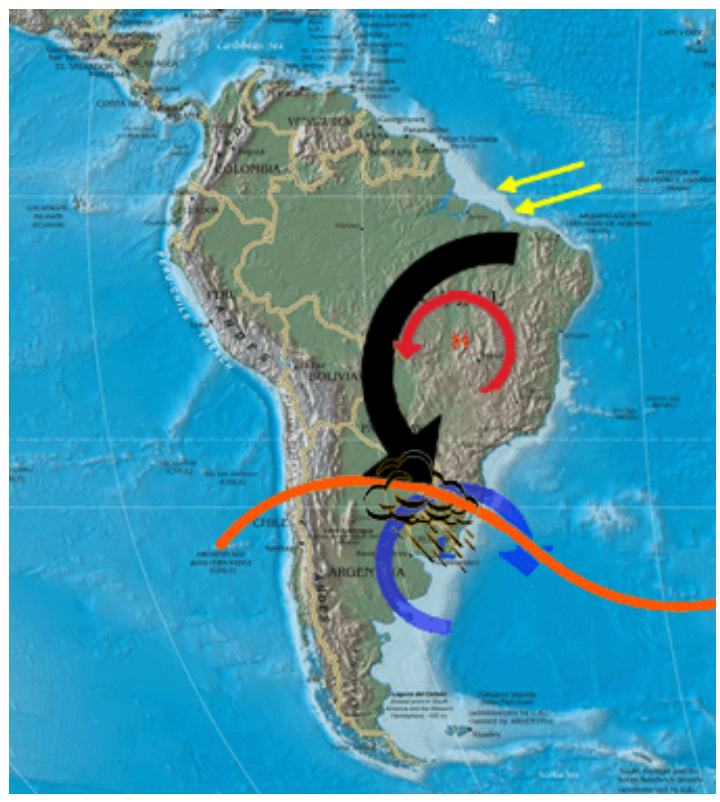

(a)

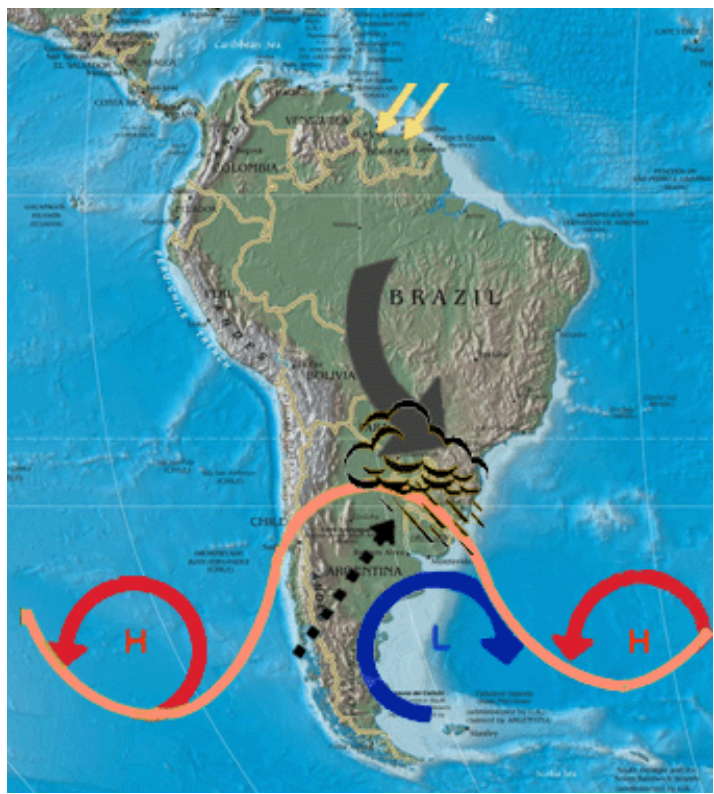

(b)

Figura 5 - Diagrama conceitual dos mecanismos físicos que podem modular a variabilidade espacial e temporal do JBN durante o verão austral de anos de (a) EN e (b) LN. As setas amarelas e pretas representam os ventos alísios e circulação do JBN, respectivamente, ambos mais intensos (setas mais escuras) em (a) do que em (b). As letras $\mathrm{H}$ (seta vermelha) e $\mathrm{L}$ (seta azul) representam altas e baixas pressões em $850 \mathrm{hPa}$. Em (b) a seta pontilhada preta indica fluxo de sul associado a $\mathrm{H}$ e $\mathrm{L}$ em $850 \mathrm{hPa}$ sobre médias latitudes. A linha laranja mostra o JST em $200 \mathrm{hPa}$ onde a cor mais escura em (a) indica que o sistema é mais intenso do que em (b). As nuvens representam a região de precipitação associada ao JBN. Fonte: Silva et al. (2009)

\section{4) Influência dos modos ENOS e ODP na variabilidade dos ciclones extratropicais da América do Sul}


Alguns estudos apontam para uma maior ocorrência de ciclones extratropicais na América do Sul durante os verões de anos de EN (Gan e Rao, 1991; Satyamurty et. al, 1990a). Resultados recentes de Magaña e Ambrizzi (2005) indicam que a conexão via PSA pode configurar no sudeste do continente, em baixos níveis, uma circulação ciclônica favorecendo a convergência de umidade via JBN (Berbery e Barros, 2002) o que favoreceria maior suporte ao desenvolvimento de ciclogêneses nesta região. As configurações deste trem de onda também foram identificadas por Cavalcanti e Kayano (1999) associadas a distúrbios de alta freqüência sobre a América do Sul.

A utilização do esquema automático de Murray e Simmonds (1991 a,b) para identificação e plotagem do deslocamento de centros de baixas/altas pressões fechados (ciclones/anticlones) de médias e altas latitudes a partir de dados de PNMM tem sido explorada em alguns estudos sobre o Hemisfério Sul. Pezza e Ambrizzi (2003) e Beu e Ambrizzi (2006) através do uso deste método objetivo estudaram a variabilidade interanual da freqüência de ciclogêneses no Hemisfério Sul e verificaram que em anos de LN existem mais trajetórias de ciclones sobre o Atlântico subtropical e o sudeste da Austrália, e que em anos de EN existem altas concentrações de ciclones sobre o Pacífico subtropical, Sul da Argentina, costa oeste da América do Sul e sobre o oceano Índico. O uso de esquemas automáticos facilita o rastreamento para um número muito elevado de dados, podendo contribuir para resultados mais consistentes com as anomalias de circulações atmosférica observadas em comparação com análises subjetivas aplicadas as imagens de satélite.

Alguns estudos como os de Schneider (2005) e Pezza et al. (2007) verificaram a relação entre os ciclones extratropicais no Hemisfério Sul associado à variabilidade decadal do Pacífico. Este último analisando as diferenças entre as composições de PNMM baseada nos índice de ODP e do Índice de Oscilação Sul (IOS) durante o verão verificaram que os campos de PNMM mostraram uma forte estrutura anular relacionada à ODP o que não é observado nas composições do IOS, com valores abaixo da normal ao redor da Antártida durante a fase positiva e vice versa. Ciclones mais intensos e menos freqüentes foram observados durante a fase positiva da ODP o que foi menos consistente para o IOS reforçando o grau de incerteza da 
independência entre estes modos, sugerindo que a oscilação decadal tenda a ser mais associada com anomalias sobre médias e altas latitudes.

\section{5) Motivação e Objetivos}

Características comuns entre os estudos mencionados anteriormente indicam que parte da variabilidade da precipitação de verão observada no SEAS pode ser devido ao fornecimento de umidade pelo JBN e por sua interação com os ciclones extratropicais sobre a região. Assim é de extrema importância um maior conhecimento sobre a dinâmica da variabilidade climática que afeta estes sistemas, principalmente no que diz respeito às forçantes interanual e interdecadal, já que o transporte de umidade na atmosfera representa um dos fatores determinantes do clima global e regional. Os recentes estudos de Marengo et al. (2004) e Silva et al. (2009) abriram margem para questionamentos a respeito de possíveis mudanças nas anomalias do regime de umidade da América do Sul relacionadas ao fenômeno EN levando em consideração fases opostas da ODP. De maneira geral, os estudos encontrados na literatura sobre o impacto da ODP em eventos ENOS sobre a o continente sul americano são baseados em observações apenas, além de negligenciarem a fase neutra do ENOS que ocorre em aproximadamente metade do período entre 1950-1999 (que compreende dois períodos da ODP). E ainda, não abordam aspectos da modelagem climática e não mencionam como tal impacto atua nos sistemas responsáveis por parte da variabilidade do transporte de umidade na SMAS (JBN e ciclones extratropicais). A modelagem climática é extremamente necessária, uma vez que juntamente com a interpretação de dados observacionais, podem fornecer uma poderosa indicação de causa-efeito. Tanto a análise baseada em observações quanto a baseada em modelagem numérica pode produzir incertezas, mas as incertezas associadas a cada uma delas são independentes.

Assim, foram levantadas algumas questões científicas:

1. Existem grandes diferenças na circulação da América do Sul ao serem analisados somente os anos neutros no Pacífico Equatorial em diferentes fases da ODP? 
2. Quais são as possíveis diferenças no fornecimento de umidade do continente durante o verão austral de eventos EN em fases opostas da ODP?

3. Um MCGA forçado com a evolução de EN canônicos no Pacífico Equatorial e regimes distintos da ODP no resto do domínio poderia explicar as anomalias observadas na questão anterior?

4. Quais as possíveis diferenças na variabilidade temporal e espacial dos casos de JBN detectados nos eventos mencionados na Questão 2?

5. Como as propriedades de densidade e pressão central dos ciclones extratropicais sobre a América do Sul respondem a modificações na circulação de verão associadas à Questão 2?

Com a finalidade de responder estas questões, o objetivo deste trabalho é realizar um estudo observacional e numérico da evolução dos eventos EN em diferentes fases da ODP caracterizando possíveis mudanças nos processos de transporte de umidade da América do Sul durante 0 verão austral. Conseqüentemente, um enfoque será dado à variabilidade do JBN e algumas propriedades dos ciclones extratropicais que são componentes principais da dinâmica do transporte de umidade sobre o continente. Experimentos numéricos com um MCGA serão realizados com domínio global, porém o objetivo aqui não é validar o modelo, e sim realizar experimentos de sensibilidade para investigar como uma mesma anomalia de EN canônico forçaria a atmosfera em dois contextos de ODP distintos. As situações modeladas poderão auxiliar na explicação da dinâmica das anomalias sazonais observadas. Uma análise das características dos ciclones extratropicais sobre a América do Sul será realizada através do esquema numérico desenvolvido por Murray e Simmonds (1991 a,b), sendo referenciado no estudo como esquema numérico de MS.

O estudo está inserido no contexto das mudanças climáticas, entretanto, o enfoque é dado as causas naturais, como as relacionadas às variações TSM da bacia do Pacífico Tropical, e não as de origem antropogênica. A variabilidade climática possui extrema importância para o meio ambiente e apesar dos avanços tecnológicos e científicos ocorridos nos últimos tempos ainda existem muitos questionamentos em torno do tema. Do ponto de vista científico, sua melhor compreensão pode contribuir para um melhor monitoramento do clima. 
Este trabalho está estruturado da seguinte forma: o Capítulo 2 apresenta os dados e a metodologia empregados, com uma descrição das ferramentas numéricas utilizadas como o MCGA e o esquema numérico de MS. Os principais resultados observacionais relativos à caracterização das circulações de verão sobre a América do Sul durante os anos neutros do Pacífico Equatorial e em anos de EN nas fases distintas da ODP são abordados no Capítulo 3. No Capítulo 4 são apresentados os resultados dos experimentos numéricos com um MCGA que poderão fornecer um melhor entendimento das anomalias observadas. Os estudos da variabilidade do JBN e propriedades dos ciclones extratropicais são relatados no Capítulo 5. Finalmente, no Capítulo 6 são sumarizados os principais resultados deste trabalho e apresentadas sugestões para pesquisas futuras. 


\section{CAPÍTULO 2}

\section{Dados e Metodologia}

\section{a) Dados}

Para o período de verão austral de Dezembro à Fevereiro (DJF) de 1950 a 1999 foram selecionados os eventos extremos de EN (fortes e fracos) e neutros no Pacífico Equatorial segundo a classificação do Climate Prediction Center (CPC, Zhou et al., 2001). O trimestre de DJF é referente a dezembro do ano anterior ao mês de referência da média trimestral. Foi escolhido por ser caracterizado pela intensificação no transporte de umidade via JBN e pela atividade sinótica, que apesar de mais freqüente no inverno, também é observada no verão geralmente alcançando latitudes tropicais, podendo afetar os maiores valores de chuva sobre o centro-leste do Brasil observados. A classificação do CPC por estação do ano é baseada nas anomalias de TSM da região de Niño 3.4, sendo escolhida por exercer forte influência na circulação extratropical da América do Sul durante o verão austral. Os eventos EN e neutros foram separados de acordo com as fases fria e quente da ODP (Mantua et al., 1997) e estão listados na Tabela 1, onde servirão de base para realização das composições do estudo. 


\begin{tabular}{|c|c|c|}
\hline & El Niños & Anos Neutros no Pacífico Equatorial \\
\hline ODP(-) & $1952 / 53,1957 / 58,1958 / 59,1963 / 64$, & $1951 / 52,1953 / 54,1956 / 57$, \\
& $1969 / 70,1972 / 73$ & $1959 / 60,1960 / 61,1961 / 62$, \\
& & $1962 / 63,1966 / 67,1967 / 68,1971 / 72$ \\
\hline ODP(+) & $1976 / 77,1977 / 78,1979 / 80,1982 / 83$, & $1978 / 79,1980 / 81,1981 / 82$, \\
& $1987 / 88,1990 / 91,1991 / 92,1992 / 93$, & $1985 / 86,1989 / 90,1993 / 94,1996 / 97$ \\
& $1994 / 95,1997 / 98$ & \\
\hline
\end{tabular}

Tabela 1 - Seleção dos eventos extremos de EN e anos neutros durante as fases fria e quente da ODP.

As análises das circulações atmosféricas do estudo observacional e numérico são feitas para a América do Sul, porém, uma maior ênfase será dada as duas regiões esquematizadas na Figura 6. O tracejado azul representa a primeira delas que fica situada entre $15^{\circ} \mathrm{S}$ e $40^{\circ} \mathrm{S}$ e representa a região do SEAS e a segunda região, delimitada pelo tracejado verde entre $30^{\circ} \mathrm{S}-90^{\circ} \mathrm{S}$ e $90^{\circ} \mathrm{W}-30^{\circ} \mathrm{W}$, foi selecionada para o estudo dos ciclones extratropicais com o objetivo de reduzir o efeito das baixas térmicas que possam vir a ser capturadas pelo esquema numérico. Os dados mensais de taxa de precipitação sobre o continente a cada $2.5^{\circ}$ de espaçamento de grade foram extraídos de Chen et al. (2002). Médias mensais de TSM foram obtidas do Met Office Hadley Centre's (Rayner et al., 2003) numa grade de $2^{\circ}$ latitude $\times 2^{\circ}$ longitude para o período de 1950-1999. As variáveis meteorológicas foram obtidas para o mesmo período e extraídas das reanálises do National Centers for Environmental Prediction (NCEP, Kalnay et al., 1996), pois representam de maneira satisfatória condições atmosféricas de grande escala associadas ao JBN (Marengo et al., 2004; Silva et al. (2009) e referências) e ciclones extratropicais. Para espaçamento de $2,5^{\circ}$ de grade foram obtidas:

- em horários sinóticos (00, 06, 12 e 18 UTC): ventos zonal (u) e meridional (v) de 1000-700 hPa e PNMM;

- médias diárias: conteúdo de água precipitável, omega ( $\omega)$ em 500 hPa e umidade específica (q) de 1000-850 hPa. Adicionalmente utilizou-se a variável função de corrente $(\Psi)$ no nível sigma de 0.21 (correspondente a $200 \mathrm{hPa}$ ). 
O conteúdo água precipitável representa a altura de água que se formaria à superfície se todo o vapor d'água na coluna vertical atmosférica sob sondagem viesse a condensar e precipitar. Assim altos valores de água precipitável em regiões com boa cobertura de dados podem indicar instabilidades locais, e conseqüentes chuvas, apesar de nem sempre isto ocorrer.

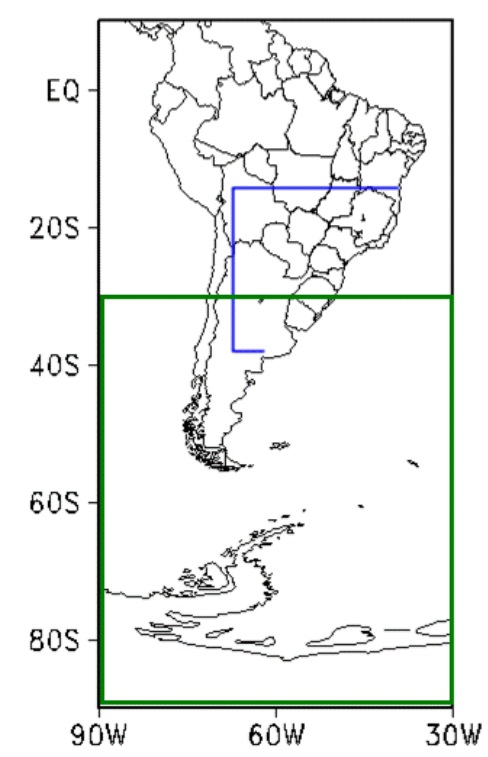

Figura 6 - Localização das regiões de análise das circulações atmosféricas sobre a América do Sul. As linhas entre $15^{\circ} \mathrm{S}$ e $40^{\circ} \mathrm{S}$ em azul delimitam o SEAS e entre $30^{\circ} \mathrm{S}-90^{\circ} \mathrm{S}$ e $90^{\circ} \mathrm{W}-30^{\circ} \mathrm{W}$ em verde delimitam a região onde as propriedades dos ciclones extratropicais foram calculadas.

\section{b) Metodologia}

\section{b.1) Estudo observacional e numérico para DJF}

Para análise dos padrões de circulação de verão em anos neutros e de EN durante a $\operatorname{ODP}(+)$ e $\operatorname{ODP}(-)$ foi utilizada a técnica de composições, o que nos permite ressaltar os padrões atmosféricos dominantes em situações específicas. Para cada fase da oscilação decadal foram calculadas as composições médias dos 
anos neutros separadamente. O mesmo procedimento foi feito para o cálculo das composições de anomalias durante eventos EN onde foi utilizada a climatologia dos anos neutros no Pacífico Equatorial. De acordo com Silvestre (2004), o uso de média climatológica de anos neutros é mais apropriado para explorar o sinal do ENOS no SEAS devido à relação de não-linearidade entre as anomalias de TSM do Pacífico Equatorial e a precipitação sobre a região. A configuração do escoamento do ar em níveis inferiores da atmosfera, devido às características da distribuição vertical do vapor d'água, é representado pelo do fluxo de vapor d'água atmosférico integrado verticalmente e divergente associado entre 1000-850 hPa.

Dois experimentos numéricos com o MCGA CAM3 foram realizados, sendo referenciados como EN_ODP(+) e EN_ODP(-). A Tabela 2 contém a descrição dos experimentos onde foram forçados com a mesma anomalia de TSM na região do Pacífico Equatorial e no restante do domínio foram prescritas duas condições diferentes de TSM e gelo marinho correspondentes aos anos neutros da ODP $(+)$ e ODP(-) separadamente. Para cada experimento foi calculado um ensemble com 10 membros cada sendo que cada membro utilizou a mesma condição inicial extraída do experimento padrão do modelo sendo aplicada perturbação randômica no campo de temperatura em superfície. Os experimentos foram integrados por seis meses sendo analisado o trimestre DJF e foram calculadas duas diferenças: a primeira dela refere-se à diferença entre o experimento EN_ODP(+) e a média observada dos eventos $E N$ da $\mathrm{ODP}(+)$. A segunda refere-se à diferença entre o experimento EN_ODP(-) e a média observada dos eventos EN da ODP(-) .

\begin{tabular}{|c|c|c|}
\hline Experimento & $\begin{array}{l}\text { Forçante no domínio entre } \\
20^{\circ} \mathrm{S}-20^{\circ} \mathrm{N} ; 120^{\circ} \mathrm{E}-175^{\circ} \mathrm{W}\end{array}$ & Nas demais regiões oceânicas \\
\hline EN_ODP(+) & $\operatorname{aTSM}_{(E I \text { Niños })}+$ TSM_média ${ }_{(\text {neu_oDP(+)) }}$ & 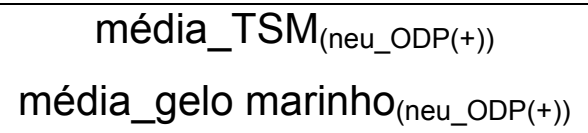 \\
\hline EN_ODP(-) & $\operatorname{aTSM}_{(E I ~ N i n ̃ o s)}+$ TSM_média ${ }_{(\text {neu_ODP(-)) }}$ & $\begin{array}{c}\text { média_TSM } \\
\text { média_geu_ODP(-)) } \\
\text { marinho } \\
(\text { neu_ODP(-)) }\end{array}$ \\
\hline
\end{tabular}

Tabela 2 - Descrição dos experimentos numéricos, onde aTSM significa anomalia de TSM; neu_ODP(+) e neu_ODP(-) significam anos neutros ocorridos na fase quente e fria da ODP, respectivamente. 


\section{b.2) Estudo observacional: JBN e propriedade dos ciclones extratropicais}

Os casos de JBN foram definidos de acordo com a metodologia dos estudos Saulo et al. (2000), Cavalcanti et al. (2002), Marengo et al. (2004) e Silva e Ambrizzi (2006), onde foi assumido que o núcleo do jato estaria posicionado na região de Santa Cruz na Bolívia (17.755; 63.06 W) no nível de $850 \mathrm{hPa}$. Apenas os casos onde a componente (v) era negativa foram selecionados. Aplicou-se o critério 1 de Bonner (1968) adaptado para a América do Sul nos campos de ventos (u,v) com base nas seguintes condições: a magnitude do vetor vento em torno de $850 \mathrm{hPa}$

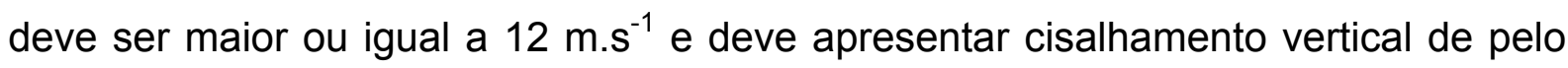
menos $6 \mathrm{~m} . \mathrm{s}^{-1}$ entre os níveis de 850-700 hPa. Foram calculadas separadamente as composições de anomalias das variáveis atmosféricas para análise dos padrões de circulação de verão um dia antes (Dia -1), durante (Dia 0) e depois (Dia +1) do máximo de atuação do JBN em anos de EN para ambas as fases da ODP selecionadas. Na ausência de uma base de dados diários de precipitação, foi utilizada a variável de conteúdo de água precipitável nas composições das anomalias diárias.

As propriedades dos ciclones extratropicais foram calculadas através dos esquema numérico de MS sendo calculadas as anomalias de Densidades Ciclogenética (DC) e Pressão Central $(P C)$, onde $D C$ média equivale à razão entre número de sistemas identificados numa região de $5^{\circ}$ latitude $\times 5^{\circ}$ longitude pela área da mesma, enquanto que a PC média corresponde a média da pressão central dentro desta área e foi usada por Sinclair $(1994,1995)$ como boa medida de intensificação de ciclones extratropicais. Com o uso da região de $5^{\circ}$ latitude $\times 5^{\circ}$ longitude é possível corrigir o efeito da latitude, que tende a favorecer a densidade dos sistemas em direção ao equador (Murray e Simmonds, 1991 a, b). Para garantir resultados mais consistentes, o algoritmo foi configurado para fazer rastreamento a cada 6 horas, além disso, são considerados os sistemas que persistam por quatro análises ou mais, o que corresponde a ciclones com duração igual ou superior a 24 horas. Esse critério tem por objetivo eliminar baixas "órfãs" (sistemas que aparecem em uma única análise). São considerados também apenas os ciclones cuja pressão 
central seja igual ou menor a $1010 \mathrm{hPa}$, pois segundo Pezza e Ambrizzi (2003) este limiar elimina sistemas muito fracos e garante resultados mais consistentes.

As significâncias estatísticas das composições dos Capítulos 3 e 4 foram obtidas através do teste t-Student bi-caudal (Wilks, 1995) sendo adotado o nível de significância de $10 \%$ devido ao pouco número de membros, e para as composições diárias do Capítulo 5 foi adotado o nível de significância de $5 \%$ devido ao maior número de membros.

\section{1) Fluxo de umidade integrado verticalmente e divergente associado}

Baseado na metodologia de Silva (2005) e Silva et al. (2009) foram calculados o conteúdo de água precipitável $(W)$, fluxo horizontal de vapor d'água $\left(Q_{\lambda}\right)$ e fluxo meridional de vapor d'água $\left(Q_{\Phi}\right)$, calculados conforme discretizado abaixo:

$$
\begin{aligned}
& W=\frac{1}{g} \sum_{n=1}^{N} \frac{\left[q_{n+1}+q_{n}\right]}{2}\left[p_{n}-p_{n+1}\right] \\
& Q_{\lambda}=\frac{1}{g} \sum_{n=1}^{N} \frac{\left[(u q)_{n+1}+(u q)_{n}\right]}{2}\left[p_{n}-p_{n+1}\right] \\
& Q_{\phi}=\frac{1}{g} \sum_{n=1}^{N} \frac{\left[(v q)_{n+1}+(v q) n\right]}{2}\left[p_{n}-p_{n+1}\right]
\end{aligned}
$$

sendo g aceleração da gravidade, q umidade específica, p pressão, $\mathrm{N}$ o número total de camadas do modelo (1000 a $850 \mathrm{hPa})$, u e $v$ as componentes zonal e meridional do vento.

O fluxo de umidade é dado por:

$$
\vec{Q}=Q_{\lambda} \vec{i}+Q_{\phi} \vec{j}
$$


E sua divergência horizontal é obtida através da função hdivg do software de manipulação e visualização de dados Grads (http://www.iges.org/grads/).

\section{2) Teste de significância estatística (teste T-Student)}

Segundo Wilks (1995) o teste de significância estatística pode ser obtido através de

$$
\mathrm{t}=\frac{x-\bar{x}}{\left[\frac{S^{2}}{n}\right]^{1 / 2}}
$$

que segue uma distribuição conhecida como t-Student em que $x$ e $\mathrm{S}^{2} / \mathrm{n}$ representam a média e a variância dos membros, $\bar{x}$ é a média climatológica e $\mathrm{n}$ o número de membros. O teste é calculado com $\mathrm{n}-1$ graus de liberdade. $\mathrm{O}$ valor absoluto de $\mathrm{t}$ obtido deve ser igual ou superior ao valor de $\mathrm{t}$ na tabela de distribuição $\mathrm{t}-S$ Student ( $\left.t_{\text {crítico }}\right)$ para que a diferença $x-\bar{x}$ seja estatisticamente significativa definindo um determinado nível de significância.

No Capítulo 4 foi verificada a significância estatística das diferenças entre a média dos ensembles e as médias observadas dos eventos EN baseada na equação:

$$
\mathrm{t}=\frac{\bar{x}_{1}-\bar{x}_{2}}{\left[\frac{S_{1}^{2}}{n_{1}}+\frac{S_{2}^{2}}{n_{2}}\right]^{1 / 2}}
$$

sendo $\bar{x}_{1}$ e $\bar{x}_{2}$ a média do ensemble do experimento $\operatorname{EN} \mathrm{ODP}(+)$ e a média observada dos eventos EN da ODP(+). O denominador representa o erro padrão da diferença entre as médias, e $S_{1}{ }^{2}, S_{2}{ }^{2}, n_{1}, n_{2}$ são as variâncias e os números de membros. O teste de diferenças é calculado com $\left(n_{1}+n_{2}-2\right)$ graus de liberdade. $\mathrm{O}$ valor absoluto de $\mathrm{t}$ obtido deve igual ou superior ao valor de $\mathrm{t}$ na tabela de 


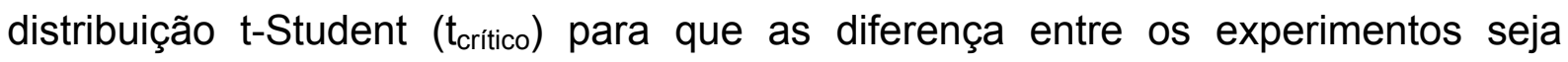
estatisticamente significativa de acordo com o nível de significância de $90 \%$. O mesmo procedimento foi feito para o experimento EN_ODP(-) e a média observada dos eventos EN da ODP(-).

\section{3) O Modelo de Circulação Geral Atmosférico CAM3}

O MCGA Community Atmosphere Model v. 3.0 (CAM3) (Collins et al., 2006) foi utilizado no estudo por representar a sexta geração de MCGA's desenvolvidos por pesquisadores do NCAR - EUA. O CAM3 é a componente atmosférica do MCG acoplado Community Climate System Model versão 3.0 (CCSM3) que é terceira geração de uma série de modelos acoplados desenvolvidos através de colaboração internacional.

O CAM3 é um modelo espectral, e foi integrado na resolução T42, possui coordenada vertical híbrido pressão-sigma (com 26 níveis), sendo o topo da camada superior em $2,9 \mathrm{hPa}$. O esquema de integração temporal é do tipo leap frog semiimplícito, sendo composto por uma fase de inicialização e outra de integração com intervalo de tempo de 20 minutos. Quando utilizado sozinho o CAM3 é integrado com um modelo de superfície e outro termodinâmico de gelo, onde os dados de entrada são TSM, ozônio, gelo marinho, tipo de solo e vegetação, topografia e umidade de solo. Se a TSM for prescrita, as características do modelo termodinâmico de gelo marinho dependerão das condições de superfície como concentração de gelo marinho e espessura que também devem ser prescritas para que variáveis como os fluxos de superfície, profundidade de neve, transferência interna de radiação de onda curta e albedo de superfície sejam calculados.

Esta versão do modelo inclui modificações profundas na física de nuvens e processos de precipitação (Boville et al., 2006), dentre as quais estão o tratamento separado para a fase líquida e sólida do processo de condensação, advecção e sedimentação das nuvens condensadas. Collins et al. (2006) aborda aspectos do balanço radiativo que recebeu novas parametrizações para a interação de radiação de onda longa e curta com vapor de água. E ainda as distribuições de sulfato, poeira, espécies de carbono e sal marinho são prescritas a partir de dados 
assimilados para calcular o efeito direto dos aerossóis na troposfera sobre os fluxos radiativos a taxas de aquecimento.

Hurrell et al. (2005) discutem que as diferenças mais importantes em relação às versões anteriores, dentre elas o Community Climate Model versão 3.0 (CCM3), são relativas a modificações na parametrizações dos processos físicos que resultaram em uma considerável melhora no tempo de processamento e simulações climáticas mais consistentes com o observado. Através de experimentos na grade T42, os autores também abordam a validação do CAM3 para o verão austral do Hemisfério Sul no período entre 1950 a 2000. O padrão observado e magnitude do fluxo divergente em altos níveis foram bem simulados sendo consistente com uma melhora na precipitação tropical simulada. As máximas precipitações associadas com as Zonas de Convergência do Pacífico Sul, América do Sul e da África foram bem simuladas. O gradiente de altura geopotencial simulado foi mais fraco em médias latitudes no Oceano Pacífico do que outras regiões na mesma latitude tanto no inverno quanto no verão. O máximo do vento zonal em médias latitudes durante o inverno do Hemisfério Sul ficou $2^{\circ}-3^{\circ}$ graus de latitude mais próximo do equador do que no inverno do Hemisfério Norte. O máximo dos ventos de oeste entre $40^{\circ} \mathrm{S}$ e $50^{\circ} \mathrm{S}$ foram similares ao observado em os ambos hemisférios apesar de uma super estimação das velocidades superiores que foram acima de $30 \mathrm{~m} . \mathrm{s}^{-1}$, sobre os oceanos Atlântico e Índico. Em termos de magnitude e localização os maiores centros de circulação e suas mudanças intersazonais foram bem simulados apesar de uma ligeiramente intensificação. Próximo à superfície, os ventos alísios simulados foram bem similares aos observados apesar de uma ligeira intensificação devido ao aumento dos centros de alta pressão simulados sobre os oceanos, onde este erro gera um ligeiro bias de leste no stress do vento em superfície. Consistentemente, a distribuição de pressão nos subtrópicos em os ambos hemisférios é maior que a observada tanto no verão quanto no inverno. O CAM3 mostrou deficiências na simulação da variabilidade intrasazonal, porém em termos de validação interanual, os padrões ondulatórios excitados pelo ENOS, como o fluxo divergente em altos níveis, foram bem representados resultando em uma melhor simulação da precipitação tropical e subtropical quando comparado com o CCM3. Estes resultados foram semelhantes aos encontrados por Collins et al. (2006) e Rasch et al. (2006).

Para a América do Sul ainda existem poucas referências relativas ao uso desta ferramenta numérica, assim os resultados aqui apresentados são inovadores e 
podem contribuir significativamente para o conhecimento das interações trópicosextratrópicos sobre o continente. Pereira (2007) investigou a sensibilidade da região do Mar de Weddell e da Confluência Brasil-Malvinas às mudanças na concentração do gelo marinho Antártico através do CCSM3 do qual o CAM3 integra sua componente atmosférica. Foram realizados dois experimentos com diferentes concentrações de gelo marinho onde o comportamento climático anual das variáveis oceânicas e atmosféricas apresentaram sensibilidade aos diferentes cenários. Os resultados mostraram que nos experimentos com maiores concentrações de gelo Antártico, a TSM mostrou maiores valores climatológicos ao norte de $60^{\circ} \mathrm{S}$, isto porque a troca de calor entre a atmosfera e o oceano adjacente é sensível a mudanças no albedo associado ao gelo marinho. A climatologia de PNMM também sofreu influência, tendo como resposta uma intensificação do centro de baixa localizado ao leste do Mar de Weddell neste experimento. Drumond (2008, comunicação pessoal) verificou através de seus experimentos a importância interação ar-mar na configuração das anomalias de TSM associadas ao modo meridional do Atlântico Tropical e, conseqüentemente, na modulação da ZCIT durante o outono austral. Os resultados numéricos mostraram o predomínio de anomalias positivas do fluxo de calor (associadas principalmente à componente turbulenta) sobre as anomalias positivas de TSM e vice-versa, indicando um fluxo anômalo de calor da superfície (atmosfera) para a atmosfera (superfície) onde havia anomalias positivas (negativas) de TSM. Sobre o norte e nordeste do Brasil, os experimentos mostraram que 0 balanço de calor na superfície está aproximadamente em equilíbrio, já que os fluxos anômalos associados às componentes turbulenta e radiativa são opostos e da mesma magnitude.

Os experimentos numéricos aqui apresentados permitirão verificar a sensibilidade do modelo em simular a evolução dos padrões de circulação atmosférica sobre a América do Sul durante os eventos canônicos de EN em cenários distintos da ODP. Vale ressaltar que a análise será feita de forma qualitativa, considerando-se que o modelo tem sido validado e tem reproduzido de maneira satisfatória os principais padrões climatológicos globais de grande escala. Os experimentos numéricos poderão auxiliar na interpretação da dinâmica das composições relativas a componente observacional do estudo. 


\section{4) Algoritmo para detecção de ciclones extratropicais}

O esquema numérico desenvolvido por Murray e Simmonds (1991 a,b) possui a vantagem de ser um método objetivo, capaz de manipular uma grande quantidade de dados em curto período de tempo, ao contrário dos métodos subjetivos de alguns estudos baseados em análises de cartas sinóticas e imagens de satélite. O processo de identificação de um ciclone é feito através do campo de PNMM e é baseado nos seguintes procedimentos:

$11^{\circ}$ etapa: Cada valor de PNMM é comparado com os valores ao redor onde são agrupadas as possíveis candidatas a baixas pressões, em uma matriz. Isto assegura que todos os mínimos intensos e bem definidos sejam identificados.

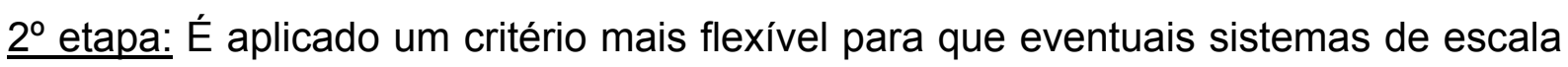
menor também sejam rastreados. Para tanto, o algoritmo utiliza o critério da vorticidade relativa que pode ser escrita como:

$$
\xi=(1 / \rho f) * \nabla^{2} p
$$

onde $\rho$ é a densidade do ar, $f$ é o parâmetro de Coriolis e $\nabla^{2} p$ é o laplaciano da PNMM. Assim, o esquema buscará por pontos de grade nos quais o laplaciano horizontal da pressão seja maior que o laplaciano em oito pontos de grade ao redor e que seja maior que um valor positivo previamente especificado. Ou seja, pontos com um laplaciano máximo (pressão mínima) significam pontos de máxima vorticidade ciclônica.

$3^{\circ}$ etapa: Para cada um dos pontos encontrados, o esquema buscará por um mínimo local de pressão. A convergência para encontrar os mínimos tende a ocorrer depois de 3 ou 4 interações, o que assegura que todos os mínimos encontrados serão realmente pontos de pressão mínima (e não vorticidade ciclônica).

Para determinação da trajetória de um centro de pressão mínima o algoritmo utiliza dois critérios. O primeiro deles considera um determinado raio de ação sobre cada ciclone encontrado em um dado instante de tempo, de modo que todos os sistemas que se encontram neste raio de ação na análise imediatamente posterior serão aceitos para serem a evolução do sistema inicial. O segundo critério é feito para determinar quais dos sistemas aceitos serão considerados na evolução do 
primeiro centro de pressão, onde é feita uma otimização atribuída à máxima probabilidade baseada em uma função decrescente de sua separação e da diferença de pressão central.

O esquema numérico de MS tem sido recentemente utilizado em alguns estudos para o Hemisfério Sul, dentre eles, estão os de Pezza e Ambrizzi (2003) que discutem sobre mudanças nas tendências de ciclones e anticiclones observadas no período de 1973-1996. Pezza e Ambrizzi (2005) estudaram as trajetórias de sistemas transientes associados com diferentes tipos de friagem sobre a América do Sul. Um estudo climatológico de ciclones extratropicais do Hemisfério Sul foi realizado por Beu e Ambrizzi (2006) destacando alguns aspectos da variabilidade intersazonal e variabilidade interanual destes sistemas. O Grupo de Estudos Climáticos (GrEC, <http://www.grec.iag.usp.br>) apresenta mensalmente nas discussões climáticas, as trajetórias e os desvios nas densidades dos sistemas transientes observados no Hemisfério Sul, e a metodologia se mostra mais consistente com as anomalias observadas do que a análise subjetiva aplicada em outros estudos.

As análises apresentadas aqui são realizadas a cada $6 \mathrm{~h}$, onde são considerados apenas os sistemas com cujo tempo de vida superior a 24 horas e cuja pressão mínima seja igual ou inferior a $1010 \mathrm{hPa}$, o que nos permite eliminar o maior número de depressões fracas, geralmente relativos a baixas térmicas que tem pouco impacto no clima devido a sua origem termo-orográfica (Pesquero, 2001; Seluchi et al., 2003; Reboita et al., 2007a). Os resultados são mostrados ao sul de $30^{\circ} \mathrm{S}$, pois esta é uma maneira simples de não considerar o efeito dos centros de baixas térmicas que porventura ainda venham ser rastreados pelo algoritmo. 


\section{CAPÍTULO 3}

\section{1) Circulações de verão sobre a América do Sul durante os anos neutros do Pacífico Equatorial em fases distintas da ODP}

Inicialmente serão ilustradas as composições médias das variáveis atmosféricas durante os anos neutros ocorridos na $\operatorname{ODP}(+)$ (Figura 7). Posteriormente, a diferença entre estas e as composições médias durante anos neutros da ODP(-) serão ilustradas na Figura 8. Na Figura 7a são observados que os centros de máxima precipitação, da ordem de $8 \mathrm{~mm}$.dia ${ }^{-1}$ ficam localizados na região Amazônica e Brasil Central sendo similar a Figura 7d de Carvalho et al. (2004) que sugerem que este padrão de chuvas está associado a ZCAS de categoria continental originada pela atuação do trem de ondas de médias latitudes. Um segundo máximo também pode ser observado no SEAS. Em altos níveis uma circulação anticiclônica centrada sobre a região da Bolívia configura a $A B$ onde sua manutenção pode estar relacionada à liberação de calor latente comum nesta época do ano e aos movimentos ascendentes sobre a região central do Brasil (Figuras 7b e 7c, respectivamente). A lesta da circulação de $A B$ é observado um centro ciclônico sobre o oceano Atlântico e adjacências do Nordeste do Brasil relacionado ao VCAN. Em torno de $40^{\circ} \mathrm{S}$ o gradiente entre o ramo sul da $A B$ e circulação ciclônica no cone sul da América do Sul favorece um escoamento de oeste associado ao JST. No campo de $\omega(500 \mathrm{hPa})$ (Figura $7 \mathrm{c})$ os movimentos ascendentes sobre o Atlântico Equatorial em torno da linha do equador e parte do Nordeste do Brasil está relacionado a atividade convectiva da ZCIT que favorece chuvas sobre o extremo norte do continente durante o verão (Uvo, 1989).

As características de $\omega(500 \mathrm{hPa})$ estão de acordo com o campo de fluxo de umidade integrado verticalmente de divergente associado entre 1000-850 hPa (Figura 7d). Os fluxos divergentes de umidade oriundos do Atlântico Equatorial Norte que adentram o continente e o localizado sobre o oeste da Amazônia contribuem para o transporte de umidade destas regiões ao centro do País e região Sul. O ramo noroeste da AAS seguido de divergência sobre o Atlântico Tropical Oeste e 
proximidades da costa contribui para a convergência de umidade sobre a região sudeste.

\section{NEU ODP(+)}
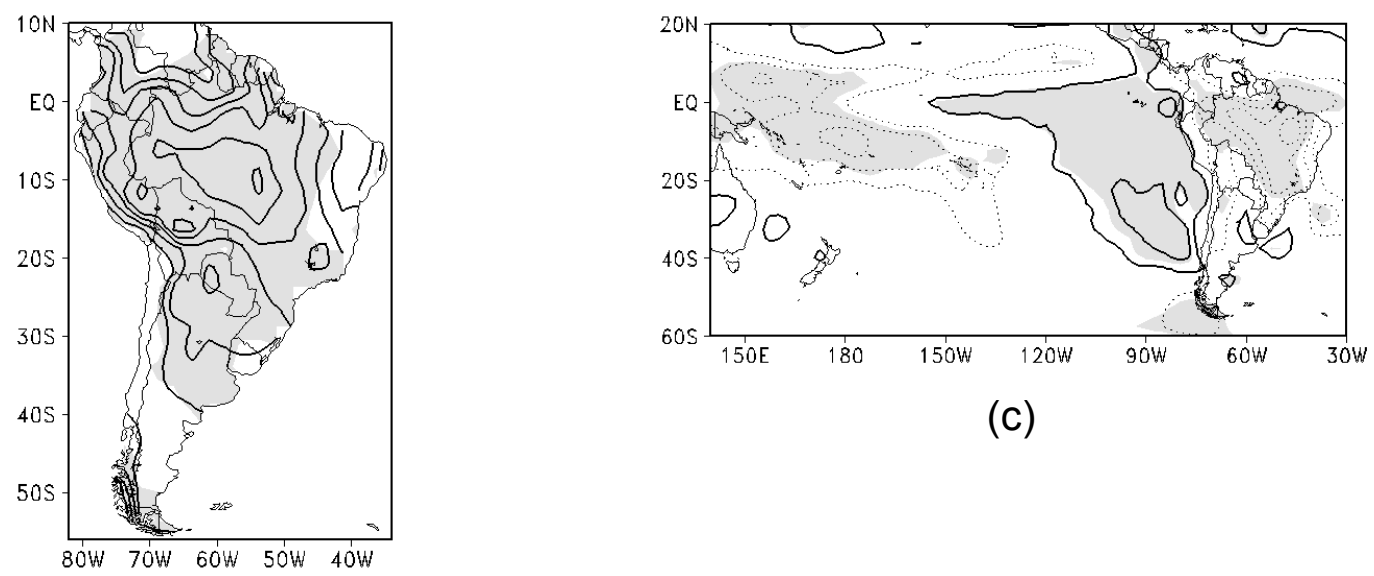

(c)

(a)
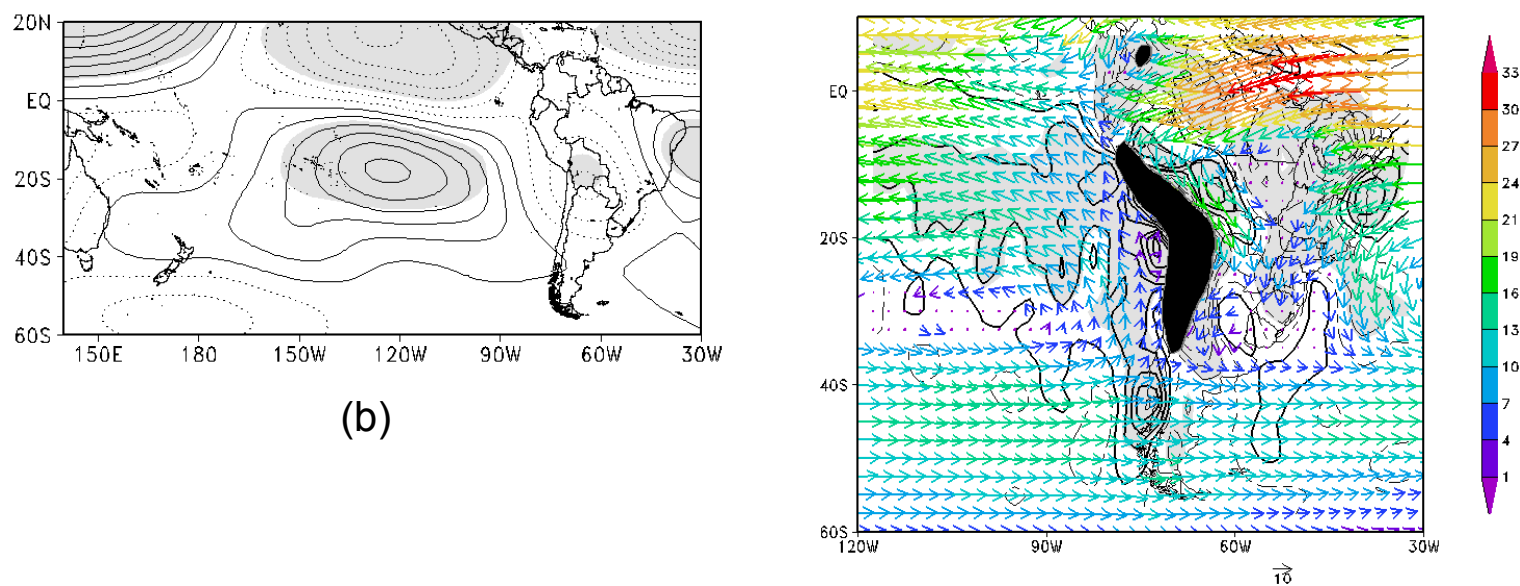

(d)

Figura 7 - Composições médias observadas durante anos neutros ocorridos na $\mathrm{ODP}(+)$ : (a) taxa de precipitação; (b) componente zonalmente assimétrica de $\psi(200$ $\mathrm{hPa}) ;(\mathrm{c}) \omega(500 \mathrm{hPa})$ e (d) fluxo de umidade integrado e divergente associado entre 1000-850 hPa. Contornos a cada $2 \mathrm{~mm} \cdot \mathrm{dia}^{-1}, 4 \times 10^{6} \mathrm{~m}^{2} \cdot \mathrm{s}^{-1}$ começando por $2 \times 10^{6}$, $2 \mathrm{hPas}^{-1}, 3 \mathrm{~g} \cdot \mathrm{m}^{-2} \cdot \mathrm{s}^{-1}$ começando por $1 \mathrm{~g} \cdot \mathrm{m}^{-2} \cdot \mathrm{s}^{-1}$. Valores positivos (negativos) estão em linhas contínuas (pontilhadas/tracejadas). Vetores de fluxo $\left(\mathrm{g} \cdot \mathrm{m}^{-1} \cdot \mathrm{s}^{-1}\right)$ plotados e áreas sombreadas indicam valores estatisticamente significativos ao nível de $90 \%$.

A Figura 8 apresenta as diferenças entre as composições médias dos anos neutros da $\mathrm{ODP}(+)$ e $\mathrm{ODP}(-)$, sendo que no caso da precipitação existem poucas 
diferenças significativas e estas são ligeiramente negativas, localizadas ao norte da região do SEAS e extremo noroeste da Amazônia. Nas diferenças relativas ao campo de TSM vale destacar aquelas com valores negativos no Pacífico Norte e positivas no Atlântico Sudoeste indicando um ligeiro aprofundamento da Baixa das Aleutas e ligeiro aquecimento do Atlântico Sudoeste nos anos neutros da ODP(+) quando comparado com a $\operatorname{ODP}(-)$. O sinal sobre o Atlântico Sudoeste possui certa similaridade com o modo de variabilidade interdecadal encontrado por Servain (1991) e Venegas (1997) porém ainda pouco entendido devido à escassez de dados nesta região, mas que tende a apresentar variabilidade decadal mais destacada do que a variabilidade interanual e ter maior destaque nas latitudes subtropicais do que no Equador.

A Figura 8c mostra uma circulação ciclônica sobre a maior parte do continente, sugerindo um enfraquecimento da componente zonalmente assimétrica da $\Psi(200$ $\mathrm{hPa}$ ) descritas na Figura $7 \mathrm{~b}$ durante os anos neutros da $\operatorname{ODP}(-)$, entretanto a diferença é estatisticamente significativa somente nas regiões centradas em $18^{\circ}$ de ambos hemisférios sobre o Atlântico Tropical e em $30^{\circ} \mathrm{W}$ e sobre o Pacífico ao redor de $150^{\circ} \mathrm{E}$. Diferenças ligeiramente negativas de $\omega(500 \mathrm{hPa})$ são encontradas na Figura 8d sobre o extremo norte da América do Sul possivelmente associadas as diferenças negativas de precipitação sobre a região encontradas na Figura 8a. Um fluxo ciclônico de umidade seguido de convergência sobre Brasil Central e um núcleo divergente sobre o Atlântico Tropical Oeste e proximidades do Nordeste são observados na Figura 8e. Isto sugere que para anos neutros da $\operatorname{ODP}(+)$ há um ligeiro aumento no fluxo divergente oriundo do Atlântico seguido de um ligeiro aumento no fluxo convergente que alimenta a convecção na ZCAS estando coerente com as diferenças na TSM (Figura 8b).

As análises acima sugerem que há poucas variações significativas, principalmente em altos e médios níveis, no regime de precipitação sobre a América do Sul e sistemas associados ao considerar a influência dos anos neutros em distintas fases da ODP. Apenas as regiões ao extremo norte do continente e ao norte do SEAS apresentaram diferenças significativas e ligeiramente negativas, sugerindo uma extensão das chuvas mais para sudeste do Brasil durante os anos neutros da ODP(-) quando comparado com os anos de $\operatorname{ODP}(+)$. Na ausência de anomalias de TSM do Pacífico Equatorial, o efeito local do Atlântico Sudoeste parece modular o regime de circulação do continente em baixos níveis, onde são 
encontradas águas ligeiramente mais quentes na $\mathrm{ODP}(+)$ nesta bacia. Goodrich $(2004,2006)$ encontrou resultados diferentes para a América do Norte onde os anos neutros têm influências opostas no continente dependendo da fase da ODP e colaboram para fortes sinais de mudanças de circulação. Assim, uma investigação observacional e numérica sobre a evolução do aquecimento do Pacífico Equatorial Centro-leste nos dois cenários de ODP poderá colaborar na explicação do que é mais importante para o regime de precipitação de verão da América do Sul: a influência da fase quente do ENOS ou sua interação com o modo de ODP. 
NEU ODP(+) menos NEU ODP(-)
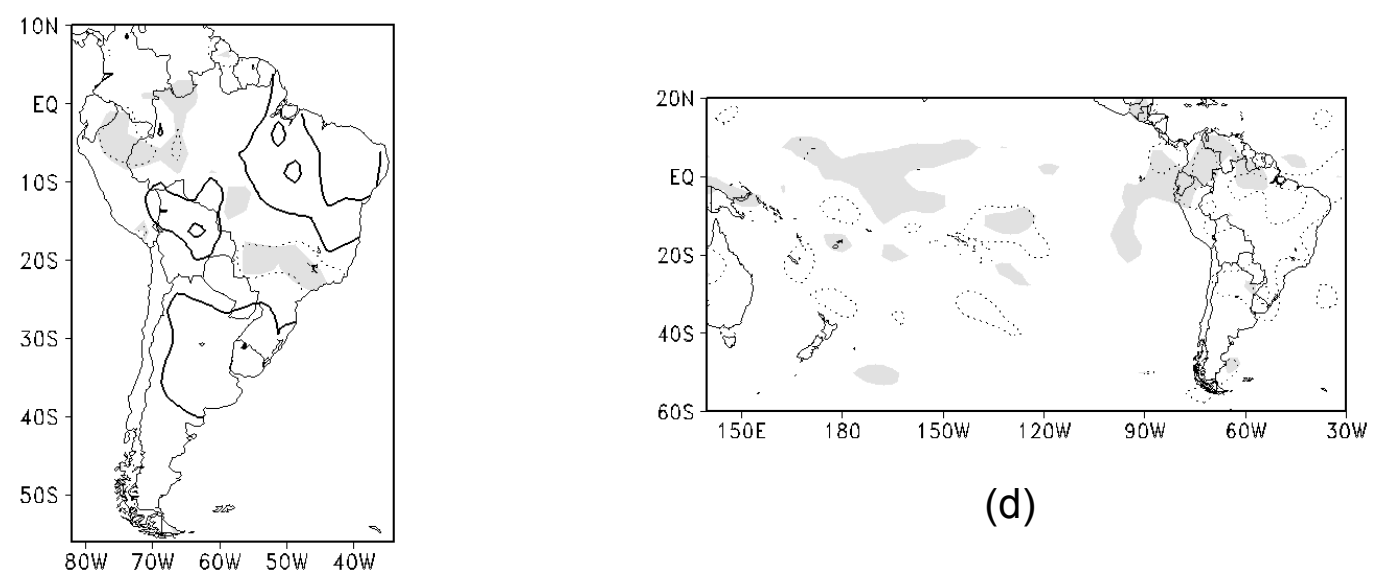

(d)

(a)

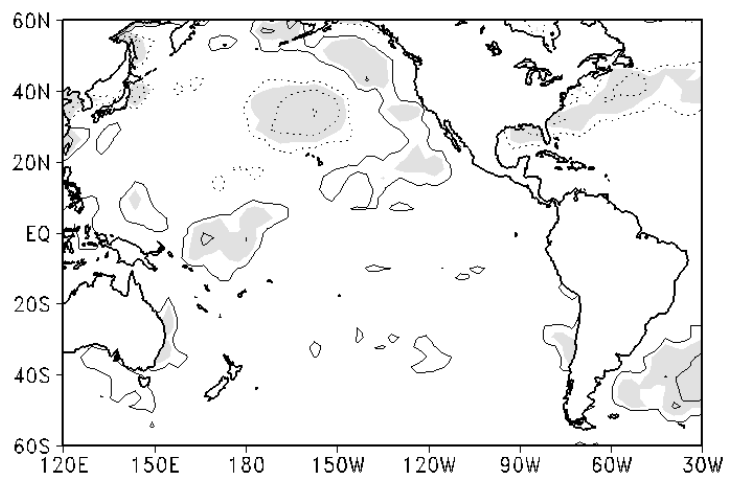

(b)

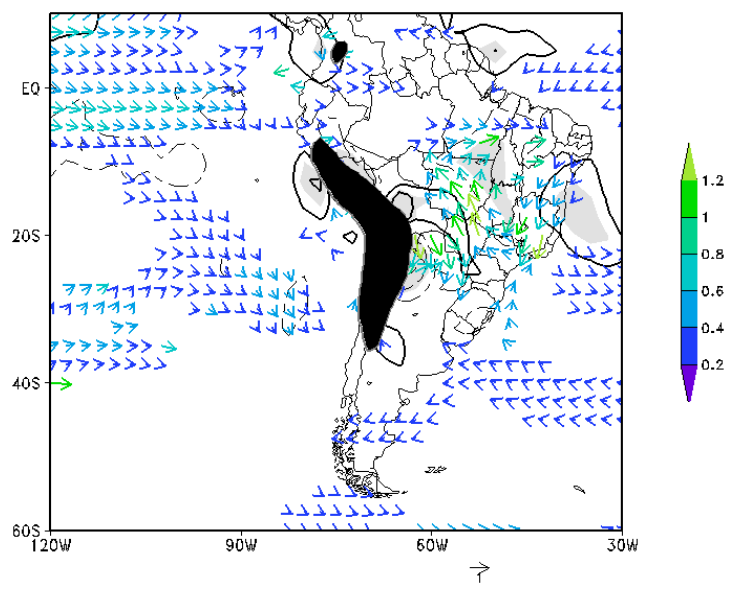

(e)

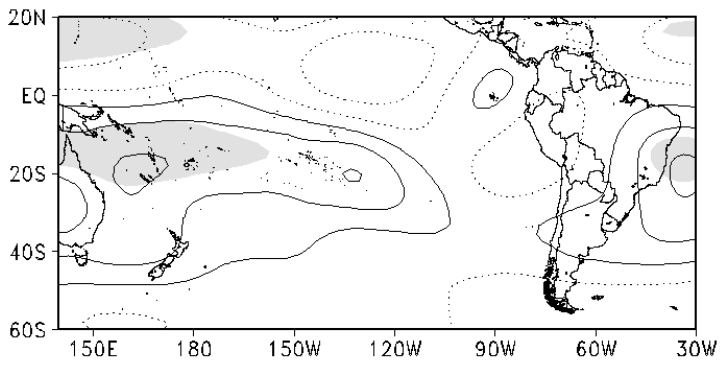

(c)

Figura 8 - Diferenças entre as composições médias observadas durante anos neutros ocorridos na ODP(+) menos os da ODP(-): (a) taxa de precipitação; (b) TSM; (c) componente zonalmente assimétrica de $\psi(200 \mathrm{hPa})$; (d) $\omega(500 \mathrm{hPa})$ e (e) fluxo de umidade integrado e divergente associado entre 1000-850 hPa. Contornos a cada 1 mm.dia ${ }^{-1}$ começando com $0.5 \mathrm{~mm} \cdot \mathrm{dia}^{-1}, 0.4^{\circ} \mathrm{C}, 4 \times 10^{6} \mathrm{~m}^{2} . \mathrm{s}^{-1}$ começando por $2 \times 10^{6}$ $\mathrm{m}^{2} \cdot \mathrm{s}^{-1}, 2 \mathrm{hPas}^{-1}$ começando por $1 \mathrm{hPas}^{-1}, 0.2 \mathrm{~g} \cdot \mathrm{m}^{-2} \cdot \mathrm{s}^{-1}$. Valores positivos (negativos) estão em linhas contínuas (pontilhadas/tracejadas). Vetores de fluxo $\left(\mathrm{g} \cdot \mathrm{m}^{-2} \cdot \mathrm{s}^{-1}\right)$ plotados e áreas sombreadas indicam valores estatisticamente significativos ao nível de $90 \%$. 


\section{2) Estudo observacional da evolução dos eventos EN em fases distintas da ODP: impactos no verão austral da América do Sul}

A Figura 9 ilustra as composições de anomalias de precipitação e TSM associadas em anos de EN durante a ODP(+), (Figuras 9a e 9b) e ODP(-), (Figuras 9c e 9d). Na Figura 9a são observadas anomalias positivas de precipitação sobre a maior parte do SEAS, com maior significância estatística nas regiões Sul, Uruguai, sul do Paraguai e centro-norte da Argentina. As anomalias negativas predominam sobre o norte do continente, principalmente sobre a região Amazônica entre o equador e $10^{\circ} \mathrm{S}$. O padrão anômalo de TSM mostra um núcleo de águas acima da normalidade sobre o Pacífico Equatorial entre $180^{\circ} \mathrm{W}-80^{\circ} \mathrm{W}$ com núcleo máximo de $1.6^{\circ} \mathrm{C}$ entre $150^{\circ} \mathrm{W}-90^{\circ} \mathrm{W}$. Na Figura $9 \mathrm{c}$ para os eventos EN da ODP(-) são observadas anomalias negativas de precipitação ao norte da Amazônia mais fracas e menos significativas quando comparadas com a Figura 9a. Isto concorda com as observações de Marengo (2004) que discute que sobre o norte da Amazônia as anomalias negativas tenderam a serem mais fracas depois da década de 70 coerentemente com o fato de ter ocorrido uma maior freqüência de eventos EN nesta época, destacando assim importância do aquecimento do Pacífico Central e Leste no decréscimo das chuvas na região Amazônica. Entretanto, certa cautela deve ser tomada já que esta é uma região de poucas observações. Sobre a maior do SEAS houve predomínio de anomalias negativas de precipitação mais ao norte, e sobre o Nordeste da Argentina e Uruguai predominaram anomalias positivas e mais fracas que na Figura $9 a$.

Águas mais quentes que o normal sobre o Pacífico Equatorial também são encontradas na Figura 9d, entretanto, mais fracas e com núcleo de máxima ligeiramente deslocado mais para oeste quando comparado com a Figura 9b. Anomalias ligeiramente positivas também são observadas sobre ○ Atlântico Equatorial nas proximidades do continente. Os padrões de anomalias de TSM sobre o Pacífico e Atlântico Equatorial, citados anteriormente, se assemelham ao modo equatorial do Atlântico Tropical encontrado por Zebiak (1993) e Chang e Li (1997) 
que varia em escala sazonal e interanual e tem similaridade com o ENOS. Os estudos discutem que ambos Pacífico e Atlântico apresentam oscilações similares centradas no equador com períodos de poucos anos, porém para longos períodos esta similaridade deixa de existir, possivelmente devido ao modo decadal dominante no Atlântico com maior sinal nos subtrópicos. O padrão geralmente ocorre semanas depois do pico máximo do ENOS em resposta a propagação das ondas de Kelvin equatoriais e Rossby, e em sua fase quente os ventos alísios no Atlântico Equatorial Oeste ficam enfraquecidos e as anomalias de TSM próximo ao equador ficam ligeiramente acima da normal. Na fase fria do modo equatorial do Atlântico Tropical são esperadas características opostas.

As características de circulação atmosférica associadas à Figura 9 são mostradas na Figura 10 para os eventos EN ocorridos na ODP(+),(Figuras 10a- 10b) e ODP (-), (Figuras 10d-10f). As anomalias observadas em altos níveis podem ser entendidas em resposta a forçante de calor simétrica em relação ao equador resultando em um trem de ondas de Rossby a oeste da forçante e de Kelvin a leste desta. Neste caso, a Figura 10a mostra que a resposta devido a onda de Kelvin é o estabelecimento de anomalias anticiclônicas de $\psi(200 \mathrm{hPa})$ sobre os trópicos da América do Sul, exceto sobre o Nordeste, dando suporte aos movimentos ascendentes sobre a região (Figura 10b). A resposta em função da onda de Rossby é o estabelecimento de circulação anticiclônica sobre o SEAS que favorece uma circulação meridional secundária sobre a região e que foi descrita por Zhou e Lau (2001) estando associada a movimentos ascendentes sobre o sul do Brasil, norte da Argentina, Uruguai e Paraguai e conseqüente aumento de convecção sobre estas regiões (Figura 10b). O fluxo de umidade integrado verticalmente e divergente associado entre 1000-850 hPa (Figura 10c) mostra que parte da divergência anômala oriunda do Atlântico Equatorial Oeste converge sobre a Amazônia coerente com o movimento vertical ascendente observado sobre a região na Figura $10 \mathrm{~b}$ e manutenção da circulação anticiclônica em altos níveis sobre os trópicos (Figura 10a). Porém, a outra parte do fluxo de umidade que adentra o continente juntamente com o fluxo divergente sobre a Amazônia seguem em direção ao SEAS que fica sob o predomínio de convergência de umidade anômala de noroeste. O campo está de coerente com as anomalias positivas de chuva observadas na Figura 9a sobre maior parte do SEAS, uma vez que maior convergência de ar quente e úmido e movimentos ascendentes sobre a região induziriam precipitação. Entretanto, não 
está coerente com as anomalias negativas de precipitação observadas sobre a Amazônia o que sugere que outro fator além do dinâmico pode ter colaborado para este padrão sendo necessárias futuras análises.

Em 200 hPa para os eventos EN da ODP(-), o anticiclone anômalo sobre o oceano Pacífico apresentou um deslocamento de aproximadamente $30^{\circ}$ para oeste quando comparado com a Figura 10a. A resposta em Rossby desencadeia um trem de onda do tipo PSA1 (Karoly, 1989 e Mo e Paegle, 2001) um trem de ondas estendendo desde o centro-leste do Pacífico retornando para nordeste próximo de $60^{\circ} \mathrm{S}$, e alcançando latitudes tropicais sobre o oceano Atlântico (Figura 10d). Sobre o sul da América do Sul predominam anomalias ligeiramente ciclônicas sobre os trópicos e anticiclônica sobre o Sul do Brasil e Uruguai o que pode favorecer a manutenção dos ventos de oeste em torno de $40^{\circ} \mathrm{S}$. Sobre os trópicos são observadas anomalias ciclônicas sobre grande parte do continente e de maneira consistente, as regiões Norte e Nordeste ficam sob o predomínio de movimento descendente (Figura 10e). Na Figura 10f a fraca divergência anômala sobre o Atlântico Equatorial Oeste e o núcleo divergente de umidade associado a uma circulação anticiclônica anômala centrada sobre o centro-sudeste do Brasil parecem contribuir para o enfraquecimento dos ventos alísios sobre a região consistente com a fase positiva do modo equatorial do Atlântico Tropical comentado por Zebiak e Chang e Li. O ramo oeste desta circulação anticiclônica contribui para um intenso fluxo meridional desde o sul da Amazônia até do sul do Brasil, entretanto, sem transporte de umidade significativa para a região, o que sugere que o aporte de umidade do Atlântico Equatorial é mais importante na manutenção de anomalias positivas no SEAS quando comparada com a umidade transportada da região Amazônica. Este padrão de circulação assemelha-se ao encontrado por Herdies et al. (2002) e Drumond (2005) os quais sugerem estar relacionado ao enfraquecimento do transporte de umidade que ocorre na região da ZCAS, desviando a umidade proveniente da Amazônia em direção ao sul do Brasil contribuindo para as anomalias positivas de precipitação nesta região. De fato, como observado na Figura 9c vimos que este padrão pode ter contribuído para anomalias negativas de precipitação no norte do SEAS, região que também é influenciada pela ZCAS. Entretanto, grande parte do Sul do Brasil também esteve sobre o predomínio de anomalias negativas e apenas anomalias positivas de precipitação foram observadas no Uruguai e Nordeste da Argentina. Isto sugere que outro mecanismo 
possa explicar o padrão anômalo de chuva sobre estas regiões, uma vez que fluxo de umidade oriundo da Amazônia sobre a região foi fraco e não significativo. Uma investigação da atividade ciclogenética sobre o cone sul da América do Sul será apresentada no Capítulo 5, o qual poderá auxiliar com explicações adicionais a respeito das anomalias de chuva da Figura 9.

Em geral, as anomalias de TSM e de circulação atmosférica ocorridas no verão austral de eventos $\mathrm{EN}$ da $\mathrm{ODP}(+)$ mostraram importante diferenças quando comparadas com as anomalias ocorridas nos eventos EN da ODP(-). Estas podem estar mais relacionadas aos padrões de teleconexão oriundos do Pacífico Equatorial do que pela configuração conjunta com as anomalias negativas de TSM no Pacífico Norte. No período entre 1977-1999 em que a ODP esteve em sua fase positiva, os eventos EN estiveram associados a águas anomalamente mais quentes e deslocadas mais para o leste do oceano Pacífico Equatorial quando comparado com os eventos ocorridos de 1950-1976, período regido pela fase fria da ODP. Os eventos da fase fria também foram seguidos de um ligeiro aquecimento do Atlântico Equatorial Oeste o que não ocorreu a partir da segunda metade da década de 1970. Tais diferenças no comportamento anômalo das TSM's contribuíram para diferentes padrões de onda em altos níveis. Como conseqüência houve diferenças nas anomalias de circulações trópicos-extratrópicos afetando o regime de umidade sobre o continente, principalmente sobre a região do SEAS. Isto reforça os resultados de Ambrizzi et al. (2004) que observaram que não necessariamente todos eventos EN ou LN produzem os impactos canônicos, isto devido à atuação conjunta do Pacífico Equatorial e do Atlântico Tropical na modulação das células de circulação regionais e conseqüentemente da precipitação. A análise numérica a seguir poderá contribuir para aprimorar esta discussão. 
EN ODP(+)

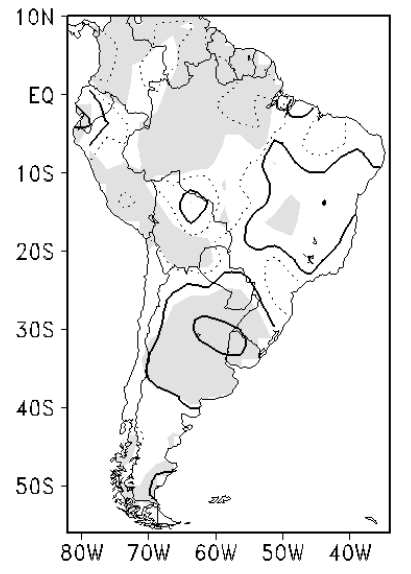

(a)
EN ODP(-)

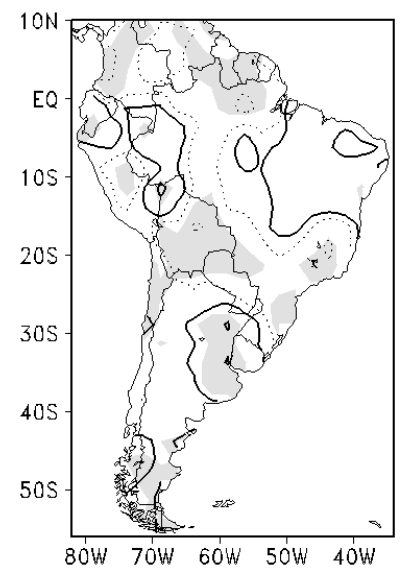

(c)

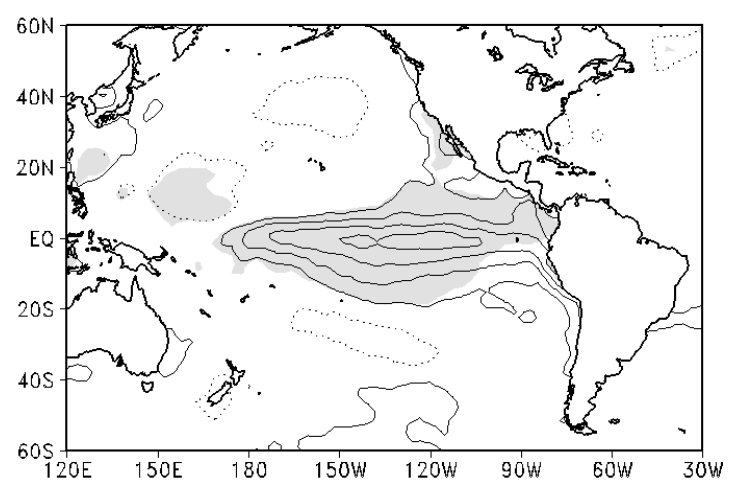

(b)

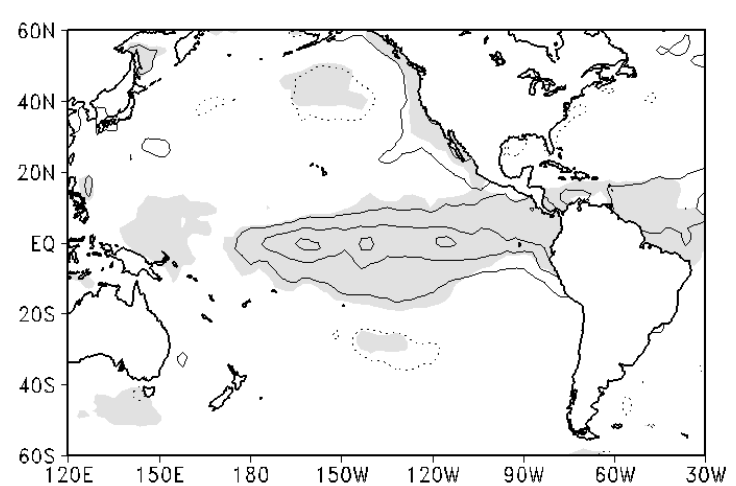

(d)

Figura 9 - Composições de anomalias observadas para os eventos EN ocorridos na $\operatorname{ODP}(+)$ : (a) taxa de precipitação, (b) TSM. Idem para as letras (c) e (d), mas para os eventos ocorridos na ODP $(-)$. Contornos a cada $0.5 \mathrm{~mm} . \mathrm{dia}^{-1}$ começando com 1 $\mathrm{mm} \cdot \mathrm{dia}^{-1}, \quad 0.4^{\circ} \mathrm{C}$. Valores positivos (negativos) estão em linhas contínuas (pontilhadas). Valores estatisticamente significativos ao nível de $90 \%$ estão sombreados. 
EN ODP (+)

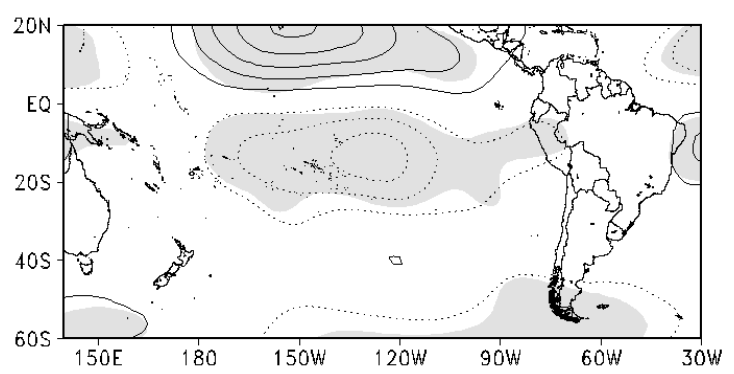

(a)

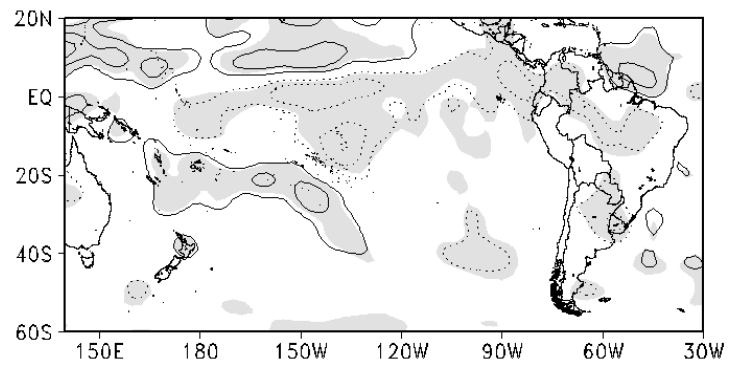

(b)

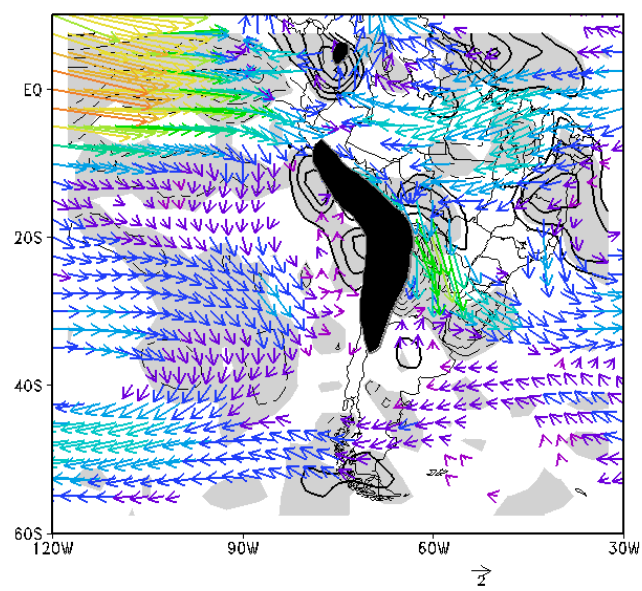

(c)
EN ODP(-)

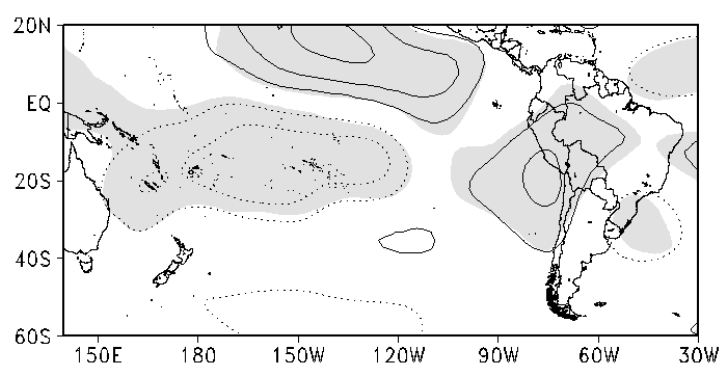

(d)

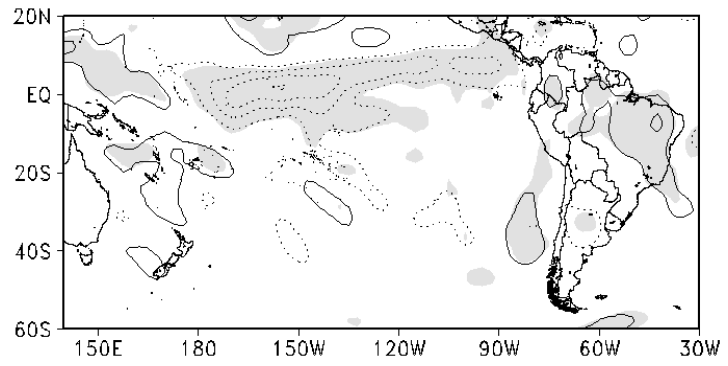

(e)

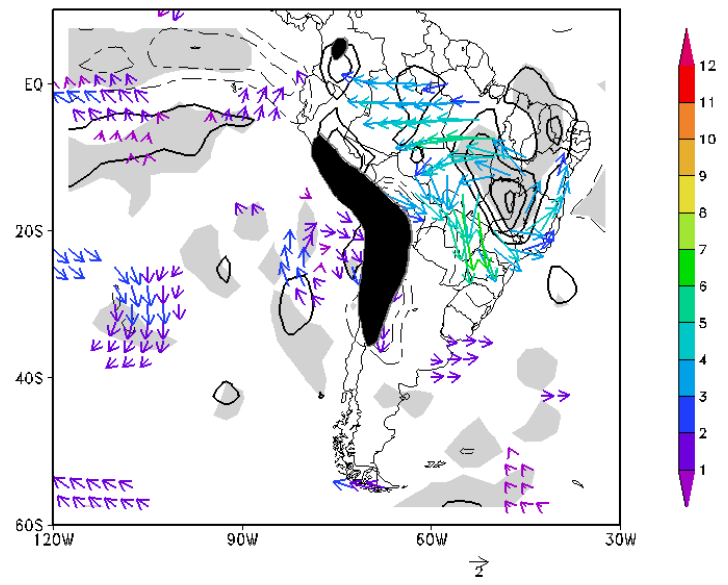

(f)

Figura 10 - Composições de anomalias observadas para os eventos EN ocorridos na ODP(+): (a) componente zonalmente assimétrica de $\psi(200 \mathrm{hPa})$; (b) $\omega(500 \mathrm{hPa}) \mathrm{e}$ (c) fluxo de umidade integrado e divergente associado entre 1000-850 hPa. Idem para as letras (d), (e) e (f), mas para os eventos ocorridos na ODP(-). Contornos a cada $4 \times 10^{6} \mathrm{~m}^{2} \cdot \mathrm{s}^{-1}$ começando por $2 \times 10^{6} \mathrm{~m}^{2} \cdot \mathrm{s}^{-1}, 1 \mathrm{hPas}{ }^{-1}, 1 \mathrm{~g} \cdot \mathrm{m}^{-}{ }^{2} \cdot \mathrm{s}^{-1}$. Valores positivos (negativos) estão em linhas contínuas (pontilhadas/tracejadas). Vetores de fluxo $\left(\mathrm{g} \cdot \mathrm{m}^{-2} \cdot \mathrm{s}^{-1}\right)$ plotados e áreas sombreadas indicam valores estatisticamente significativos ao nível de $90 \%$. 


\section{CAPÍTULO 4}

\section{Estudo numérico da evolução dos eventos EN em fases distintas da ODP: impactos na circulação de verão da América do Sul}

Neste Capítulo serão apresentados os resultados dos experimentos numéricos realizados com o MCGA CAM3. Estudos com MCGA's mostram que a partir de uma forçante baseada em anomalias positivas de TSM sobre o Pacífico Equatorial centroleste, o modelo poderá produzir através de uma média de ensembles uma resposta realística do clima sobre a América do Sul similar a anomalia observada em EI Niños canônicos. Entretanto, o que aconteceria se o modelo fosse forçado com esta mesma forçante e no restante do domínio fossem atribuídos valores de TSM e gelo marinho correspondentes a dois cenários distintos de ODP? Assim, foram realizados dois experimentos contendo um ensemble médio de 10 membros cada, e que foram descritos na Tabela 2 do Capítulo 2. Posteriormente, para se averiguar a sensibilidade do modelo foram calculadas duas diferenças. A primeira dela é referente à diferença entre o experimento EN_ODP(+) e a média observada dos eventos EN da ODP(+), denominada de DIF_ENODP(+). E a segunda é referente à diferença entre o experimento EN_ODP(-) e a média observada dos eventos EN da ODP(-), ou DIF_ENODP(-).

Os experimentos EN_ODP(+) e EN_ODP(-) mostraram-se bem similares em termos de posicionamento das variáveis simuladas, havendo uma ligeira diferença apenas em intensidade. Assim, será ilustrado apenas o experimento EN_ODP(+), Figura 11, onde a precipitação simulada mostra um máximo desde a Amazônia até o Brasil central alcançando o norte do SEAS (Figura 11a). No campo simulado de componente zonalmente assimétrica de $\psi(200 \mathrm{hPa})$ são observados o anticiclone relativo a circulação de $A B$ centrado em $15^{\circ} \mathrm{S} ; 65^{\circ} \mathrm{W}$, o cavado no Oceano Atlântico próximo ao litoral Nordeste do Brasil que pode ser associado ao VCAN e ao sul da circulação da $A B$ existe um escoamento de oeste entre $30^{\circ} \mathrm{S}-50^{\circ} \mathrm{S}$ (Figura $11 \mathrm{~b}$ ). Valores significativos e negativos de $\omega(500 \mathrm{hPa})$ entre $10^{\circ}-25^{\circ} \mathrm{S}$ sobre o continente 
são observados, indicando movimento ascendente coerente com os máximos de precipitação simulados na região (Figura 11a e 11c, respectivamente). Sobre o extremo norte do continente e Atlântico Equatorial Norte os valores positivos foram simulados possivelmente em resposta ao deslocamento do ramo subsidente da circulação do Walker sobre a região quando da ocorrência de eventos canônicos de EN assim como sugerem Ambrizzi et al. (2004).

O fluxo divergente de umidade sobre o Atlântico Equatorial adentra no interior do continente onde parte converge sobre a Amazônia e parte associa-se com a divergência no oeste da Amazônia sendo direcionados para o centro-sul do País (Figura 11d). Sobre o Atlântico Tropical é observado um núcleo de divergência que está relacionado a uma circulação anticiclônica que transporta umidade do Atlântico Sudoeste e proximidades do extremo sudeste do Brasil. Esta configuração em baixos níveis, associada ao movimento ascendente mostrado na Figura 11c, colaboram para a precipitação simulada na região. 


\section{Experimento EN_ODP(+)}

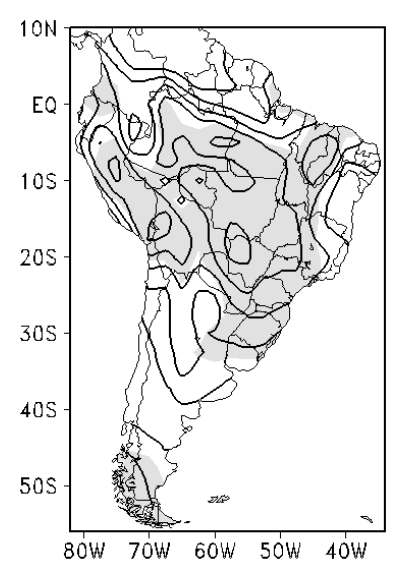

(a)

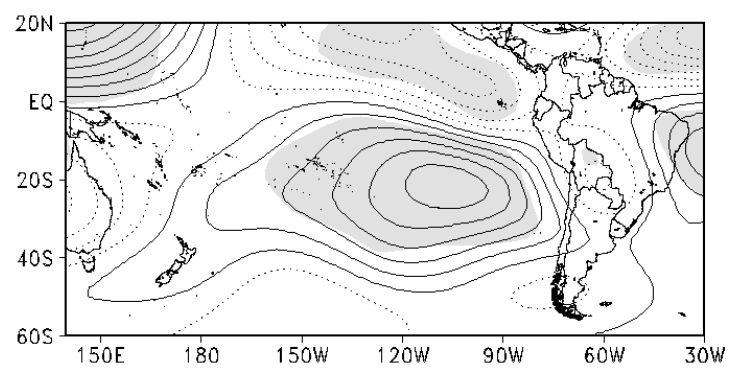

(b)

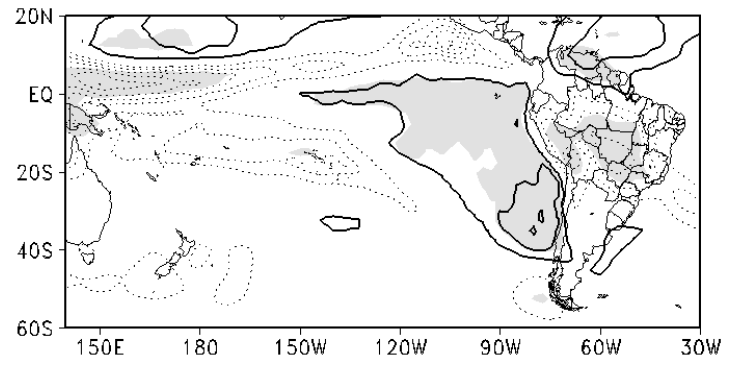

(c)

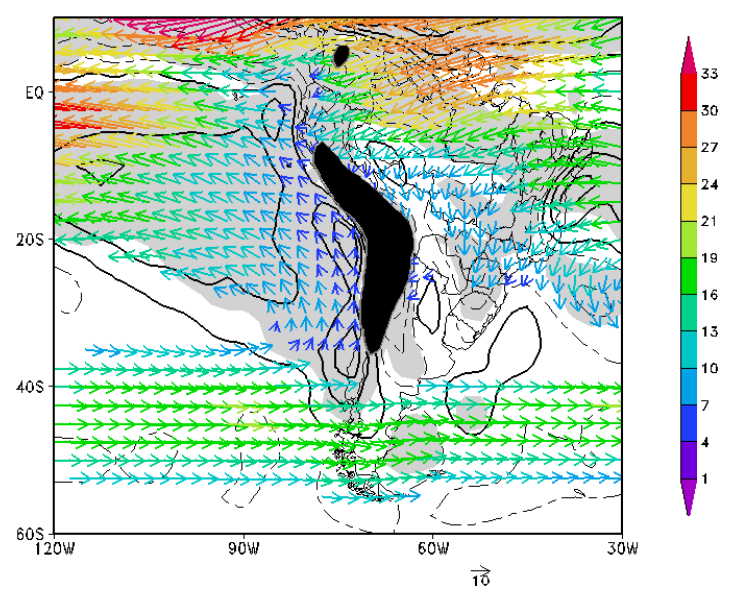

(d)

Figura 11 - Ensemble médio do experimento EN_ODP(+): (a) taxa de precipitação, (b) componente zonalmente assimétrica de $\psi(200 \mathrm{hPa})$; (c) $\omega(500 \mathrm{hPa})$ e (d) fluxo de umidade integrado e divergente associado entre 1000-850 hPa. Contornos a cada 2 $\mathrm{mm} \cdot \mathrm{dia}^{-1}, 4 \times 10^{6} \mathrm{~m}^{2} \cdot \mathrm{s}^{-1}$ começando por $2 \times 10^{6} \mathrm{~m}^{2} \cdot \mathrm{s}^{-1}, 2 \mathrm{hPas}{ }^{-1}, 3 \mathrm{~g} \cdot \mathrm{m}^{-2} \cdot \mathrm{s}^{-1}$. Valores positivos (negativos) estão em linhas contínuas (pontilhadas/tracejadas). Vetores de fluxo $\left(\mathrm{g} \cdot \mathrm{m}^{-1} \cdot \mathrm{s}^{-1}\right)$ plotados e áreas sombreadas indicam valores estatisticamente significativos ao nível de $90 \%$.

As Figuras 12 a-d, ilustram as diferenças entre o experimento EN_ODP(+) e os campos médios observados em anos de EN ocorridos na ODP(+), enquanto que as Figuras 12 e-h, ilustram as diferenças entre a simulação EN_ODP(-) e os campos médios observados em anos de EN ocorridos na ODP(-). É possível perceber que ambas as diferenças possuem certa similaridade para todas as variáveis, entretanto 
com menos significância na DIF_ENODP(+) e intensidade ligeiramente maior na DIF_ENODP(-), principalmente sobre os subtrópicos da América do Sul.

De acordo com as Figuras 12a e 12e são observadas diferenças negativas de precipitação com orientação noroeste-sudeste desde o sudeste da Amazônia até o leste do Brasil entre as latitudes entre $15^{\circ}-25^{\circ} \mathrm{S}$ o que indica que a chuva simulada pelo modelo nesta região foi subestimada. Ao contrário, sobre a região do SEAS e Nordeste há diferenças positivas indicando super estimativa pelo modelo. As Figuras $12 b$ e $12 f$ mostram que sobre grande parte dos trópicos não existem diferenças significativas entre os campos de $\psi(200 \mathrm{hPa})$ simulados e os médios observados. Entretanto, os valores positivos nos subtrópicos indicam que há predomínio de circulação ciclônica mais intensa simulada pelo modelo sobre a região. Na Figura 12c e $12 \mathrm{~g}$ são observadas diferenças positivas de $\omega(500 \mathrm{hPa})$ sobre o extremo norte da América do Sul indicando que o modelo superestimou o movimento descendente nesta região, concordando com as diferenças no campo de chuva das Figuras 12a e 12e, entretanto sobre o interior do Nordeste as diferenças positivas indicam movimento ascendente menos intenso simulado, o que não concorda com as diferenças positivas de precipitação sobre a região. Sobre a faixa noroeste-sudeste do Brasil as diferenças negativas de $\omega(500 \mathrm{hPa})$ indicam que o movimento ascendente simulado foi mais intenso o que pode explicar a precipitação mais intensa sobre a região simulada pelo modelo. As diferenças no fluxo de umidade integrado verticalmente e divergente associado entre 1000-850 hPa mostram valores positivos relacionados a divergência de umidade sobre a faixa noroeste-sudeste do Brasil indicando que o modelo subestimou o fluxo convergente de umidade do Atlântico transportado pelos alísios. Como conseqüência, houve uma simulação mais fraca do escoamento de noroeste-sudeste sobre a região o que pode explicar as diferenças negativas de precipitação desde o sudeste da Amazônia até o leste do Brasil entre as latitudes entre $15^{\circ}-25^{\circ} \mathrm{S}$ (Figuras $12 \mathrm{~d}$ e $12 \mathrm{~h}$ ). O núcleo divergente sobre Nordeste indica que o fluxo convergente simulado sobre a região foi mais fraco o que não é coerente com as Figuras 12a, pois, foram observadas diferenças positivas de precipitação (Figuras 12a e 12e). 
DIF_ENODP $(+)$

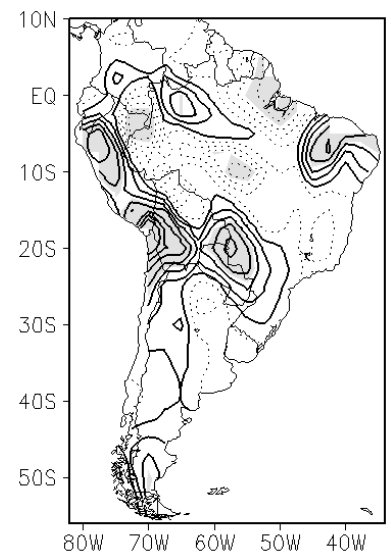

(a)

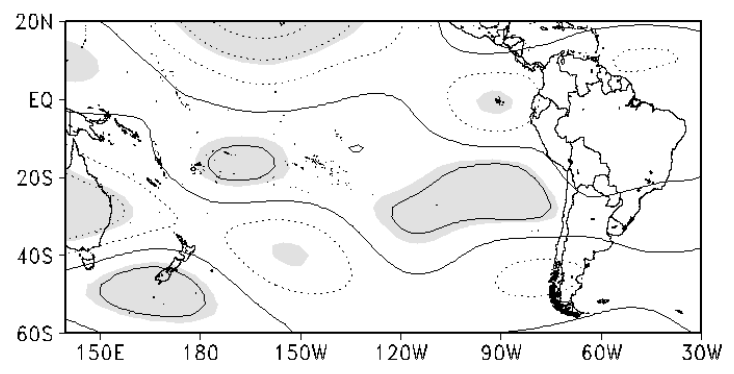

(b)

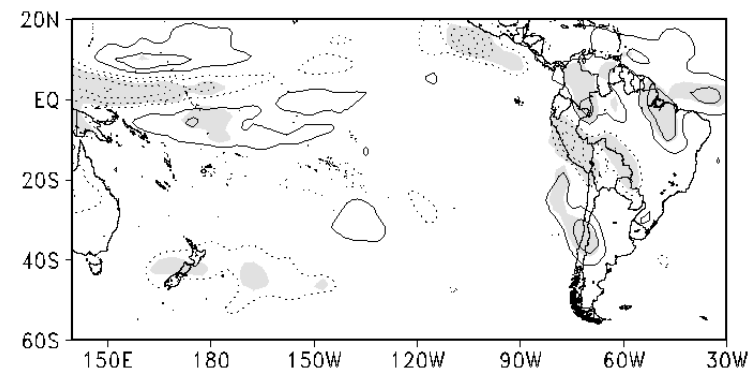

(c)

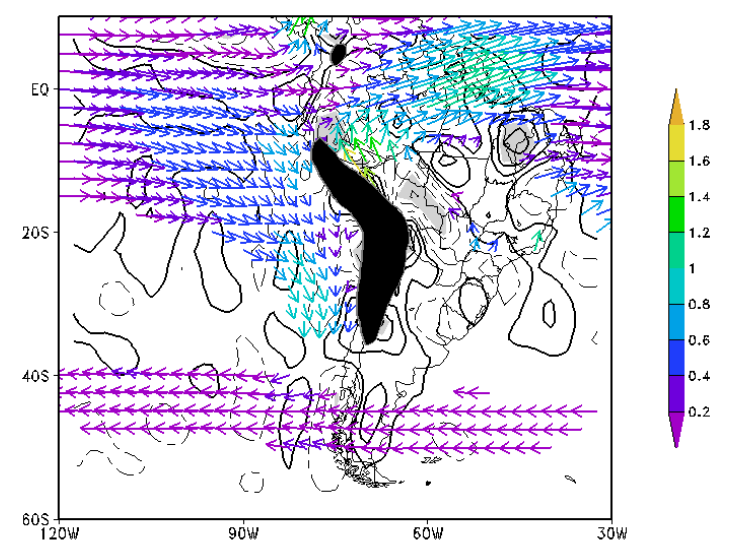

(d)
DIF_ENODP(=)

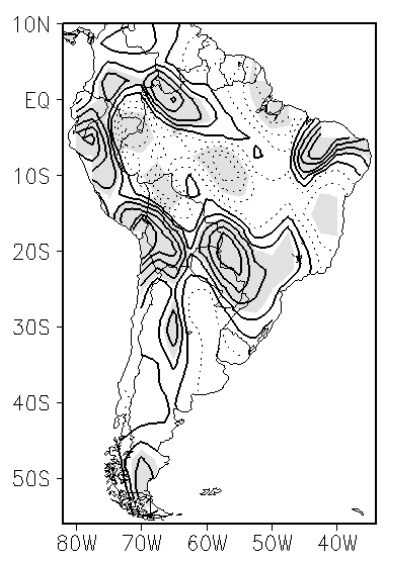

(e)

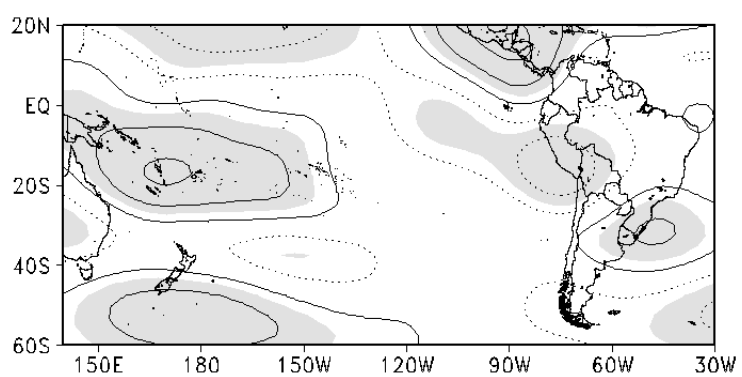

(f)

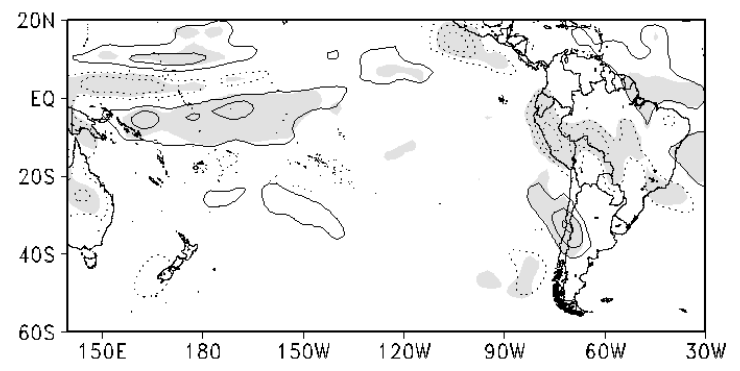

(g)

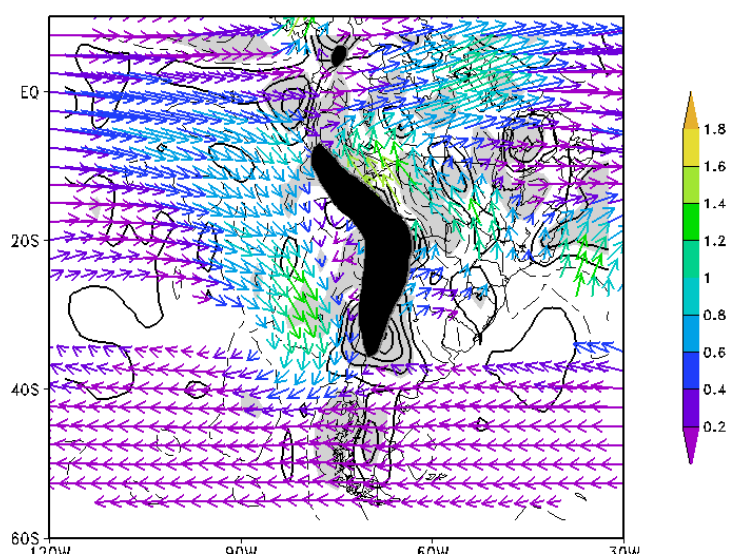

(h)

Figura 12 - Diferença entre o ensemble médio do experimento EN_ODP $(+)$ e a composição média observada durante eventos EN na ODP(+). continua... 
Continuação ...

Seqüência das letras (a) - (d) idem a Figura 11. Idem para as letras (e)-(g), mas para a diferença entre o ensemble médio do experimento EN_ODP(-) e a composição média observada durante eventos EN na ODP(-). Contornos a cada 1 $\mathrm{mm} \cdot \mathrm{dia}^{-1}$ começando por $0.5 \mathrm{~mm} \cdot \mathrm{dia}^{-1}, 4 \times 10^{6} \mathrm{~m}^{2} . \mathrm{s}^{-1}$ começando por $2 \times 10^{6} \mathrm{~m}^{2} . \mathrm{s}^{-1}$, $2 \mathrm{hPas}^{-1}$ começando por $1,3 \mathrm{~g} \cdot \mathrm{m}^{-2} \cdot \mathrm{s}^{-1}$ começando com $1 \mathrm{~g} \cdot \mathrm{m}^{-2} \cdot \mathrm{s}^{-1}$. Valores positivos (negativos) estão em linhas contínuas (pontilhadas/tracejadas). Vetores de fluxo $\left(\mathrm{g} \cdot \mathrm{m}^{-1} \cdot \mathrm{s}^{-1}\right)$ plotados e áreas sombreadas indicam valores estatisticamente significativos ao nível de $90 \%$.

Através das diferenças DIF_ENODP(+) e DIF_ENODP(-) foi verificado que o modelo apesar de forçado com a mesma evolução de eventos EN no Pacífico Equatorial em dois cenários de ODP diferenciados no restante do domínio, simulou respostas bem similares. Isto sugere que para a América do Sul o impacto da ODP é menos importante que a configuração de TSM encontrada no Pacífico Equatorial. Os resultados numéricos reforçam as observações do Capítulo 3.1 onde foram verificadas poucas diferenças sobre a América do Sul entre os anos neutros das fases quente e fria da ODP. Também reforçam os resultados do Capítulo 3.2 onde o deslocamento de $30^{\circ}$ para leste do máximo aquecimento no Pacífico Equatorial depois de meados de 1970 modificou a resposta atmosférica do trem de ondas em altos níveis sobre a América do Sul, principalmente nos trópicos com grande impacto na circulação subtropical.

No capítulo a seguir a aplicação de critérios para identificação de casos de JBN e ciclones extratropicais irá permitir uma investigação mais específica sobre o comportamento desses sistemas durante evolução dos eventos EN na $\operatorname{ODP}(+)$ e ODP(-). 


\section{CAPÍTULO 5}

\section{1) Estudo observacional da evolução dos eventos $E N$ em fases distintas da ODP: impactos nos casos de JBN durante o verão austral}

Neste Capítulo serão analisadas quais são possíveis mudanças na variabilidade do JBN associadas aos eventos EN de acordo com as fases opostas da ODP. Estes resultados podem ser encontrados em Silva e Ambrizzi (2008) e estão inclusos no Anexo 2.

Nas Tabelas 3 e 4 são listados os dias e horários (UTC) das ocorrências de JBN detectados com a aplicação do critério 1 de Bonner, onde é possível inferir que a razão entre os 223 casos de JBN e os 10 eventos $E N$ da ODP(+) é maior que a razão entre os 98 casos de JBN e os 6 eventos EN da ODP(-) o que sugere que tais freqüências são proporcionais às quantidades de eventos EN selecionados em cada categoria.

As composições de anomalias de água precipitável durante o Dia 0 da ocorrência do máximo do JBN para o verão austral estão ilustradas na Figura 13. Para os casos ocorridos em anos de $\operatorname{EN}$ da $\operatorname{ODP}(+)$ são observadas anomalias positivas e significativas na maior parte da América do Sul, com valores mais intensos sobre a região do SEAS (Figura 13a). Para os casos ocorridos em anos de EN da ODP(-) são encontradas anomalias ligeiramente negativas sobre grande parte do centro norte do País (Figura 13b) e anomalias positivas sobre o SEAS, porém ligeiramente mais intensas que na Figura 13a. 


\begin{tabular}{|c|c|c|}
\hline \multirow{4}{*}{$\begin{array}{l}\text { EI Niños } \\
\text { da ODP(+) } \\
1976 / 77\end{array}$} & \multicolumn{2}{|r|}{ Dias e horários (UTC) da ocorrência de JBN } \\
\hline & Dez & $\begin{array}{l}14 \text { (06), } 15 \text { (06 e 12), } 20 \text { (12), } 21 \text { (06 e 12), } 22 \text { (06), } 26 \text { (06 e 12), } 27 \text { (06 } \\
\text { e 12) }\end{array}$ \\
\hline & Jan & $\begin{array}{l}01 \text { (06), } 03 \text { (06 e 12), } 04 \text { (06), } 11 \text { (12), } 18 \text { (12 e 18), } 19 \text { (06 e 12), } 22 \text { (06), } \\
23 \text { (06), } 28 \text { (06 e 12), } 29 \text { (06), } 30 \text { (06 e 12) }\end{array}$ \\
\hline & Fev & $09(06)$ \\
\hline \multirow[t]{3}{*}{$1977 / 78$} & Dez & 04 (12 e 18), $05(06,12$ e 18), $06(00,0006,12$ e 18) \\
\hline & Jan & $05(06), 06(06), 13(12), 14(00,0006$ e 12), $27(06)$ \\
\hline & Fev & - \\
\hline \multirow[t]{3}{*}{$1979 / 80$} & Dez & $\begin{array}{l}01 \text { (06 e 12), } 04 \text { (12), } 11 \text { (12), } 12 \text { (06 e 12), } 13 \text { (06 e 12), } 14 \text { (06 e 12) e } \\
19 \text { (06) }\end{array}$ \\
\hline & Jan & $\begin{array}{l}07 \text { (06 e 12), } 08 \text { (00, } 0006 \text { e 12), } 23 \text { (06 e 12), } 24 \text { (06 e 12), } 25 \text { (06 e 12), } \\
26 \text { (06 e 12), } 27 \text { (06), } 30 \text { (12), } 31 \text { (06 e 12) }\end{array}$ \\
\hline & Fev & 05 (06 e 12), 06 (06 e 12), 07 (06 e 12), 10 (06), 12 (06 e 12) e 13 (06) \\
\hline \multirow[t]{3}{*}{$1982 / 83$} & Dez & $01(00), 13$ (06 e 12), 14 (06 e 12), 17 (06) \\
\hline & Jan & 14 (06), 20 (06 e 12), 24 (06), 25 (06), 26 (06), 29(06 e 12), 30 (06 e 12) \\
\hline & Fev & - \\
\hline \multirow[t]{3}{*}{$1987 / 88$} & Dez & $\begin{array}{l}04 \text { (06), } 16 \text { (06 e 12), } 17 \text { (06 e 12), } 19 \text { (06 e 12), } 20 \text { (06), } 25 \text { (06 e 12), } \\
27(12), 29(06)\end{array}$ \\
\hline & Jan & $\begin{array}{l}05 \text { (06 e 12), } 10 \text { (06 e 12), 11(06 e 12), } 12 \text { (06 e 12), } 13 \text { (06 e 12), } 14 \text { (06 } \\
\text { e 12), } 21 \text { (06 e 12), } 28 \text { (12) }\end{array}$ \\
\hline & Fev & - \\
\hline \multirow[t]{3}{*}{$1990 / 91$} & Dez & 10 (12 e 18), 11 (06), 12 (12), 13 (06 e 12), 21 (06), 22 (06 e 12) \\
\hline & Jan & 28 (06), 29 (06 e 12), 30 (06 e 12) \\
\hline & Fev & $01(06), 02$ (06), 09 (06), 27 (06), 28 (06 e 12) \\
\hline \multirow[t]{3}{*}{$1991 / 92$} & Dez & $\begin{array}{l}05(06), 13(06), 17(12), 19(06 \text { e } 12), 20(06 \text { e } 12), 22 \text { (06 e 12), } 23(00, \\
0006 \text { e 12), } 24(06), 25(06), 26(00 \text { e } 0006), 28(18), 29(06 \text { e } 12), 30 \\
(06)\end{array}$ \\
\hline & Jan & $02(06), 14(12)$ \\
\hline & Fev & 09 (06 e 12), 27 (06) \\
\hline \multirow[t]{2}{*}{$1992 / 93$} & $\begin{array}{l}\text { Dez } \\
\text { Jan }\end{array}$ & $\begin{array}{l}17(06), 19(06), 20(06), 21 \text { (06 e 12), } 22(06), 23(06), 28(06), 29(06 \text { e } \\
12), 30 \text { (06 e 12) } \\
08 \text { (06 e 12), } 19(06), 25 \text { (06 e 12), } 27(06)\end{array}$ \\
\hline & Fev & 06 (12), 07 (06 e 12) \\
\hline \multirow[t]{3}{*}{$1994 / 95$} & Dez & $06(06), 14(06)$ \\
\hline & Jan & 01 (06 e 12), 02 (06 e 12), 04 (06), 05 (06 e 12) \\
\hline & Fev & 01 (06 e 12), 11 (06), 21 (12), 22 (06 e 12), 23 (12), 24 (06) \\
\hline \multirow[t]{3}{*}{$1997 / 98$} & Dez & $\begin{array}{l}10 \text { (12), } 12 \text { (06 e 12), } 13 \text { (12), } 23 \text { (06), } 27 \text { (00, } 0006 \text { e 12), } 28 \text { (06 e 12), } \\
29(12), 30(06)\end{array}$ \\
\hline & Jan & 01 (06 e 12), 06 (06), 11 (12), 17 (12), 27 (06 e 12), 28 (06 e 12) \\
\hline & Fev & $02(06), 18(06), 24(06,12$ e 18), $25(06), 26(06)$ \\
\hline
\end{tabular}

Tabela 3: Dias e horários dos casos de JBN detectados durante o verão austral de anos de EN selecionados da ODP(+). 


\begin{tabular}{|c|c|c|}
\hline $\begin{array}{l}\text { El Niños } \\
\text { da ODP(-) }\end{array}$ & & Dias e horários (UTC) da ocorrência de JBN \\
\hline \multirow[t]{3}{*}{$1952 / 53$} & Dez & 26 (12), 27 (06 e 12), 28 (06), 29 (12), 31 (12) \\
\hline & Jan & 07(06 e 12), 13 (06), 17 (06 e 12), 18 (06 e 12), 26(06 e 12), 31 (06 e 12) \\
\hline & Fev & 01 (06), 20 (12), 24 (12) \\
\hline \multirow[t]{3}{*}{$1957 / 58$} & Dez & 05(06 e 12), 12 (12), 13 (06 e 12), 14 (06), 15 (12), 28 (12) \\
\hline & Jan & 10 (12), 11 (06 e 12), 14 (12), 15 (06 e 12), 18 (06 e 12) \\
\hline & Fev & 06 (12), 07 (06), 14 (06 e 12), 19 (06 e 12), 20 (06 e 12) \\
\hline \multirow[t]{3}{*}{$1958 / 59$} & Dez & $08(06), 11(06), 13(06), 18(06)$ \\
\hline & Jan & 25 (06 e 12), 26 (06 e 12), 28 (06 e 12) \\
\hline & Fev & 05 (06), $09(06), 14(06)$ \\
\hline \multirow[t]{3}{*}{$1963 / 64$} & Dez & $11(06), 17$ (06 e 12), $31(06)$ \\
\hline & Jan & 19 (12), 26 (06 e 12), 27 (06), 31 (12) \\
\hline & Fev & 01(06 e 12), 07 (06), 08 (06 e 12), 10 (12), 14 (12), 15 (12), 17 (06 e 12) \\
\hline \multirow[t]{3}{*}{$1969 / 70$} & Dez & $22(06)$ \\
\hline & Jan & 02 (06), 06 (06), 24 (06 e 12), 29 (12) \\
\hline & Fev & 02 (06 e 12), 03 (06), 05 (06) \\
\hline \multirow[t]{3}{*}{$1972 / 73$} & Dez & $31(06)$ \\
\hline & Jan & $21(12), 22(06,12$ e 18), 23(06 e 12), 24 (06) \\
\hline & Fev & $03(06), 11(06$ e 12$), 12(06)$ e $13(06)$ \\
\hline
\end{tabular}

Tabela 4: Idem a Tabela 3, mas para os anos de EN da ODP(-). 


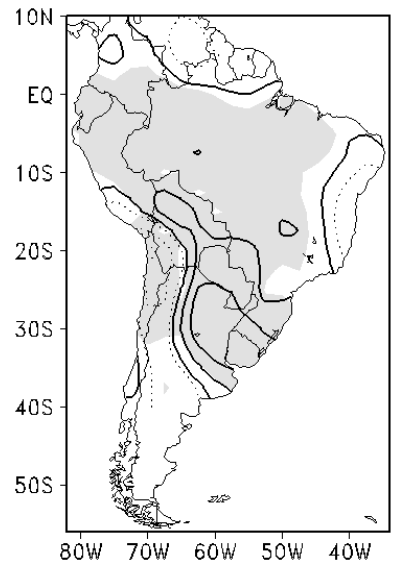

(a)

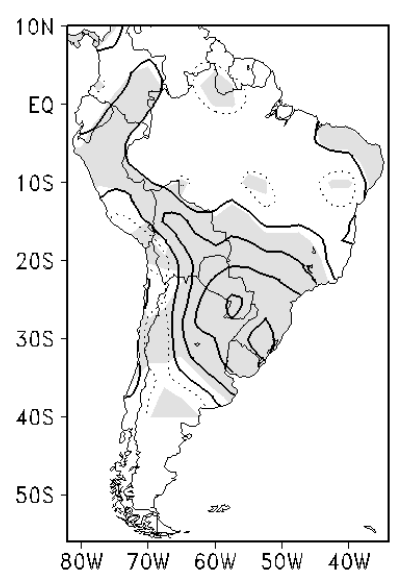

(b)

Figura 13 - Composições de anomalias do conteúdo de água precipitável durante o Dia 0 da atividade máxima dos casos de JBN detectados em anos de EN na: (a) $\mathrm{ODP}(+)$; (b) ODP(-). Isolinhas a cada $2 \mathrm{~kg} \cdot \mathrm{m}^{-2}$, começando com $0.5 \mathrm{~kg} \cdot \mathrm{m}^{-2}$. Anomalias estatisticamente significativas ao nível de $95 \%$ estão sombreadas.

Para verificar quais foram as circulações anômalas que possam ter influenciado as anomalias da Figura 13 , foram calculadas composições de anomalias das variáveis atmosféricas desde o Dia -1 ao Dia +1 da ocorrência do máximo do JBN. As Figuras 14, 15, 16, mostram tais composições para os casos de JBN detectados em anos de EN da ODP(+) e ODP(-). A Figura 14a mostra que a componente assimétrica de $\psi(200 \mathrm{hPa})$ apresenta um trem de ondas com mesma fase sobre os trópicos e subtrópicos quando comparado com a composição sazonal da Figura 10a, porém com maior amplitude. A característica de intensificação de JST em torno de $40^{\circ} \mathrm{S}$ fica evidente devido à predominância de anomalias anticiclônicas sobre o SEAS e ciclônicas no cone sul do continente, sendo intensificado nos Dias 0 e +1 (Figuras 14b e 14c). Sobre a maior do continente são observados movimentos ascendentes desde o Dia -1 ao Dia 0 , com maiores valores sobre a SEAS e enfraquecimento destas anomalias a partir do Dia +1 (Figuras $15 \mathrm{a}-\mathrm{c}$ ).

Com relação à composição de anomalias do vento em 850 hPa e PNMM é possível notar, desde o Dia -1 a predominância de uma alta pressão sobre o Atlântico Equatorial e baixas pressões sobre o resto do continente (Figura 16a). Isto pode ter favorecido a entrada dos ventos alísios de nordeste em direção ao interior do continente que ao encontrarem a barreira dos Andes sofreram deflexão rumo à região do SEAS. No Dia 0 o núcleo do JBN mostra-se intensificado em relação ao dia anterior com velocidade máxima de $8 \mathrm{~m}^{-\mathrm{s}^{-1}}$ e o escoamento dos alísios de 
nordeste persiste sobre o continente podendo ter contribuído para transporte de umidade desde o oceano Atlântico Equatorial até a região do SEAS. Conseqüentemente houve redução da PNMM associado a uma circulação ciclônica fechada centrada sobre a região e adjacências do oceano Atlântico (Figura 16b) o que pode ter colaborado com as anomalias positivas de água precipitável da Figura 13a. No Dia -1 este núcleo de pressão mínima se desloca para leste associado ao ligeiro deslocamento para norte da saída do JBN e redução da velocidade dos ventos no seu núcleo (Figura 16c). O perfil vertical do vento meridional no Dia 0 mostra que o JBN anômalo possui forte componente (v) negativa até $500 \mathrm{hPa}$ e intensidade máxima em $850 \mathrm{hPa}$ em torno de $|4| \mathrm{m} . \mathrm{s}^{-1}$ (Figura 17a).

Na Figura 14d para o Dia -1 dos casos de JBN detectados em EN na ODP(-), a anomalia da componente zonalmente assimétrica de $\psi(200 \mathrm{hPa})$ apresenta um padrão similar ao da Figura $10 \mathrm{~d}$, porém, com uma maior amplitude. As características de circulações anticiclônica sobre os SEAS e ciclônica no restante do continente podem ter contribuído para uma maior intensificação do JST em torno de $40^{\circ} \mathrm{S}$ em relação à Figura 14a. Sobre a maior parte dos trópicos do continente as anomalias positivas de $\Psi(200 \mathrm{hPa})$ e $\omega(500 \mathrm{hPa})$ estão coerentes com as anomalias negativas de água precipitável observadas na região (Figura 13b). No Dia 0 o JST é intensificado e mantido até o Dia +1 (Figuras 14 e-f). Em níveis médios, é observado no Dia -1 movimento ascendente sobre a parte centro-sul da SEAS e descendente no restante do continente (Figura 15d). No Dia 0 o movimento ascendente se intensifica sobre o SEAS associado a intensificação do JST, e no Dia +1 o núcleo de máximo movimento ascendente se desloca para leste em direção ao oceano Atlântico (Figuras 15 e-f, respectivamente). A composição de anomalia do vento em 850 hPa e PNMM mostra que desde o Dia -1 há predomínio de um núcleo de alta pressão posicionada sobre o centro leste do Brasil associada a circulação anticiclônica sobre a região e vizinhanças do Atlântico (Figura 16d). Este padrão também foi observado na Figura $10 f$ e parece estar relacionado à redução do transporte de umidade do Atlântico Equatorial e região Amazônica para os subtrópicos. As regiões mais ao sul do SEAS e o cone sul do continente ficam sobre o predomínio de baixas pressões associada a atuação de um ciclone nos extratrópicos sobre o oceano Atlântico em $60^{\circ} \mathrm{W}-505^{\circ}$. A característica de alongamento na escala meridional do sistema de baixa pressão ao cruzar os Andes foi observada por Gan e Rao (1994), indicando um padrão de ciclogênese a 
sotavento dos Andes. O intenso gradiente de pressão leste-oeste entre os sistemas anômalos de alta pressão centrada sobre o centro-leste do continente e a baixa pressão citada anteriormente pode favorecer o giro anticiclônico e aceleração geostrófica dos ventos de noroeste em direção ao interior do continente. $O$ escoamento associado ao JBN anômalo adquire um alongamento desde a Amazônia até o Sul do Brasil e Nordeste da Argentina.

No Dia 0 a alta pressão citada anteriormente se mantém e o ciclone sofre um deslocamento de $10^{\circ}$ para leste sobre o Atlântico (Figura 16e) onde a velocidade dos ventos no núcleo do JBN se intensifica e alcança valores superiores a $8 \mathrm{~m} \cdot \mathrm{s}^{-1}$. Apesar de ser mais intenso que o JBN anômalo da Figura 16b, o jato da Figura 16d esteve associado a subsidência e a alta pressão sobre os trópicos podendo ter contribuído com um menor fornecimento de umidade para o SEAS. Entretanto, isto não está coerente com as anomalias positivas de água precipitável observadas no SEAS (Figura 13b), indicando que outro fator que não esteja associado ao transporte de umidade dos trópicos possa ter contribuído para essas anomalias. No Dia +1 o ciclone se desloca mais $10^{\circ}$ para leste reduzindo o gradiente de pressão sobre o continente e conseqüentemente a velocidade no núcleo do JBN (Figura 16f). O perfil vertical do vento meridional mostra que o JBN anômalo possui forte componente $(\mathrm{v})$ negativa até $400 \mathrm{hPa}$ e intensidade máxima em $850 \mathrm{hPa}$ de $|6| \mathrm{m} . \mathrm{s}^{-1}$ (Figura 17b). À leste do Planalto Brasileiro os ventos de sul estiveram associados à alta pressão anômala sobre os trópicos discutida anteriormente. 
EN ODP(+) Dia -1

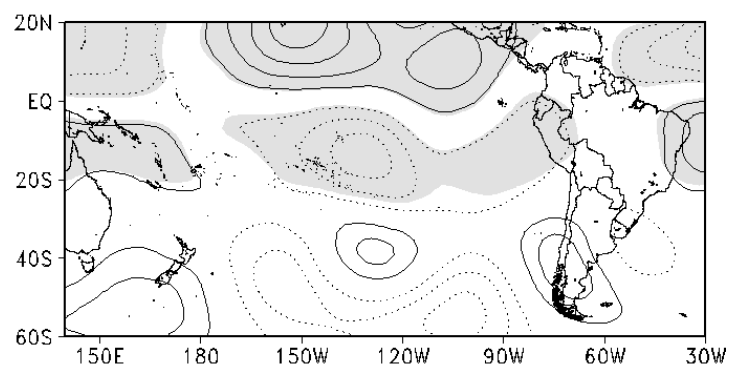

(a)

\section{EN ODP(+) Dia 0}

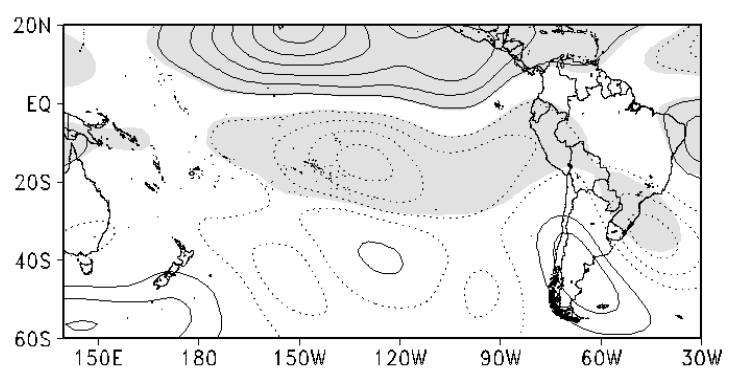

(b)

\section{EN ODP(+) Dia +1}

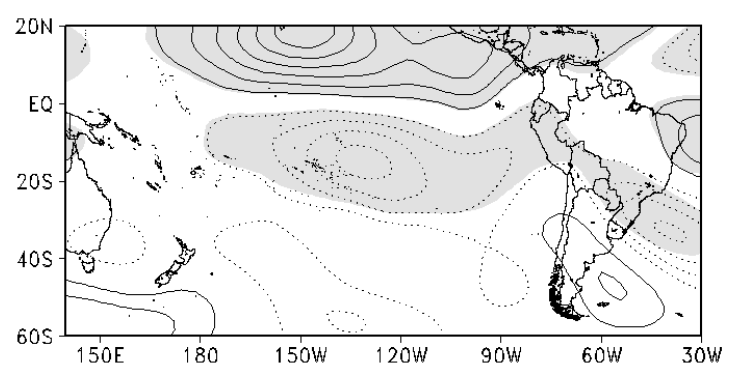

(c)
EN ODP(-) Dia -1

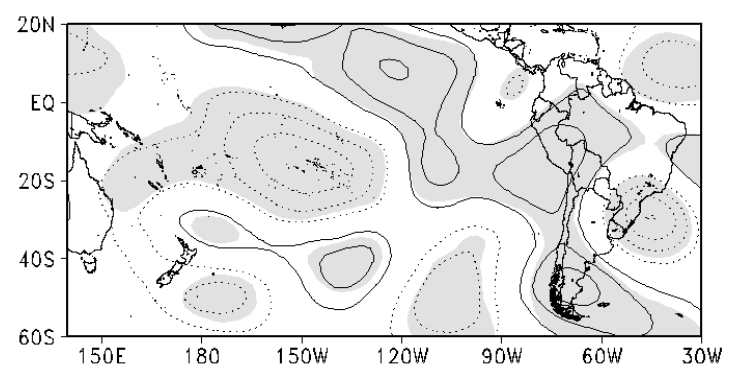

(d)

EN ODP(-) Dia 0

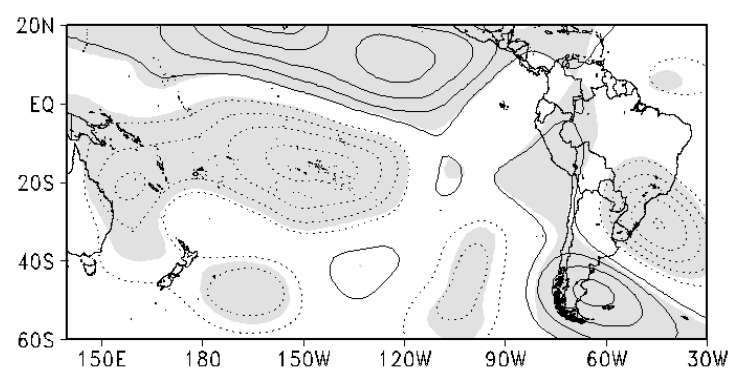

(e)

\section{EN ODP(-) Dia +1}

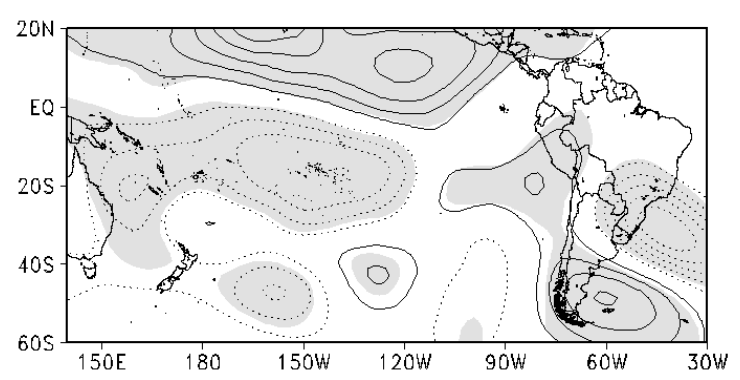

(f)

Figura 14 - Composições de anomalias da componente zonalmente assimétrica da $\psi$ (200 hPa) durante o: (a) Dia -1; (b) Dia 0 e (c) Dia +1 da máxima atividade dos casos de JBN detectados em anos de EN na ODP $(+)$. Idem para as letras (d) a (f), mas durante a ODP(-). Isolinhas a cada $2 \times 10^{-6} \mathrm{~m}^{2} \cdot \mathrm{s}^{-1}$. Valores positivos (negativos) estão em linhas contínuas (pontilhadas/tracejadas). Anomalias estatisticamente significativas ao nível de $95 \%$ estão sombreadas. 
EN ODP(+) Dia -1

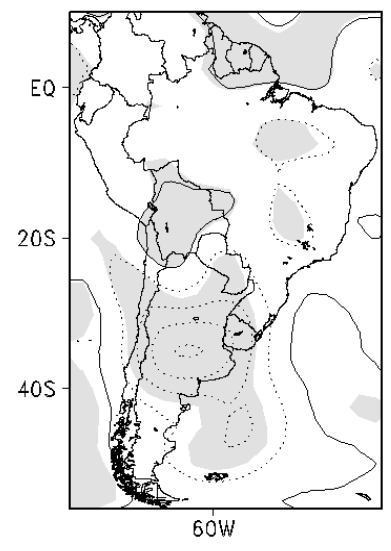

(a)
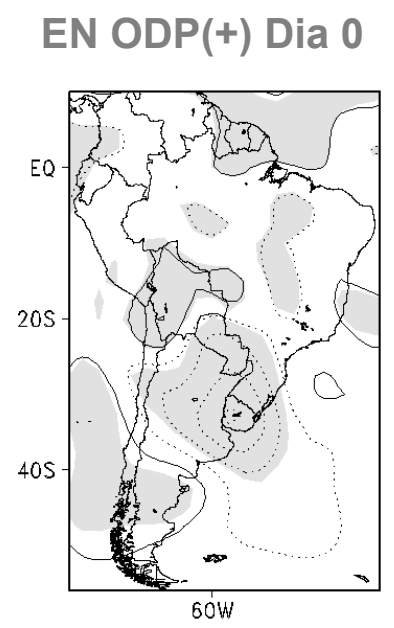

(b)

EN ODP(+) Dia +1

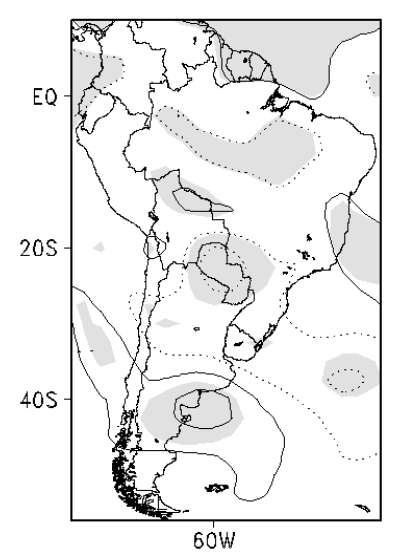

(c)
EN ODP(-) Dia -1

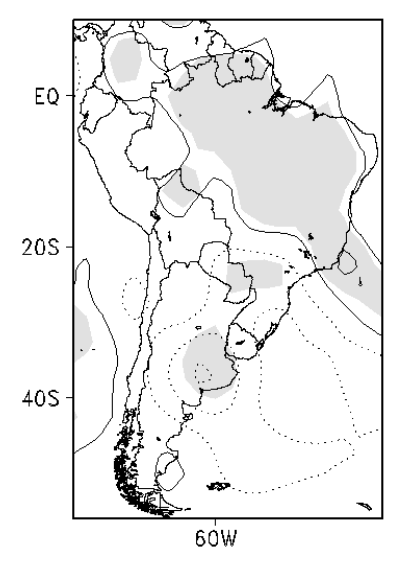

(d)

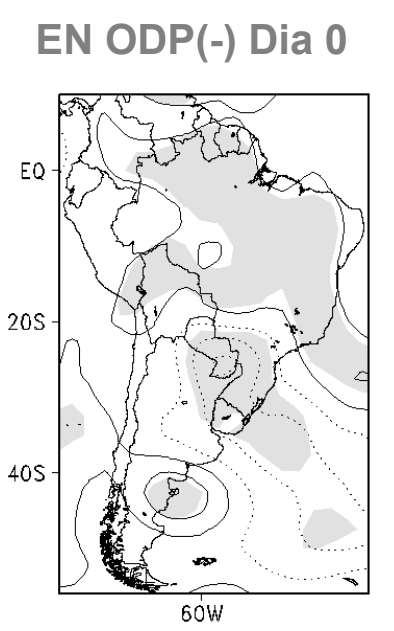

(e)

\section{EN ODP(-) Dia +1}

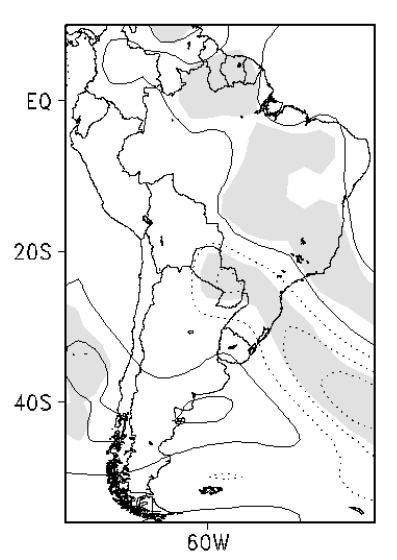

(f)

Figura 15 - Idem a Figura 14, mas para $\omega(500 \mathrm{hPa})$. Isolinhas a cada $2 \mathrm{hPa} . \mathrm{s}^{-1}$, iniciando em $1 \mathrm{hPa} . \mathrm{s}^{-1}$. 
EN ODP(+) Dia -1

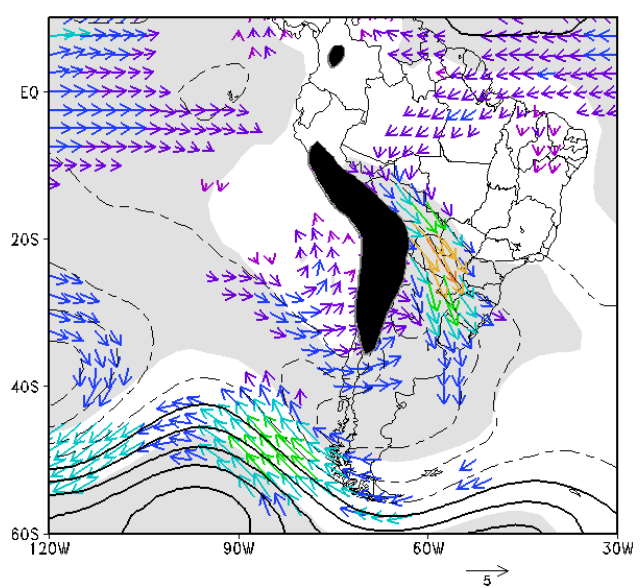

(a)

EN ODP(+) Dia 0

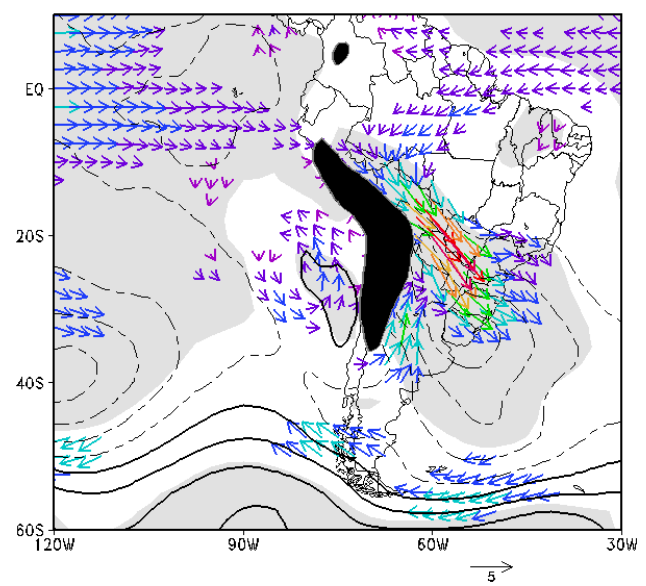

(b)

EN ODP(+) Dia +1

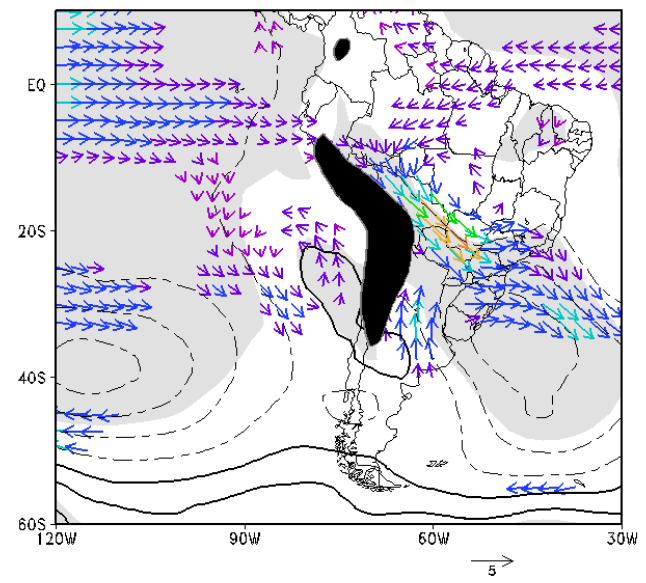

(c)
EN ODP(-) Dia -1

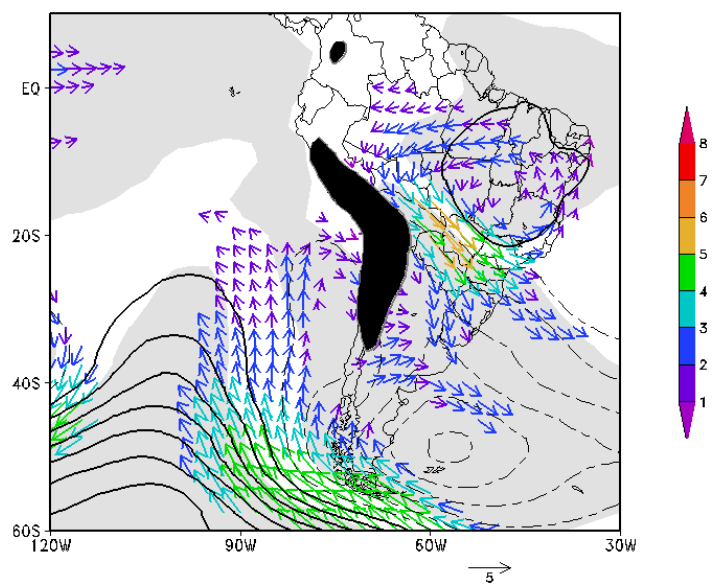

(d)

\section{EN ODP(-) Dia 0}

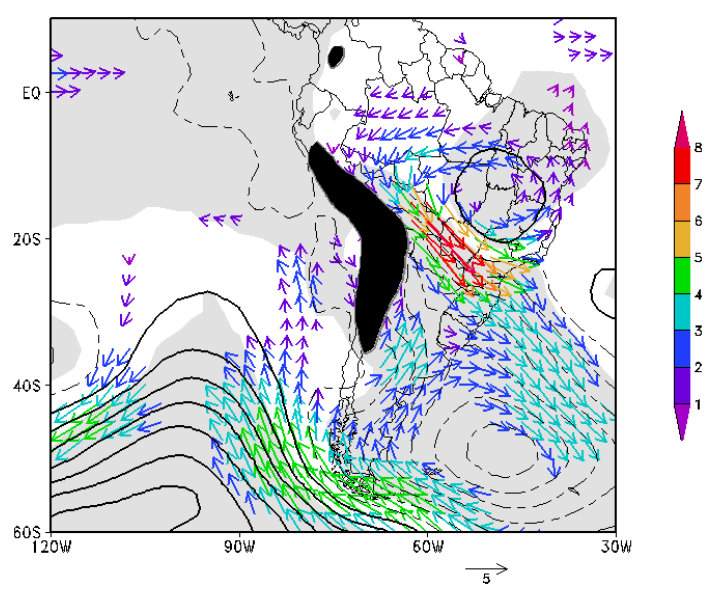

(e)

EN ODP(-) Dia +1

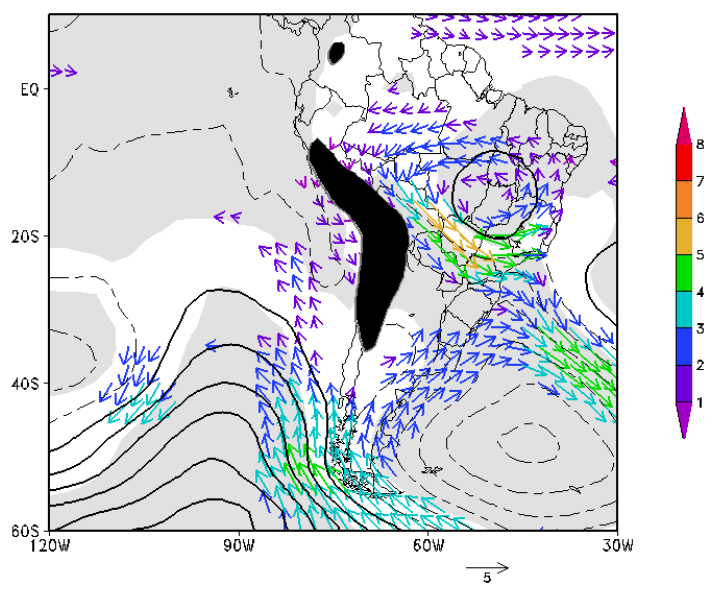

(f)

Figura 16 - Idem a Figura 14, mas para o fluxo de umidade integrado verticalmente e divergente associado entre $1000-850 \mathrm{hPa}$. Isolinhas a cada $3 \mathrm{~g} \cdot \mathrm{m}^{-2} \cdot \mathrm{s}^{-1}$ começando por $1 \mathrm{~g} \cdot \mathrm{m}^{-2} \cdot \mathrm{s}^{-1}$, e vetor vento em $\mathrm{m} \cdot \mathrm{s}^{-1}$. 


\section{EN ODP(+) Dia 0}

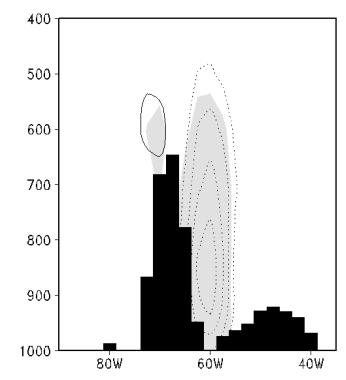

EN ODP(-) Dia 0

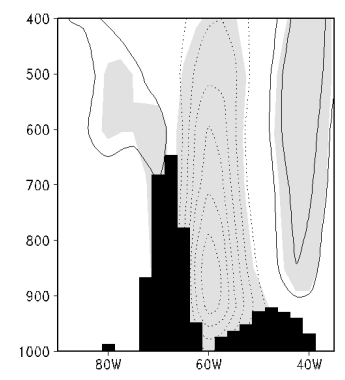

Figura 17 - Idem a Figura 13, mas para o perfil vertical do vento (v) em Santa Cruz. Isolinhas a cada 1 m.s . $^{-1}$.

\section{2) Estudo observacional da evolução dos eventos EN em fases distintas da} ODP: impactos nas propriedades dos ciclones extratropicais

Inicialmente será fornecida uma breve discussão sobre a DC e PC médias dos ciclones extratropicais observados nos anos neutros selecionados usando o esquema numérico de MS (Figura 18). Assim como definido na Metodologia, DC média é igual à razão entre número de sistemas identificados numa região de $5^{\circ}$ latitude $\times 5^{\circ}$ longitude pela área da mesma, e PC média corresponde a média das pressões centrais dentro desta área. Estas características ajudarão na compreensão da Figura 19, que ilustra os resultados relativos à comparação entre as anomalias de DC e PC dos ciclones extratropicais durante o verão austral dos eventos EN da $\mathrm{ODP}(+)$ e ODP(-). Apenas sistemas com pressão menores que $1010 \mathrm{hPa}$ rastreados a cada 6h são considerados. Com o intuito de reduzir o efeito das baixas térmicas, são ilustrados apenas os resultados ao sul de $30^{\circ} \mathrm{S}$.

Através da Figura 18a é possível notar uma grande concentração de sistemas ao redor de $65^{\circ} \mathrm{S}$ o que está de acordo com os resultados de Taljaard (1967) que sugere que durante o verão os ciclones extratropicais concentram-se ao redor de latitudes mais próximas do continente Antártico. Sobre a América do Sul, é notável a existência de intensa DC sobre o noroeste da Argentina, entre $30^{\circ} \mathrm{S}-40^{\circ} \mathrm{S}$, possivelmente associada à presença de baixas térmicas (Seluchi et al., 2003) 
formadas quando o ar que atravessa a cordilheira do Andes aquece por subsidência formando baixas pressões a leste desta. No Atlântico, nas proximidades do sul do Brasil, a concentração de ciclones pode estar associada a fatores relacionados à influência do gradiente produzido pela confluência das correntes Brasil-Malvinas ou anomalias positivas de TSM (Dal Piva, 2001; Reboita et al., 2007b), ou ainda a influência do gradiente entre a temperatura de superfície continente-oceano (Saraiva, 1996), entretanto não é objetivo do estudo investigar a influência desses fatores. A Figura 18b mostra que em termos de PC média, os maiores valores entre 1005-1010 hPa encontram-se sobre o cone sul do continente, e os menores ficam em torno de $65^{\circ} \mathrm{S}$ onde se observa a maior concentração de ciclones. As áreas em branco indicam regiões sem significância quando o algoritmo realizou os cálculos.

DC NEU

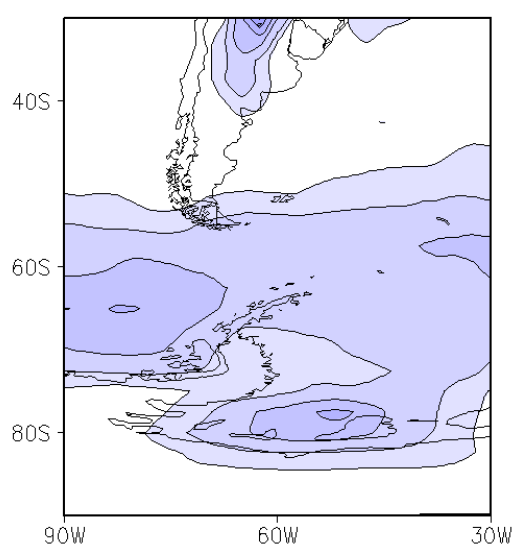

(a)
PC NEU

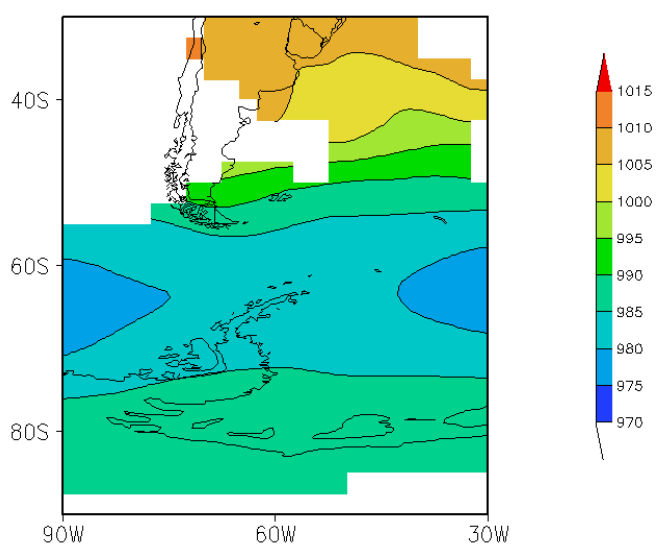

(b)

Figuras 18 - Médias de (a) Densidade Ciclogenética (b) Pressão Central dos ciclones extratropicais detectados durante o verão austral de anos de neutros no Pacífico Equatorial usando o algoritmo de MS. Apenas sistemas com tempo de vida superior a $24 \mathrm{~h}$ foram considerados. Contorno de intervalo a cada 1 ciclones/ ( ${ }^{\circ}$. lat $)^{2} ; 5 \mathrm{hPa}$.

Sobre a América do Sul, as anomalias de DC para os ciclones rastreados em anos de $\mathrm{EN}$ durante a $\mathrm{ODP}(+)$ mostram duas regiões com valores ligeiramente positivos (Figura 19a). A primeira delas sobre o extremo sul do SEAS, ou seja, o extremo sul do Brasil, Nordeste da Argentina, Uruguai, e vizinhanças do Atlântico Sudoeste e a segunda sobre o Golfo de São Matias sendo estas regiões apontadas por Gan e Rao (1991) como favoráveis a ciclogênese. A Figuras 10c mostrou que o extremo sul do SEAS ficou sob o predomínio de convergência de umidade anômala oriunda dos trópicos podendo estar associada à redução da PNMM sobre esta 
região (Figura 19a), já que este mecanismo foi citado por Berbery e Barros (2002) e Magaña e Ambrizzi (2005) como favorável ao desenvolvimento de ciclogêneses nesta região. A Figura 19b mostra anomalias negativas de PC (ciclones mais intensos que a média) sobre maior parte do domínio, exceto em torno de $60^{\circ} \mathrm{S}$, e sobre a região do Golfo de São Matias não há valores significativos.

Comparando as anomalias de DC dos ciclones extratropicais detectados em anos de EN durante a ODP(-) (Figura 19c) com as anomalias da Figura 19a, é possível notar uma região com DC abaixo da média sobre o Nordeste da Argentina e parte do sul do Brasil o que está coerente com o menor fornecimento de umidade observado na Figura $10 f$ sobre esta região, e de DC acima da normal entre $50^{\circ} \mathrm{S}$ $60^{\circ} \mathrm{S}$ sobre o Atlântico. Ao contrário da Figura 19b foram observadas anomalias positivas PC sobre a maior parte do domínio indicando ciclones menos intensos quando comparado com a Figura $19 b$.

O mecanismo responsável pela maior intensidade dos ciclones extratropicais atuantes no cone sul da América do Sul e vizinhanças do Atlântico durante os anos de $\mathrm{EN}$ da OPD(+) em comparação com a ODP(-) parece estar relacionado ao maior fluxo convergente de ar quente e úmido tropical para estas regiões. Os resultados reforçam o estudo de Pezza et al. (2007) que apesar de ter utilizado um período relativamente diferente para o rastreamento dos ciclones baseado apenas no índice da ODP, também verificou que na fase positiva da oscilação decadal os ciclones extratropicais foram mais intensos neste mesmo domínio. 
DC EN ODP(+)

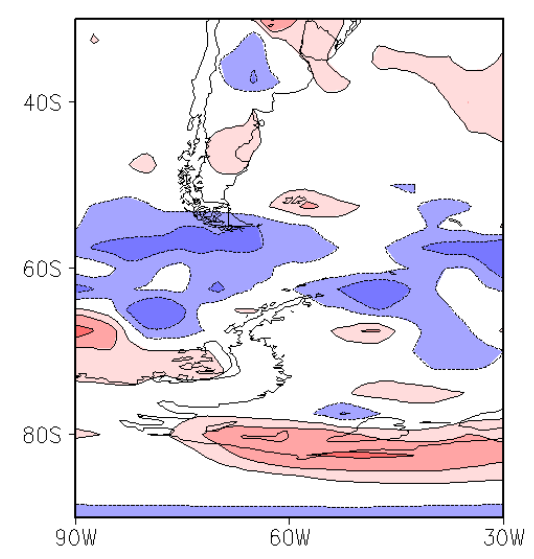

(a)

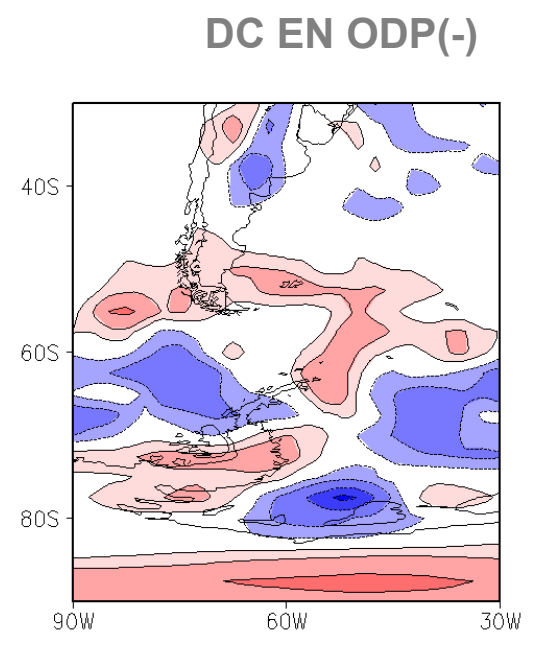

(c)

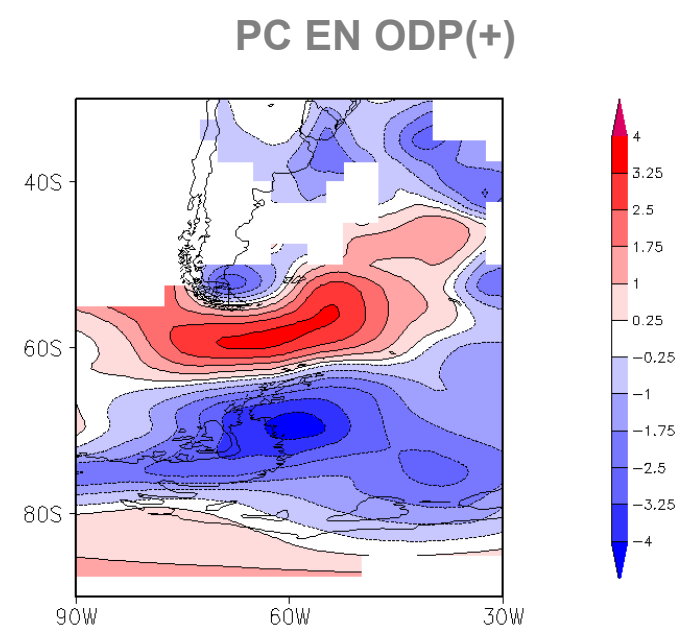

(b)

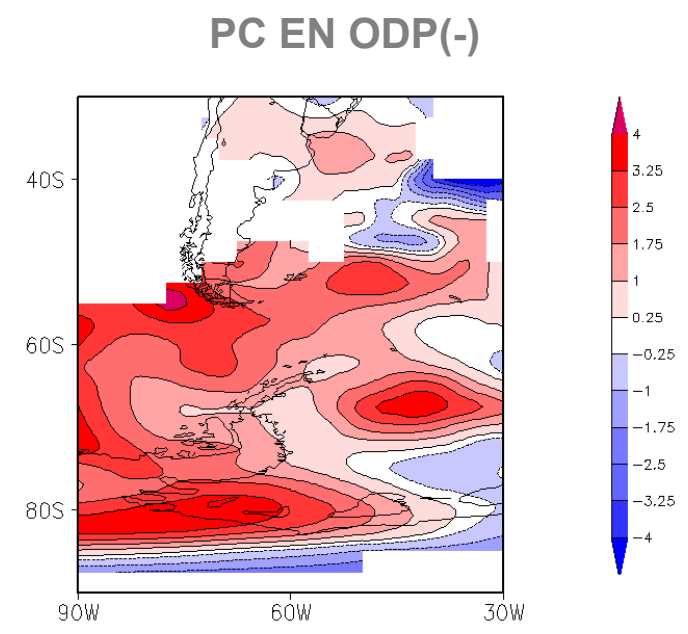

(d)

Figura 19 - Anomalias de (a) Densidade Ciclogenética (b) Pressão Central dos ciclones extratropicais detectados durante o verão austral de anos de EN da ODP(+) usando o algoritmo de MS. Idem para (c) e (d), mas para a ODP(-). Apenas sistemas com tempo de vida superior a $24 \mathrm{~h}$ foram considerados. Contorno de intervalo a cada 0.5 ciclones $/\left(^{\circ} \text {. lat }\right)^{2}$ e $0.75 \mathrm{hPa}$. 


\section{CAPÍTULO 6}

\section{Conclusões}

Recentes estudos têm mostrado que o ciclo sazonal de precipitação sobre a América do Sul é correlacionado com a Oscilação Decadal do Pacífico (ODP), todavia, a complexidade entre a variabilidade da Temperatura de Superfície do Mar (TSM) do oceano Pacífico e outros tipos de forçantes, como a antropogênica, por exemplo, ainda deixa questões em aberto no que diz respeito à relação de impacto sobre o globo. Através dos resultados apresentados neste estudo foi possível esclarecer algumas questões que ainda não haviam sido exploradas relativas ao impacto da variabilidade natural de TSM do Pacífico sobre a América do Sul.

O estudo teve como finalidade realizar uma análise observacional e numérica da importância da evolução dos eventos $\mathrm{EN}$ e anos neutros nas fases positiva e negativa da ODP sobre a América do Sul, referenciadas como ODP(+) e ODP(-), respectivamente. $A$ análise foi baseada nas comparações entre as composições de circulação atmosférica, em específico, as de fluxo de umidade integrado verticalmente e divergente associado. Aspectos da modelagem climática também foram abordados e uma ênfase foi dada à variabilidade do JBN e algumas propriedades dos ciclones extratropicais. O período utilizado foi de 1950-1999 e diferentemente dos estudos anteriores foi analisado o trimestre Dezembro-Fevereiro por ser esta estação em que é observada a fase madura da monção sul americana.

No Capítulo 2, através da análise da Figura 8 foi possível notar que existem poucas mudanças significativas no regime de precipitação sobre a América do Sul e sistemas associados, principalmente em altos e médios níveis, ao considerar a influência dos anos neutros do Pacífico Equatorial levando em consideração a $\mathrm{ODP}(+)$ e ODP(-). Os anos neutros compõem aproximadamente metade do período entre 1950-1999, porém ainda não haviam sido considerados em estudos anteriores. Entretanto, foi relatada que em outras regiões do globo como na América do Norte (Goodrich, 2004,2006), por exemplo, o impacto da ODP pode ser até oposto em anos de neutralidade, colaborando para fortes sinais de mudanças de circulação.

Foram encontradas diferenças no padrão de anômalo de TSM quando comparados os eventos EN da ODP(+) com os eventos da ODP(-) o que resultou em 
diferentes padrões anômalos de ondas em altos níveis e conseqüentes mudanças na disponibilidade de umidade sobre o continente (Figura 10). Os eventos EN durante a $\mathrm{ODP}(+)$ apresentaram anomalias negativas de precipitação sobre o norte da Amazônia e positivas sobre a maior parte do Sudeste da América do Sul (SEAS) associados a águas mais quentes sobre o Pacífico Central e Leste com núcleo de máximo centrado entre $150^{\circ} \mathrm{W}-90^{\circ} \mathrm{W}$. A anomalia zonalmente assimétrica de $\Psi(200$ hPa) apresentou circulações anticiclônicas sobre a maior parte da América do Sul exceto sobre o Nordeste, dando suporte aos movimentos ascendentes sobre as regiões Amazônica e o SEAS (Figura 10b). O fluxo anômalo de umidade integrado em baixos níveis (Figura 10c) mostrou que a divergência sobre o Atlântico Equatorial Oeste convergiu sobre a Amazônia coerente com o movimento vertical ascendente observado sobre a região, ajudando a manter a circulação anticiclônica em altos níveis sobre os trópicos. Todavia, a outra parte do fluxo de umidade que adentrou o continente juntamente com o fluxo divergente sobre a Amazônia foi direcionado ao SEAS contribuindo para convergência de umidade anômala de noroeste sobre a região. Já os eventos EN durante a $\operatorname{ODP}(-)$ apresentam precipitação acima da normal apenas ao sul da região do SEAS e abaixo da normal ao norte desta. Estas tiveram associadas às águas mais quentes sobre o Pacífico Equatorial Central, porém com menor magnitude que as anomalias da $\operatorname{ODP}(+)$, e anomalias ligeiramente positivas sobre o Atlântico Equatorial nas proximidades da costa da América do Sul semelhantes a fase positiva do modo equatorial do Atlântico Equatorial discutido por Zebiak (1993) e Chang e Li (1997). A resposta do trem de ondas em altos níveis mostrou-se deslocada de aproximadamente $30^{\circ}$ para oeste em relação a $\mathrm{ODP}(+)$ resultando em anomalias ciclônicas sobre os trópicos favorecendo movimento descendente sobre a região, e anticiclônica sobre o Sul do Brasil e Uruguai associado a ligeiro aumento do movimento ascendente nesta região. Em baixos níveis, fluxo convergente de umidade oriundo da Amazônia em direção ao SEAS além de ter sido fraco não foi significativo e esteve associado a um fluxo anticiclônico divergente sobre maior parte do centro-leste do Brasil. Esta característica pode ter contribuído com o enfraquecimento do fluxo de umidade transportado pelos alísios e supressão da convecção sobre o norte do SEAS.

A análise numérica do Capítulo 3 com o Modelo de Circulação Geral Atmosférico Community Atmosphere Model v. 3.0 (MCGA CAM3) contribuiu para interpretação das análises observadas. Dois experimentos numéricos com o MCGA 
CAM3 foram realizados, sendo denominados de EN_ODP(+) e EN_ODP(-). Ambos foram forçados em uma caixa entre $20^{\circ} \mathrm{S}-20^{\circ} \mathrm{N} ; 120^{\circ} \mathrm{E}-175^{\circ} \mathrm{W}$ com a anomalia de TSM de EN's canônicos de 1950-1999, enquanto que no resto do domínio foram prescritas condições de TSM e gelo marinho médios diferentes para cada experimento. Ou seja, no restante do domínio do experimento EN_ODP(+) foi prescrito a composição de TSM e gelo marinho observado em anos Neutros da $\mathrm{ODP}(+)$, enquanto que no experimento EN_ODP(-) foi prescrito a composição das mesmas variáveis mas durante os anos neutros da ODP(-).

Posteriormente foram calculadas duas diferenças, sendo a primeira referente ao experimento EN_ODP(+) e a média observada dos eventos EN da ODP(+), denominada de DIF_ENODP(+); enquanto que a segunda é referente a diferença entre o experimento EN_ODP(-) e a média observada dos eventos EN da ODP(-), chamada de DIF_ENODP(-). Através da comparação entre DIF_ENODP(+) e DIF_ENODP(-) foi possível observar que o modelo apesar de forçado com a mesma evolução de EN's canônicos em cenários de ODP quente e fria separadamente simulou respostas bem similares. Isto reforça as observações mostradas no Capítulo 3.1 onde foi visto que existem poucas diferenças sobre a América do Sul em anos neutros ocorridos em fases opostas da ODP. Os resultados numéricos também reforçam aqueles do Capítulo 3.2 onde o deslocamento de aproximadamente $30^{\circ}$ para leste do máximo aquecimento no Pacífico Equatorial modificou a resposta atmosférica do trem de ondas sobre a América do Sul, principalmente nos trópicos afetando a circulação nos extratrópicos deste continente. Este resultado concorda com o estudo de Magaña e Ambrizzi (2005) que realizaram experimentos numéricos com um modelo baroclínico simples e verificaram mudança no padrão de onda sobre a América do Sul quando a forçante térmica era deslocada ao longo do Oceano Pacífico Equatorial Centro-leste. Os resultados sugerem que para o verão da América do Sul o impacto do modo de variabilidade interanual de TSM do Pacífico Equatorial relacionado à fase quente do ENOS é mais importante do que o modo de variabilidade decadal relacionado a OPD. Isto pode explicar os resultados semelhantes encontrados por Kayano (2005), Garcia e Kayano (2006), Kayano e Andreoli (2007), Gershunov e Barnett (1998) e Dettinger et al. (2001), que verificaram um efeito construtivo (destrutivo) quando eventos EN estavam em fase com a $\operatorname{ODP}(+)(\operatorname{ODP}(-))$. 
Alguns aspectos da variabilidade dos sistemas climáticos responsáveis por parte do transporte de umidade para o SEAS foram verificados no Capítulo 5 . Apesar dos dados da reanálise não estarem livres de problemas na assimilação os resultados mostraram características de grande escala bem robustos e reforçam estudos anteriores que utilizaram diferentes fontes de dados. Foi visto que o impacto canônico dos eventos EN na modulação do Jato de Baixos Níveis (JBN) discutido em Silva e Ambrizzi (2006) pode ser diferente quando se considera a existência de uma maior freqüência e intensidade de eventos EN associados à mudança de fase da ODP depois de meados da década de 70 . Foi encontrado que a razão entre os 223 casos de JBN durante os 10 eventos $\mathrm{EN}$ da $\mathrm{ODP}(+)$ foi maior que a razão entre os 98 casos de JBN durante os 6 eventos EN da ODP(-). Através das análises das Figuras 13 a 17, observou-se que os casos de JBN foram acompanhados de anomalias positivas de água precipitável sobre a região do SEAS tanto em anos de $\mathrm{EN}$ da $\mathrm{ODP}(+)$ quanto naqueles da $\operatorname{ODP}(-)$, entretanto os valores mais altos ocorreram na $\operatorname{ODP}(-)$. Não foi observada mudança significativa em relação ao posicionamento do JBN de uma fase para outra. De maneira geral o sistema deslocou-se desde a Amazônia até o Sul do Brasil e Nordeste da Argentina. Entretanto, foi durante a $\mathrm{ODP}(-)$ que os casos detectados mostraram-se mais intensos, porém com menos potencial de transporte de umidade dos trópicos para o SEAS que os casos da ODP(+). As análises diárias tiveram padrões de circulação bem similares às análises sazonais, porém apresentaram maiores intensidades devido a aplicação do critério para identificação do JBN e destacaram a interação da atividade ciclônica transiente sobre os extratrópicos aspecto que não pode ser observado nas composições sazonais da Figura 10. Assim, os eventos de JBN em anos de $\mathrm{EN}$ na $\operatorname{ODP}(+)$ são associados a um maior transporte de umidade dos trópicos para o SEAS, seguido de redução da PNMM e movimento vertical ascendente sobre a região contribuindo com os altos valores de água precipitável observados. As anomalias positivas e mais intensas de água precipitável sobre o SEAS (Figura 13b) parecem não ter relação com a maior intensificação dos casos de JBN encontrados nos anos de EN da ODP(-) quando comparado com a ODP(+) já que a forte subsidência e presença de uma alta pressão sobre a região tropical podem ter contribuído com um menor fornecimento de umidade para o SEAS via JBN. 
Através da Figura 19 foi verificado que a maior densidade de ciclones detectados em anos de EN da ODP(+) sobre o extremo Sul do Brasil, Uruguai e nordeste da Argentina foram seguidos de pressões centrais mais baixas do que a média dos anos neutros selecionados, o que pode ser explicado pela convergência de ar quente e úmido dos trópicos para esta região observado na Figura 10c. Isto explica parte das anomalias positivas de precipitação observadas sobre o centro-sul da região do SEAS (Figura 9a). Os ciclones extratropicais ocorridos em anos de EN da ODP(-) foram menos freqüentes sobre maior parte do sul do SEAS e tiveram pressão central inferior quando comparado com a ODP(+). Tal característica juntamente com a redução do fornecimento de umidade dos trópicos para o SEAS explica parcialmente as anomalias negativas de precipitação observadas sobre a maior parte do SEAS (Figura 9c). Uma investigação mais detalhada de outras propriedades ciclogenéticas e do tipo de interação entre a ODP e ciclones extratropicais ainda é necessária para se obter uma conclusão mais detalhada.

Os resultados mencionados na conclusão podem ser sintetizados nos diagramas conceituais da Figura 20, que ilustram as mudanças nas anomalias de circulação trópicos-extratrópicos da América do Sul associada à maior freqüência e intensidade de EN's depois de 1976, reforçando assim a importância deste estudo no monitoramento e previsão do clima do continente. É importante notar que a seta verde representa o escoamento associado ao transporte de umidade. As cores mais escuras na Figura 20a representam anomalias mais intensas que na Figura 20b. 


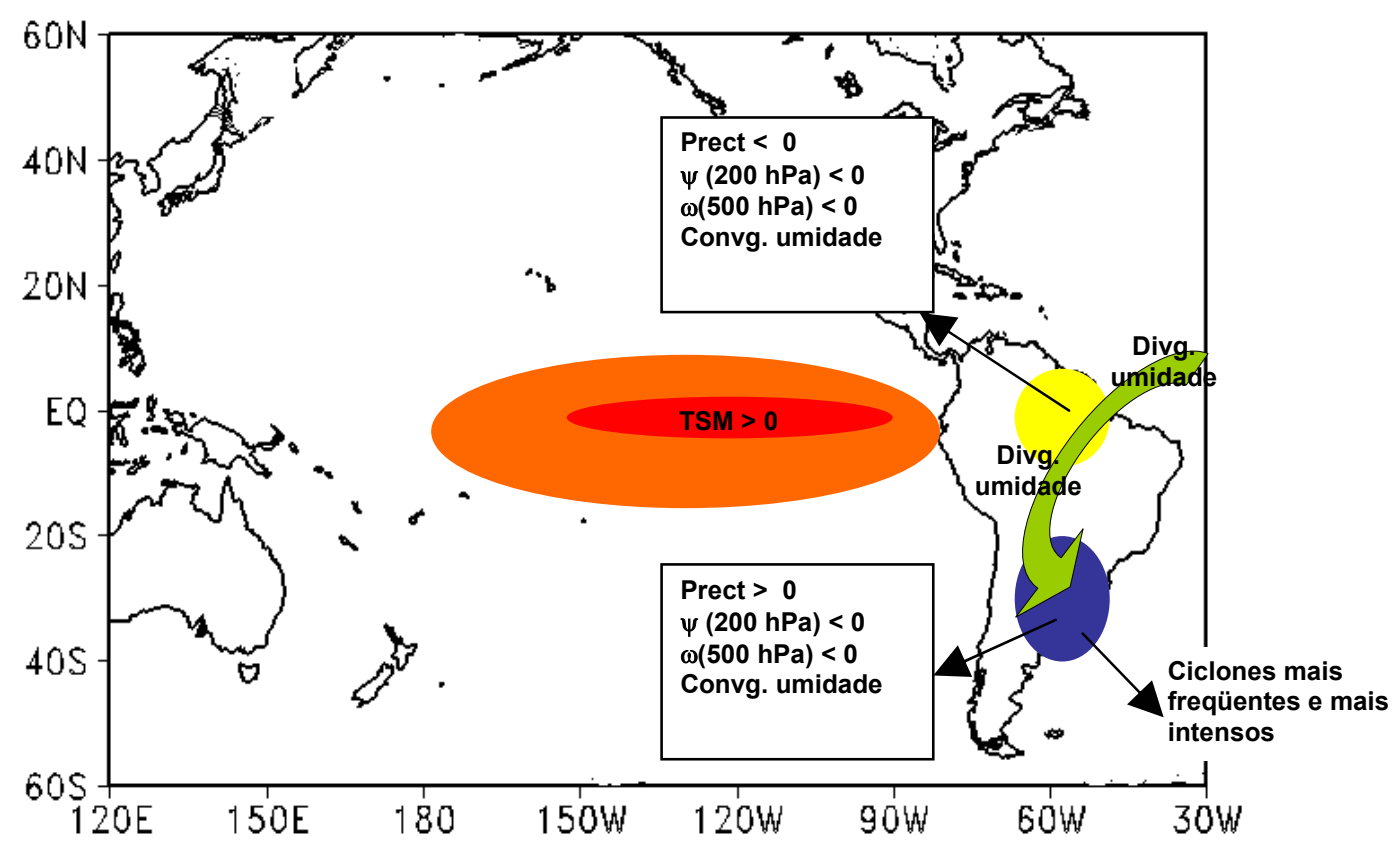

(a)

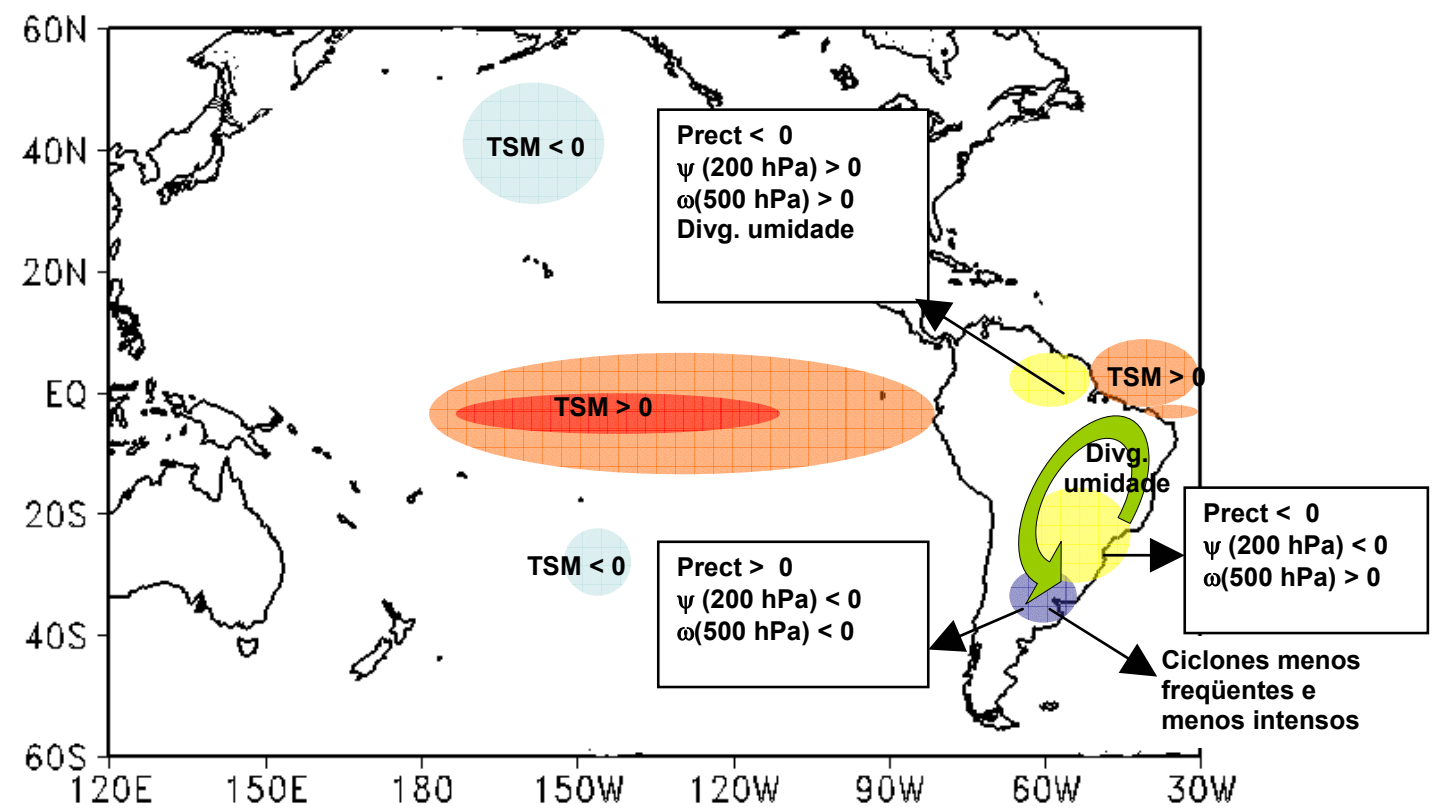

(b)

Figura 20 - Diagramas conceituais das anomalias observadas na ocorrência de eventos EN durante a (a) ODP(+) e (b) ODP(-). A seta verde indica o escoamento associado ao transporte meridional de umidade dos trópicos para os subtrópicos. As cores mais escuras em (a) indicam anomalias mais intensas do que em (b). 


\section{Sugestões para trabalhos futuros}

- Reproduzir os experimentos numéricos forçados com um MCG acoplado com o intuito de explorar os possíveis feedbacks entre oceano-atmosfera na modulação da ODP.

- Explorar o uso da ferramenta numérica CAM3 em outros tipos de estudo, por exemplo, investigar quais são as tendências observadas da variabilidade da

dinâmica de extremos climáticos de seca durante os últimos anos sobre o Brasil, através de variabilidade remota e local de TSM.

- Comparar as saídas dos modelos do Intergovernmental Panel on Climate Change com os padrões observados de extremos do clima presente e rodadas do CAM3 usando distribuições de TSM desses modelos. 


\section{REFERÊNCIAS BIBLIOGRÁFICAS}

AMBRIZZI, T.; HOSKINS, J.; HSU, H.-H. Rossby wave propagation and teleconnection patterns in the austral winter. J.Atmos. Sci., v. 52, p. 3661-3672, 1995.

AMBRIZZI, T.; MAGAÑA, V. Dynamics of the impactos of El niño/Southern Oscillation on the Americas Climate: The december-january-february signal". In: $14^{\mathrm{TH}}$ CONFERENCE ON HYDROLOGY - $79^{\text {TH }}$ MAS ANNUAL MEETING, 1, 307-308, Dallas, Texas, 1999.

AMBRIZZI, T.; SOUZA, E. B.; PULWARTY, R. S. The Hadley and walker regional circulations and associated ENSO impacts on South American seasonal rainfall. In: THE HADLEY CIRCULATION: PRESENT, PAST AND FUTURE, Diaz H.F. and Bradley R.S. (Eds.). Kluwer Publishers, Chapter 7, p. 203-235, 2004.

ANDREOLI, R. V.; KAYANO, M. T. ENSO-related rainfall anomalies in South America and associated circulation features during warm and cold Pacific Decadal Oscillation regimes. Int. J. Climatol, V. 25, p. 2017-2030, 2005. doi: 10.1002/joc.1222.

BERBERY, E. H.; BARROS, V. The hydrological cycle of the La Plata Basin in South America. Journal Hydrometeorology, Boston, v. 3, n. 1, p. 630-645, 2002.

BEU, C. M. L; AMBRIZZI, T. Variabilidade Interanual e Intersazonal da Freqüência de Ciclones no Hemisfério Sul. Rev. Bras. Meteor., v. 21, n. 1, p. 44-55, 2005.

BLUESTEIN, H. B. Synoptic-Dynamic Meteorology in Midlatitudes. Oxford University Press, 431 pp, 1992.

BONNER, W. D. Climatology of the Low Level Jet. Monthly Weather Review, v. 96, p. 833-50, 1968.

BOVILLE, B.; GENT, P. The NCAR Climate System Model, Version One. Journal of Climate, v. 11, p.1115-1130, 1998.

CARVALHO, L. M. V; JONES, C.; LIEBMANN, B. The South Atlantic convergence zone: Intensity, form, persistence, and relationships with intraseasonal to interannual activity and extreme rainfall. J. Climate, v. 17, p. 88-108, 2004.

CAVALCANTI, I. F. A.; KAYANO, M. T. High frequency patterns of the atmospheric circulation over the Southern Hemisphere and South America. Meteorology and Atmospheric Physics, v. 69, p. 179-183, 1999.

CAVALCANTI, I. F. A.; SOUZA, C. A.; KOUSKY, V. E. Características atmosféricas associadas ao jato em baixos níveis a leste dos Andes em uma simulação com 0 MCGA CPTEC/INPE e em dados da Reanálise NCEP/NCAR. In: XII Congresso Brasileiro de Meteorologia, 2002. 
CHANG, P. L.; LI, H. A decadal climate variation in the tropical Atlantic Ocean from thermodynamic air-sea interactions. Nature, Londres, v. 385, p. 516-518. 1997.

CHEN, M.; XIE, P.; JANOWIAK, J. E.; ARKIN, E P.A. Global land precipitation: A 50yr monthly analysis based on gauge observations. J. Hydrometeor., v. 3, n. 3, p. 249266, 2002.

CITEUA, J.; BERGÉS, J. C.; DEMARCQ, H.; MAHÉ, G. Position de la Zone de Convergence a $28^{\circ} \mathrm{N}$ et température de surface de l'ocean. Veille Climatique Satellitaire, v 21, p. 3-7, 1988a.

COLLINS, W. D.; RASCH, P. J.; BOVILLE B. A.; HACK, J. J.; MCCAA, J. R.; WILLIAMSON, D. L.; BRIEGLEB, B.; BITZ, C.; LIN, S-J.; ZHANG, M. The formulation and atmospheric simulation of the Community Atmosphere Model: CAM3. J. Climate, v. 19, n. 11, p. 2144-2161, 2006. doi:10.1175/JCLI3760.1.

DAL PIVA, E. Estudo de caso sobre o papel dos fluxos de calor latente e sensível em superfície em processos de ciclogênese de costa leste ocorrido na costa da América do Sul. 2001. 162 f. Dissertação (Mestrado em Meteorologia) - Instituto Nacional de Pesquisas Espaciais, São José dos Campos, 2001.

DESER, C.; PHILLIPS, A. S.; HURRELL, J. W. Pacific interdecadal climate variability: Linkages between the tropics and the north Pacific during boreal winter since 1900, J. Clim., v. 17, p. 3109-3124, 2004.

DETTINGER, M. D.; BATTISTI, D. S; GARREAUD, R. D.; MCCABE JR., G. J.; BITZ, C. M. Interhemispheric effects of interannual and decadal ENSOlike climate variations on the Americas. In: Interhemispheric Climate Linkages, edited by V. Markgraf, Academic, San Diego, Calif., p. 1 -16, 2001.

DRUMOND, A. R. M . Comunicação Pessoal, 2008.

DRUMOND, A.R.M.; AMBRIZZI, T. The role of SST on the South American atmospheric circulation during January, February and March 2001. Climate Dynamics, v. 24, p.: 781-791, 2005.

FIGUEROA, S. N.; SATYAMURTY, P.; SILVA DIAS, P. L. Simulations of the summer circulation over the South American region with an ETA coordinate model. Journal of Atmospheric Sciences, v. 52, n. 10, p.1573-1584, 1995.

GANDU, A. W.; GEISLER, J. E. A primitive equations model study of the effect of topography on the summer circulation over tropical South America. J. Atmos. Sci., v. 48, p. 1822-1836, 1991.

GAN, M. A. Ciclogêneses e Ciclones sobre a América do Sul. 1992. 225 f. Tese (Doutorado em Meteorologia) - Instituto Nacional de Pesquisas Espaciais, São Jose dos Campos, 1992. 
GAN, M. A.; KOUSKY, V. E. Vórtices ciclônicos da alta troposfera no oceano Atlântico Sul. Revista Brasileira de Meteorologia, v. 1, p. 19-28, 1986.

GAN, M. A.; RAO, B. V. Surface ciclogenesis over South America. Mon. Wea. Rev., v. 119, p. 293-302, 1991.

GAN, M. A.; RAO, B. V. The influence of the Andes Cordillera on transient disturbances. Monthly Weather Review, v. 122, p. 1141-1157, 1994.

GAN, M. A.; RAO, B. V. Case studies of cyclogenesis over South America. Meteorology Applied, v. 3, p. 359-369, 1996.

GARCIA, S. R.; KAYANO, M. T. South American Monsoon during the two phases of the Pacific Decadal Oscillation. In: Proceedings of 8 ICSHMO, 2006, 1049-1055, Foz do Iguaçu.

GARREAUD, R. D.; BATTISTI, D. S. Interannual (ENSO) and interdecadal (ENSOlike) variability in the Southern Hemisphere tropospheric circulation. J. Climate, v. 12, p. 2113-2123, 1999.

GERSHUNO, V. A.; BARNETT, T. Interdecadal modulation of ENSO teleconnections. Bull. Amer. Met. Soc., v. 79, p. 2715-2726, 1998.

GILL, A. E. Some simple solutions for heat-induced tropical circulation. Quart. J. R. Meteor. Soc., v. 106, p. 447-462, 1980.

GOODRICH, G. B. Influence of the Pacific decadal oscillation on Arizona winter precipitation during years of neutral ENSO. Wea. Forecasting, v. 19, p. 950-953, 2004.

GOODRICH, G. B. Influence of the Pacific Decadal Oscillation on Winter Precipitation and Drought during Years of Neutral ENSO in the Western United States. Weather and Forecasting, v. 22, n. 1, p. 116-124, 2006.

GRAHAM, N. E.; BARNETT, T. P.; WILDE, R.; PONATER, M.; SCHUBERT, S. On the Roles of Tropical and Midlatitude SSTs in Forcing Interannual to Interdecadal Variability in the Winter Northern Hemisphere Circulation. J. Clim. V. 7, p. 14161441, 1994.

HERDIES, D. L.; DA SILVA, A.; SILVA DIAS, M. A.; FERREIRA, R.N. Moisture budget of the bimodal pattern of the summer circulation over South America. Journal of Geophysical Research, v. 107, p.8075-8084, 2002.

HOLTON, J. R. An Introduction to Dynamic Meteorology. Elsevier Academic Press, New York, $4^{\text {a }}$ ed., 2004.

HOSKINS, B. J.; AMBRIZZI, T. Rossby wave propagation on a realistic longitudinally varying flow. J.A.S., v. 50, n. 12, p. 1661-1671,1993. 
HURRELL, J. W.; HACK, J. J.; PHILLIPS, A.; CARON, J.; YIN, J. The dynamical simulation of the NCAR Community Atmosphere Model version 3 (CAM3). J. Climate, v. 19, n. 11, p. 2162-2183.2005.

INZUNZA, B. J.; BERRI, G. J. Campo de Movimiento y transporte de humedad asociado en la baja tropos fera en el norte de Argentina. Meteorologica, 17, 17-25, 1980.

JONES, C.; CARVALHO, L. M. V. Active and break phases in the South America monsoon system. J. Climate, v. 15, p. 905-914, 2002.

JONES, D. A.; SIMMONDS, I. A climatology of Southern Hemisphere extratropical cyclones. Clim.Dynam, v. 9, p. 131-145, 1993.

JUSEVICIUS, M. A. R. Ciclogênese a Sotavento dos Andes: Estudo Observacional e Simulação Numérica de um Evento. 1999, 109 f. Dissertação (Mestrado em Meteorologia). Instituto Nacional de Pesquisas Espaciais, São José dos Campos, 1999.

KALNAY, E.; KANAMITSU, M.; KISTLER, R.; COLLINS, W.; DEAVEN, D.; GANDIN, L.; IREDELL, M.; SAHA, S.; WHITE, G.; WOOLLEN, J.; ZHU, Y.; CHELLIAH, M.; EBISUZAKI, W.; HIGGINS, W.; JANOVIAK, J.; MO, K.C.; ROPELEWSKI, C.; WANG, J.; LEETMAA, A.; REYNOLDS, R.; ROY, J.; JOSEPH, D. The NCEP/NCAR 40-year Reanalysis Project. Bulletin of the American Meteorological Society, v. 77, n. 3, p. 437-471, 1996.

KAROLY, D. J. Southern Hemisphere circulation features associated with EI NiñoSouthern Oscillation events. J. Climate, v. 2, p. 1239-1252, 1989.

KAYANO, M. T.; ANDREOLI, R. V. Relations of South American summer rainfall interannual variations with the Pacific Decadal Oscillation. International Journal of Climatology, v.27, p. 531-540, 2007.

KIDSON, J. W. Principal modes of Southern Hemisphere low frequency variability obtained from NCEP/NCAR reanalysis. J. Climate, v. 12, p. 2808-2823, 1999.

KILADIS, G. N.; DIAZ, H. F. Global climatic anomalies associated with extremes in the Southern Oscillation. J. Climate, v. 2, p. 1069-1090, 1989.

KIM, K. M.; LAU, K. M. Dynamics of monsoon-induced biennial variability in ENSO. Geophy. Res. Lett., v. 28, p. 315-318, 2001.

KODAMA, Y. Large-Scale Common Features of Subtropical Precipitation Zones (the Baiu Frontal Zone, the SPCZ and the SACZ), Part I: Characteristics of Subtropical Precipitation Zones. J. Met. Soc. Japan, v. 70, p. 813- 836, 1993.

KOUSKY, V. E.; CAVALCANTI, I. F. A. Pentad outgoing longwave radiation climatology for the South American sector. Rev. Bras. Meteor., v. 3, p. 217-231, 1988. 
KOUSKY, V. E.; KAYANO, M. T.; CAVALCANTI, I. F. A. A review of the Southern oscillation: oceanic-atmospheric circulation changes and related rainfall anomalies. Tellus, 36A, p. 490-504, 1984.

KRISHNAMURTHY, V.; GOSWAMI, B. N. Indian monsoon-ENSO relationship on interdecadal timescale. J. Climate, v. 13, p. 579-595, 2000.

KRISHNAN, R.; SUGI, M. Pacific decadal oscillation and variability of the Indian summer monsoon rainfall. Climate Dynamics, v. 21, p. 233-242, 2003.

LAU, K. M.; ZHOU, H. Anomalies of the South American summer monsoon associated with the 1997-99 El Niño-Southern Oscillation. International. Journal of Climatology, v. 23, p. 529-539, 2003.

LIEBMANN, B.; KILADIS, G. N.; MARENGO, J. A.; AMBRIZZI, T.; GLICK, J. D. Submonthly convective variability over South America and the south Atlantic convergence zone. Journal of Climate, v.12, p. 1877-1891, 1999.

LIEBMANN, B.; KILADIS, G. N.; VERA, C.S.; SAULO, A. C.; CARVALHO, L. M. V. Subseasonal variations of rainfall in South America in the vicinity of the low-level jet east of the Andes and comparison to those in the South Atlantic convergence zone. Journal of Climate, v. 17, n. 19, p. 3829-3842, 2004. doi: 10.1175/1520-0442.

MAGAÑA, V.; AMBRIZZI, T. Dynamics of subtropical vertical motions over the Americas during El Niño boreal winters, Atmósfera, v. 18, n. 4, p. 211-233, 2005.

MARENGO, J. Interdecadal and long term rainfall variability in the Amazon basin. Theoretical and Applied Climatology, v.78, p. 79-96, 2004.

MARENGO, J. A.; SOARES, W. R.; SAULO, C.; NICOLINI, M. Climatology of the Low-Level Jet east of the Andes as derived from the NCEP reanalyses. Journal of Climate, v. 17, p. 2261-2280, 2004.

MANTUA, N. J. ; HARE, S. R. ; ZHANG, Y.; WALLACE, J. M. ; FRANCIS, R. C. A. Pacific interdecadal climate oscillation with impacts on salmon production. Bull. Amer. Meteor. Soc., v. 78, p. 1069-1079, 1997.

MENDES, D.; SOUZA, E. P.; TRIGO, I. F.; MIRANDA, P. M. A. On precursors of South American Cyclogenesis. Tellus, v. 59A, p. 114-121, 2007.

MESTAS-NUÑEZ, A. M.; ENFIELD, D. B. Eastern equatorial Pacific SST variability: ENSO and non-ENSO components and their climatic associations, J. Climate, v. 14, p. 391-402, 2001.

MO, C.K. Relationships between low-frequency variability in the Southern Hemisphere and sea surface temperature anomalies. J. Climate, v. 13, p. 3599-3610, 2000. 
MO, K. C.; NOGUE'S-PAEGLE, J. The Pacific-South American modes and their downstream impact. J. Climatol., v. 21, p. 1211-1229, 2001.

MURRAY, R.J.; SIMMONDS, I. A numerical scheme for tracking cyclone centres from digital data. Part I: Develpment and operation of the scheme. Austr. Meterol.Mag., v. 39, p. 155-166, 1991a.

MURRAY, R.J.; SIMMONDS, I. A numerical scheme for tracking cyclone centres from digital data. Part II: Application to January and July general circulation model simulations. Austral. Meterol. Mag., v. 39, p. 167-180, 1991b.

NECCO, G. V. Comportamiento de Vortices Ciclonicos En El Area Sudamerica Durante EI FGGE: Trayectorias y Desarrollos. Meteorologica, v. 13, n. 1, p. 21-34, 1982b.

NEWMAN, M.; COMPO, G. P.; ALEXANDER, M. A. ENSO-forced variability of the Pacific Decadal Oscillation, J. Clim., v. 16, p. 3853-3857, 2003.

NIETO, R. F.; RICKENBACH, T. M.; HERDIES, D. L.; CARVALHO, L. M. V. Variability of South American convective cloud systems and tropospheric circulation during January-March 1998 and 1999. Monthly Weather Review, v. 131, p. 961-973, 2003.

NOGUÉS-PEAGLE, J.; MO, K. C. Linkages between summer rainfall variability over South America and sea surface temperature anomalies. Journal of Climate, v.15, n. 12, p. 1389-1407, 2002.

PEIXOTO, J. P.; OORT, A. H. Physics of Climate. American Institute of Physics, 1992, $520 \mathrm{p}$.

PEREIRA J. Influência do Gelo Marinho Antártico no Setor Austral e Sudoeste do Atlântico Sul. 2007. 169 f. Tese (Doutorado em Oceonografia). Instituto Oceanográfico, Universidade de São Paulo, São Paulo, 2007.

PESQUERO, J. F. Um estudo de avaliação estatística do modelo global do CPTEC com relação ao número, trajetória e intensidade de ciclones e anticiclones para o Hemisfério Sul. 2001. 149 f. Dissertação (Mestrado em Meteorologia) - Instituto Nacional de Pesquisas Espaciais, São José dos Campos. 2001.

PETTERSSEN, S. Weather analysis and forecasting - Motion and motion systems. New York, McGraw Hill Book Co. Inc., v. 1, 1956, 428p.

PEZZA, A. B.; AMBRIZZI, T. Variability of Southern Hemisphere Cyclone and Anticyclone Behavior - Further Analisis. Journal of Climate, v. 16, n. 7, p. 1075-1083, 2003.

PEZZA, A. B.; AMBRIZZI, T. Cold waves in South America and freezing temperatures in São Paulo: Historical background (1888-2003) and case studies of cyclones and anticyclones tracks. Rev. Bras. Meteor, v. 20, n. 1, p. 141-158, 2005. 
PEZZA, A.; SIMMONDS, I.; RENWICK, J. Southern Hemisphere cyclones and anticyclones: Recent trends and links with decadal variability in the Pacific Ocean. Int. J. Climatol.,v. 27, p. 1403 - 1419, 2007. doi:10.1002/joc.1477.

RAO, V.B.; HADA, K. Characteristics of rainfall over Brazil: annual variation and connections with southern oscilation, Theor. Appl. Climatol, v. 42, p. 81-91, 1990.

RASCH, P. J.; STEVENS, M. J.; RICCIARDULLI, L.; DAI, A.; NEGRI, A.; WOOD, R.; BOVILLE, B. A; EATON, B.; HACK, J.J. A characterization of tropical transient activity in the CAM3 atmospheric hydrologic cycle. J. Climate, v. 19, n. 11, p. 22222242, 2006.

RAUPP, C. F. M. Efeitos de processos não-lineares na influência inter-hemisférica de fontes de calor. 2002, 240 f. Dissertação de (Mestrado em Meteorologia) Instituto Astronomia, Geofísica e Ciências Atmosféricas, Universidade de São Paulo, 2002.

RAYNER; N. A.; PARKER, D. E.; HORTON, E. B.; FOLLAND, C. K.; ALEXANDER, L. V.; ROWELL, D. P.; KENT, E. C.; KAPLAN, A. Globally complete analyses of sea surface temperature, sea ice and night marine air temperature. J. Geophys. Res., v. 108, 4407, p. 1871-2000, 2003. doi 10.1029/2002JD002670.

REBOITA, M.S.; DA ROCHA, R. P.; AMBRIZZI, T. SST impact on the cyclogeneses simulated by RegCM3 over the South Atlantic. In: 7th EMS Annual Meeting / 8th ECAM, 4, 2007b, Madrid. Abstracts.

REBOITA, M.S.; DA ROCHA, R. P.; AMBRIZZI, T. Latent and sensible heat fluxes impact on the extratropical cyclones over South Atlantic ocean. In: 9TH INTERNATIONAL CONFERENCE ON SOUTHERN HEMISPHERE METEOROLOGY AND OCEANOGRAPHY, 2009, Melbourne. Disponível em: <http://www.bom.gov.au/events/9icshmo/manuscripts/PTH_G14_Reboita.pdf>.

REBOITA, M. S.; MORAIS, M. S.; AMBRIZI, T. Baixas Térmicas no Hemisfério Sul: uma análise climatológica. In: IV CONGRESO CUBANO DE METEOROLOGÍA, 2007a, Havana. Disponível em: <http://www.sld.cu/galerias/pdf/red/tiempo/programa_y_articulos_en_pdf.>.

ROBERTSON, A. W.; MECHOSO, C. R. Interannual and interdecadal variability of the South Atlantic convergence zone. Monthly Weather Review, v. 128, p. 29472957, 2000.

SARAIVA, J. M. B. Previsto de Tempo na Região Sul: Efeitos da Liberação de Calor Latente. 1996. 205 f. Tese (Doutorado em Meteorologia) - Instituto Astronomia, Geofísica e Ciências Atmosféricas, Universidade de São Paulo, 1996.

SATYAMURTY, P.; FERREIRA, C. C.; GAN, M. A. Cyclonic Vortices over South America. Tellus, v. 42A, p. 194-201, 1990a. 
SAULO, C.; NICOLINI, M.; CHOU, S.C. Model characterization of the South American low-level flow during the 1997-98 spring-summer season. Climate Dynamics, v.16, p. 867-881, 2000.

SCHNEIDER, N. The forcing of the Pacific Decadal Oscillation, J. Clim., v. 18, p. 4355- 4373, 2005. doi:10.1175/JCLI3527.1.

SCHWERDTFEGER, W. Stromungs- und Temperaturfeld der freien Atmospha"re u"ber den Anden. Meteor. Rundsch., v. 14, p. 1-6, 1961.

SELUCHI, M.; SAULO, C.; NICOLINI, M.; SARYAMURTY, P. The Northwestern Argentinean Low: A Study of Two Typical Events. Mon. Wea. Rev., v. 131, p. 23612378, 2003.

SERVAIN, J.; BUSALACCHI, A. J.; MCPHADEN, M. J.; MOURA, A. D.; REVERDIN, G.; VIANNA, M.; ZEBIAK, S. E. A pilot research moored array in the tropical Atlantic (PIRATA). Bulletin of American Meteorological Society, v. 79, n. 10, p. 2019- 2031,1998.

SILVA DIAS, P. L. The role of latent heat release in the dynamics of the LLJ's along the Andes. In: Preprints of the 6th International Conference on Southern Hemisphere Meteorology and Oceanography. Santiago, Chile, 2000.

SILVA DIAS, P. L.; BONATTI, J. P.; KOUSKY, V. E. Diurnally forced tropical tropospheric circulation over South America. Mon. Wea. Rev., v. 115, p. 1465-1478, 1987.

SILVA, G. A. M. Variabilidade inter-El Niños e seu impacto no jato de baixos níveis a leste dos Andes durante o verão austral. 2005. 84 f. Dissertação (Mestrado em Meteorologia) - Instituto Astronomia, Geofísica e Ciências Atmosféricas, Universidade de São Paulo, São Paulo, 2005.

SILVA, G. A. M., AMBRIZZI. T. Inter-El Niño variability and its impact on the South American low-level jet east of the Andes during austral summer - two case studies. Advances in Geosciences, v.6, p. 283-287, 2006, SRef-ID: 1680-7359/adgeo/20066-283

SILVA G. A. M., AMBRIZZI, T., MARENGO J. A. Observational evidences on the modulation of the South American Low Level Jet east of the Andes according the ENSO variability. Ann. Geophys., v. 27, p. 645-657, 2009.

SILVESTRE, G. E. El Niño signal variability in the precipitation over southeastern South America during austral Summer. Geophysical Research Letters, v. 31, p. 1-5 , 2004. doi:10.1029/2004GL020590.

SINCLAIR, M. R. An objective cyclone climatology for the Southern Hemisphere. Monthly Weather Review, v. 122, p. 2239-2256, 1994.

SINCLAIR, M. R. A climatology of cyclogenesis for the Southern Hemisphere. Monthly Weather Review, v. 123, p. 1601-1619, 1995. 
SUGAHARA, S.; ROCHA, R. P.; RODRIGUES, M. L. Condições atmosféricas de grande escala associadas a jato de baixos níveis na América do Sul. In: VIII Congresso Brasileiro de Meteorologia, 2, 573-577, 1994. Anais.

TALJAARD, J. J. Development, distribution and movement of cyclones and anticyclones in the Southern Hemisphere during IGY. J. Appl. Meteor., v. 6, p. 973987, 1967.

TRENBERTH, K. E. The Definition of El Niño. Bull. Amer. Meteor. Soc., v. 78, n. 12, p. 2771-2777, 1997.

UVO, C. B. A Zona de Convergência Intertropical (ZCIT) e sua relação com a precipitação da Região Norte do Nordeste Brasileiro. 1989. 99 f. Dissertação (Mestrado em Meteorologia) - Instituto Nacional de Pesquisas Espaciais, São Jose dos Campos, 1989.

VENEGAS, S. A.; MYSAK, L. A.; STRAUB, D. N. Atmosphereocean coupled variability in the South Atlantic, J. Clim., v. 10, p. 2904-2920, 1997.

VERA, C.; HIGGINS, W.; AMBRIZZI, T.; AMADOR, J.; GARREAUD, R.; GOCHIS, D.; GUTZLER, D.; LETTENMAIER, D.; MARENGO, J.; MECHOSO, C. R.; NOGUESPAEGLE;. SILVA DIAS, P. L; ZHANG, C. Toward a Unified View of the American Monsoon Systems. J. Climate, v. 19, p. 4977-5000, 2006.

VERA, C.; VIGLIAROLO, P. K.; BERBERY, E. H. Cold season synoptic scale waves over subtropical South America. Monthly Weather Review, v. 130, p. 684-699, 2002.

WANG, B.: Interdecadal changes in El Niño onset in the last four decades. J. Climate, v. 8, p. 267-285, 1995.

WEYKAMP, F. V. Eventos Extremos de Precipitação no Sul/Sudeste da América do Sul associados a Jatos de Baixos Níveis. 2006. 102 f. Dissertação de (Mestrado em Meteorologia) - Instituto Astronomia, Geofísica e Ciências Atmosféricas, Universidade de São Paulo, 2006.

WILKS, D. S. Statistical methods in the Atmospheric Sciences. Academic Press, New York, 468 p. , 1995.

ZEBIAK, S. E. Air-sea interactions in the equatorial Atlantic region. Journal of Climate, Boston, v. 6, p. 1567-1586, 1993.

ZHANG, Y.; WALLACE, J. M.; BATTISTI, D. ENSO-like interdecadal variability: 1900-93. J. Climate, v. 10, p. 1004-1020, 1997.

ZHOU, J.; LAU, K-M. Does a monsoon climate exist over South America? Journal of Climate, v. 11, p. 1020-1040, 1998. 
ZHOU, J.; LAU, K-M. Principal modes of interannual and decadal variability of summer rainfall over South America. International Journal of Climatology, v. 21, p. 1623-1644. 2001. DOI: 10.1002/joc.700.

ZHOU, Y. P.; HIGGINS, R.W.; KIM, H-K. Relationships among EI Niño- Southern Oscillation and the Arctic Oscillation: A Climate- Weather Link. NCEP/Climate Prediction Center Atlas, 8 , 2001. $<$ http://www.cpc.ncep.noaa.gov/products/outreach/research_papers/ncep_cpc_atlas/ 8/> 


\section{APÊNDICE 1}

Cópia do artigo Silva et al. (2009) 


\title{
Observational evidences on the modulation of the South American Low Level Jet east of the Andes according the ENSO variability
}

\author{
G. A. M. Silva ${ }^{1}$, T. Ambrizzi ${ }^{1}$, and J. A. Marengo ${ }^{2}$ \\ ${ }^{1}$ Department of Atmospheric Sciences, Institute of Astronomy, Geophysics and Atmospheric Sciences, University of São \\ Paulo, São Paulo, Brazil \\ ${ }^{2}$ Center for Weather Forecasts and Climate Studies, National Institute for Space Studies, Cachoeira Paulista, Brazil
}

Received: 20 May 2008 - Revised: 16 December 2008 - Accepted: 16 January 2009 - Published: 11 February 2009

\begin{abstract}
The differences on the phase and wavelength of the quasi-stationary waves over the South America generated by El Niño (EN) and La Niña (LN) events seem to affect the daily evolution of the South American Low Level Jet east of the Andes (SALLJ). For the austral summer period of 19772004 the SALLJ episodes detected according to Bonner criterion 1 show normal to above-normal frequency in EN years, and in $\mathrm{LN}$ years the episodes show normal to below-normal frequency.

During EN and LN years the SALLJ episodes were associated with positive rainfall anomalies over the La Plata Basin, but more intense during LN years. During EN years the increase in the SALLJ cases were associated to intensification of the Subtropical Jet (SJ) around $30^{\circ} \mathrm{S}$ and positive Sea Level Pressure (SLP) anomalies over the western equatorial Atlantic and tropical South America, particularly over central Brazil. This favored the intensification of the northeasterly trade winds over the northern continent and it channeled by the Andes mountain to the La Plata Basin region where negative SLP are found. The SALLJ cases identified during the $\mathrm{LN}$ events were weaker and less frequent when compared to those for EN years. In this case the SJ was weaker than in EN years and the negative SLP anomalies over the tropical continent contributed to the inversion of the northeasterly trade winds. Also a southerly flow anomaly was generated by the geostrophic balance due to the anomalous blocking over southeast Pacific and the intense cyclonic transient over the southern tip of South America. As result the warm tropical air brought by the SALLJ encounters the cold extratropical air from the southerly winds over the La
\end{abstract}

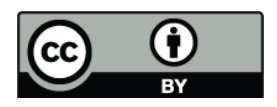

Correspondence to: G. A. M. Silva (gyrlene@model.iag.usp.br)
Plata basin. This configuration can increase the conditional instability over the La Plata basin and may explain the more intense positive rainfall anomalies in SALLJ cases during $\mathrm{LN}$ years than in EN years.

Keywords. Meteorology and atmospheric dynamics (Climatology; General circulation; Ocean-atmosphere interactions)

\section{Introduction}

The rainy season in Brazil (December-February) is related to monsoon system on the South American continent were higher rainfall values are found in Central Brazil. However, precipitation is observed in La Plata Basin (southeastern South America) throughout the year with values about $9 \mathrm{~mm} \mathrm{day}^{-1}$ toward the northern boundary and about $5 \mathrm{~mm} \mathrm{day}^{-1}$ over the central region of the basin (Fig. $6 \mathrm{~b}$ of Berbery and Barros, 2002). This is in part due the low level northerly jet that develops along the eastern slopes of the Andes, here called South American Low-Level Jet east of the Andes (SALLJ). The SALLJ is responsible for transporting moist air from the Amazon region into central and southern South America mainly during austral summer (e.g. NoguésPaegle and Mo, 1997; Saulo et al., 2000; Silva Dias, 2000; Marengo et al., 2004). It also generates turbulence through shear and participates actively as trigging mechanism for the formation of severe storm and Mesoscale Convective Systems over Paraguay, Northern Argentina and South of Brazil (e.g. Guedes and Silva Dias, 1985; Nicolini et al., 2002; Nieto Ferreira et al., 2003). Some studies using data from large field experiments such as the LBA WET AMC (Marengo et al., 2002; Silva Dias et al., 2002) and the SALLJEX (Vera et

Published by Copernicus Publications on behalf of the European Geosciences Union. 
Table 1. El Niño, La Niña and neutral events selected according the Oceanic Niño Index (ONI)/NOAA criterion.

\begin{tabular}{lll}
\hline El Niños & La Niñas & Neutral events \\
\hline $1976 / 77,1977 / 78$, & $1984 / 85,1988 / 89$, & $1978 / 79,1980 / 81$, \\
$1979 / 80,1982 / 83$, & $1995 / 96,1998 / 99$, & $1981 / 82,1983 / 84$, \\
$1986 / 87,1987 / 88$, & $1999 / 2000$ & $1985 / 86,1989 / 90$, \\
$1991 / 92,1994 / 95$, & & $1990 / 91,1992 / 93$, \\
$1997 / 98,2002 / 03$ & & $1993 / 94,1996 / 97$, \\
& & $2000 / 01,2001 / 02$, \\
& & $2003 / 04$ \\
\hline
\end{tabular}

al., 2006), as well as the reanalysis from the National Center for Environmental Prediction - NCEP (Paegle, 1998; Douglas et al., 2000; Saulo et al., 2000; Marengo et al., 2004) have shown the occurrence of SALLJ in different seasons of the year. However, it is in the summer that most intense events seem to occur.

On diurnal timescales the presence of a boundary layer inversion is responsible to modulate the maximum wind profiles at low level (Marengo et al., 2004). Silva Dias (2000) has also suggested that the position of the jet, its intensity and diurnal cycle may be substantially altered by the impact of latent heating in the central Brazilian Amazon basin. On submonthly timescales the frontal passages and the South Atlantic Convergence Zone (SCAZ) activity (Saulo and Nicolini, 2000; Vera et al., 2002; Campetella and Vera, 2002) may modulate the SALLJ. For example, when moisture flux into southeastern South America via the low-level jet is strong, SACZ convection is weaker than normal (Sugahara et al., 1994; Liebmann et al., 1999). Moreover, Liebmann et al. (2004) have shown the relationship among the SALLJ and extreme precipitation events over subtropical South America during austral summer. Using lead and lag composites of circulation for rainfall anomalies associated with the jet, they suggested that on a daily time scale, a preference for rain (no rain) in the SACZ may agree with a weak (strong) jet and dry (wet) conditions downstream of it.

On interannual timescales, some study cases linking El Niño/Southern Oscillation (ENSO) and SALLJ have already been documented in the literature. For instance, Berbery and Barros (2002) suggested that during the austral summer of the three more relevant El Niños (EN) that occurred in the 1980-2000 period, the large-scale patterns showed increased southward component of moisture flux over La Plata Basin. Lau and Zhou (2003) observed a reduction of rainfall over the Amazon associated with a poleward shift of the South American monsoon circulation and rainfall system during the 1997/98 El Niño. They indicated that the Bolivian high was hydrostatically enhanced by the anomalous tropospheric warm ridge extending from the Niño-3 re- gion to the Altiplano Plateau. They found a much stronger SALLJ penetrated deeply into the extratropics along the eastern side of the subtropical Andes, coinciding with the reinforcement of the upper tropospheric subtropical westerly and the local meridional overturning. Marengo et al. (2004), Lau and Zhou (2003) and Nieto Ferreira et al. (2003) have also indicated that the 1997/98 EN had more frequent and strong SALLJ episodes when compared to the 1999/2000 La Niña (LN) event. Silva and Ambrizzi (2006) verified that during the event of 1997/98 a low-level anomalous anticyclonic circulation over the central part of Brazil enhanced the wind in the core of the SALLJ and displaced the jet to the Northern Argentina and South of Brazil. On the other hand, during the weak EN 2002/03 the SALLJ was less intense and displaced towards the southeast of Brazil.

From the above discussion one can suggest that there are many different mechanisms to explain the formation of SALLJ. The goal of this paper is to investigate if El Niño and La Niña signal variability can modulate the frequency, position and intensity of the SALLJ activity during the austral summer. This study is organized as follows. Section 2 describes the data and the methodology. Section 3 summarizes the large-scale patterns found during the ENSO events of austral summer from 1977 to 2004 period. In Sect. 4 the interannual variability on the frequency of the SALLJ episodes during the same period is investigate. Some aspects related to the modulation of the SALLJ variability by EN and LN events are described in Sect. 5. Section 6 summarizes the main findings.

\section{Data and methodology}

In view of the poor observational data in the east Andes region, the NCEP-NCAR reanalysis (Kalnay et al., 1996) have been used in this study. They satisfactorily represent the large-scale atmospheric conditions associated to the SALLJ (Marengo et al., 2004; Silva and Ambrizzi, 2006 and references). The data for December-January-February (DJF) from 1977 to 2004 period are reported on a $2.5^{\circ} \times 2.5^{\circ}$ grid every $6 \mathrm{~h}(00: 00,06: 00,12: 00$ and 18:00 UTC). The period of the study was chosen based on the shift toward warmer tropical Pacific Sea Surface Temperatures (SST) that occurred in 1976 (Zhang et al., 1997) and because the improvement of quality of the observational network. The meteorological variables used are: zonal and meridional winds $(u, v)$ in $850 \mathrm{hPa}$; Sea Level Pressure (SLP) and 500-hPa geopotential height $(\Phi)$. Daily mean streamfunction $(\psi)$ at the 0.21 sigma level (about $200 \mathrm{hPa}$ ) are also used. Daily gridded precipitation data from Liebmann and Allured (2005) on $1^{\circ}$ grid for the same period was used. This dataset was generated from daily precipitation observations over the South American continent based on 7900 meteorological stations. The Oceanic Niño Index (ONI), which is the main index used by NOAA to identify ENSO events in the tropical Pacific 
(NOAA Magazine, 23 February 2005, http://www.noaanews. noaa.gov/stories2005/s2394.htm) was used in the study. ONI is calculated using a 3-months running mean of NOAA's Extended Reconstruction SST (ERSST.v2) anomalies in the Niño 3.4 region $\left(5^{\circ} \mathrm{N}-5^{\circ} \mathrm{S}, 120^{\circ} \mathrm{W}-170^{\circ} \mathrm{W}\right)$. The EN (LN) is defined as condition whereby the ONI is more (less) than or equal to $0.5^{\circ}\left(-0.5^{\circ}\right) \mathrm{C}$. On the basis of this classification, 28 cases were chosen for the study, where December represents the initial year (0) and February the following year (Table 1). The period of 1977-2004 was chosen due to the precipitation data limitations.

Seasonal composites anomalies of EN and LN years of atmospheric circulation variables considered in the study were constructed. This procedure was applied to help to understand links between the different frequencies of SALLJ cases (cases per event) and different evolution during ENSO events. For instance these seasonal composites anomalies were determined as the difference between the composite mean of the $\mathrm{EN}(\mathrm{LN})$ events and the composite mean of the neutral years.

The methodology of previous studies (Saulo et al., 2000; Marengo et al., 2002, 2004; Silva and Ambrizzi, 2006) was applied to wind data $(u, v)$ to select the SALLJ episodes according to each ENSO event. It was assumed that the region of Santa Cruz in Bolivia $\left(17.75^{\circ} \mathrm{S} ; 63.06^{\circ} \mathrm{W}\right)$ is where the core of the jet is usually located and only the northerly wind was selected. Also, the maximum flow should be located around $850 \mathrm{hPa}$ which is less restrictive than the $925 \mathrm{hPa}$ generally used. The Bonner criterion 1 (Bonner, 1968) was applied to the selected wind fields and it is based on the following conditions: the level of maximum wind must be equal or exceed $12 \mathrm{~m} \mathrm{~s}^{-1}$ and must decrease by at least $6 \mathrm{~m} \mathrm{~s}^{-1}$ to the next higher minimum or to the $3-\mathrm{km}$ level, whichever is lower.

Based on the SALLJ episodes detected the interannual variability on the frequency, positioning and intensity was analyzed. For this purpose, daily composite anomalies from day -1 to day +1 , assuming day 0 where the SALLJ reaches it maximum intensity where constructed. For each ENSO event the day 0 composite anomaly was defined as the difference between the day average of the SALLJ maximum intensity and the composite mean of the neutral years. Day -1 and day +1 are defined as the anomalous fields during -1 (+1) day before (after) each original day 0 .

In order to assess the statistical significance of all composites, a two-tailed Student t-test (Harrison and Larkin, 1998) was used. The composite anomalies were accepted with the confidence level at $95 \%$. Only absolute anomalies equal or exceeding

$\frac{Z_{95}(n) \times \sigma_{c}}{\sqrt{n}}$

were accepted, where $n$ is the number of values used in the composite, $\sigma_{c}$ is the corresponding standard deviation and
$Z_{95}$ is the value of t-distribution for $n$ degrees of freedom (number of events in each group) for $95 \%$ confidence level.

\section{ENSO-related anomalies circulation during the aus- tral summer (1977-2004)}

The seasonal anomalies composites of EN and LN years during austral summer are illustrated in Fig. 1. The EN-related 200-hPa zonally asymmetric $\psi$ anomaly composite shows anticyclones over the central-eastern tropical Pacific centered in the latitudinal bands of $20^{\circ}$ of both hemispheres (Fig. 1a). This pattern is part of a Rossby wave train pattern stretching from the heating source in the equatorial eastern Pacific to northeastern Brazil through the Southern Hemisphere midlatitudes. Cyclonic and anticyclonic centers over northeastern Brazil and southeast SA are observed. The LN events shows an opposite pattern mainly over the tropics where the most significant anomalies were found (Fig. 1d).

The 500-hPa $\Phi$ anomaly pattern in the EN composite shows positive values over the tropical and subtropical SA and negative ones in the extratropics (Fig. 1b). The gradient among these systems favor the intensification of the $\mathrm{SJ}$ around $30^{\circ} \mathrm{S}$. During the LN events (Fig. 1e) negative anomalies dominate over the South American continent. In fact, the cyclonic center over $40^{\circ} \mathrm{W}-30^{\circ} \mathrm{S}$ contributes to the intensification of SJ though it is weaker than in Fig. 1b.

The $850 \mathrm{hPa}$ winds and SLP anomalies for the EN and LN composites show many differences (Fig. 1c and f, respectively). For EN years the positive SLP anomalies over the eastern equatorial Atlantic and tropics contributes to intensify the northeasterly trade winds over northern SA (Fig. 1c). The positive SLP nucleus over central Brazil contributes to channel the wind to the southeast part of the continent bringing moisture over this region where there is negative SLP anomalies. In contrast, the LN composites show an inversion of the northeasterly trade winds over SA. A positive (negative) SLP nucleus centered over the southwestern Pacific (southern Atlantic) related to the anticyclonic (cyclonic) circulation are observed in high and mid-latitudes (Fig. 1d and e, respectively) and having a vertical equivalent barotropic structure. This configuration contributes to strong low level southerly winds which prevail over the subtropical SA favoring the southerly transport of moist air to the east of the Andes and weakening the northerly LLJ. Due to the extratropical cyclone anomaly, this flow can be accompanied by synoptic-scale bands of deep convection at the leading edge, frequently associated with SACZ intensification (e.g. Garreaud and Wallace 1998).

In the next section, a detailed daily evolution of the SALLJ episodes during EN and $\mathrm{LN}$ years which will be compared to the seasonal anomalies of the atmospheric circulation patterns during ENSO events analyzed here. This analysis will help to strengthen the main ideas proposed in the study, i.e. how the EN and LN signal variability can modulate the 


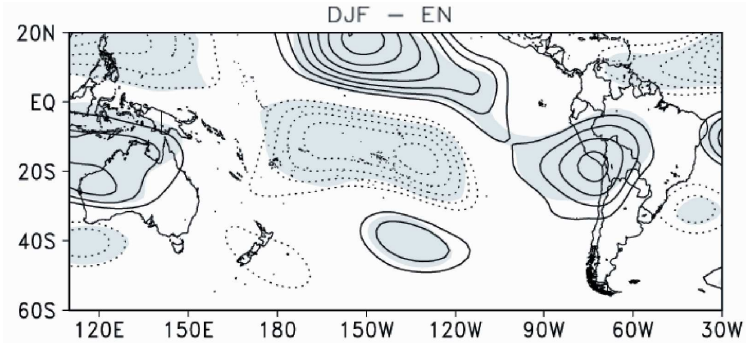

(a)

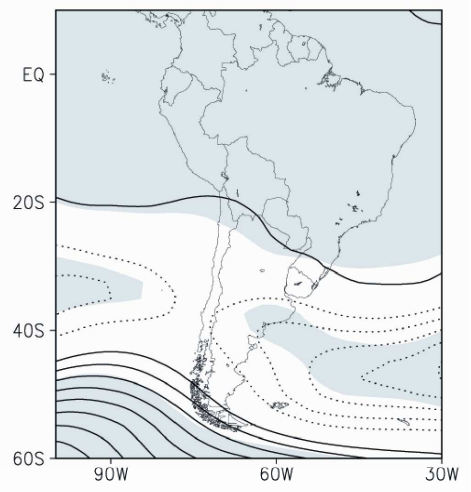

(b)

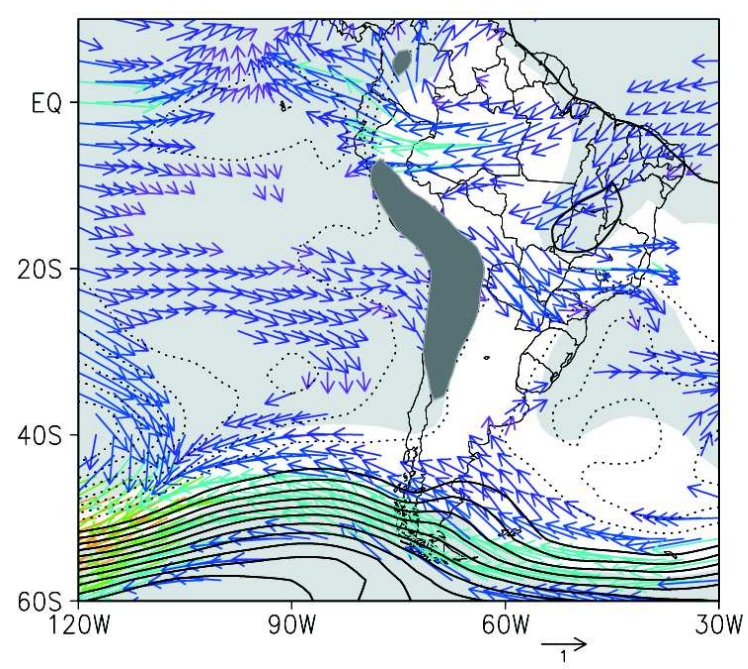

(c)

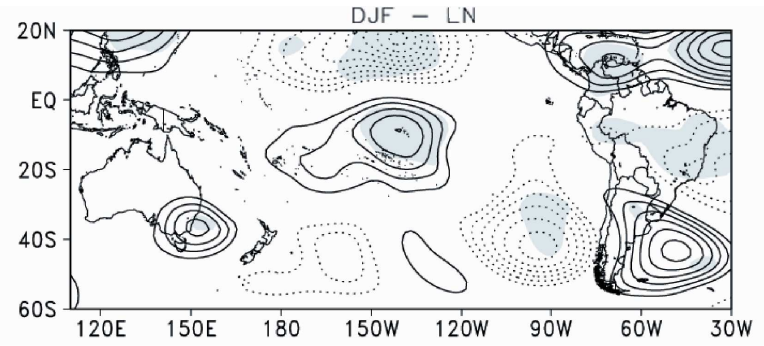

(d)

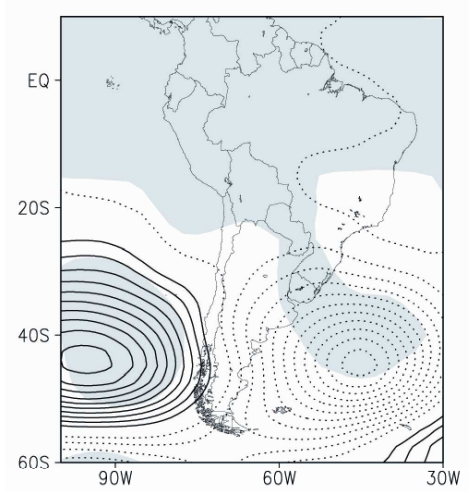

(e)

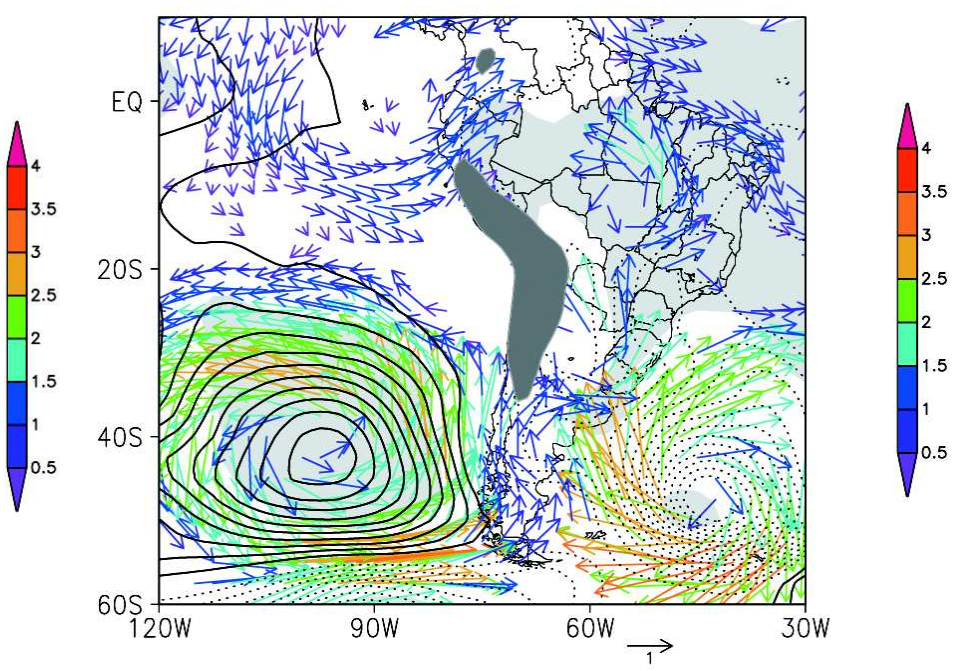

(f)

Fig. 1. Anomaly composites during austral summer from 1977-2004. On the left panel (a) $200 \mathrm{hPa}$ zonally asymmetric streamfunction; (b) $500 \mathrm{hPa}$ geopotential height and (c) $850 \mathrm{hPa}$ wind and SLP for EN years; on the right panel the same as left panel but for LN years. Contour interval is $1 \times 10^{6} \mathrm{~m}^{2} \mathrm{~s}^{-1}, 5 \mathrm{~m}, 1 \mathrm{hPa}$. A reference vector of $1 \mathrm{~m} \mathrm{~s}^{-1}$ is shown at the lower right-hand side of each panel. Negative contours are dashed and the zero contours are omitted. Areas where anomalies are statistically significant at the $95 \%$ level are shaded in gray. 


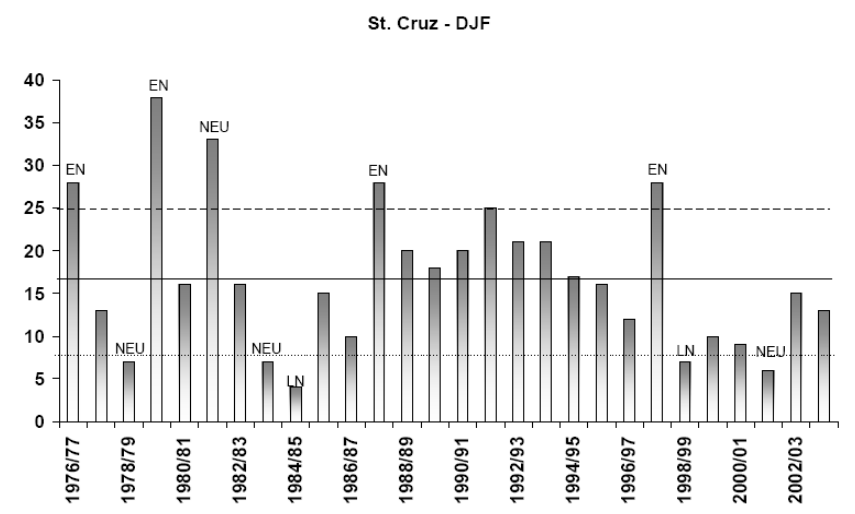

Fig. 2. Frequency of SALLJ detected according the Bonner criterion 1 during DJF season in Santa Cruz- Bolivia. The full, dashed and dotted lines represent the mean, one standard deviation above normal and one standard deviation below normal, respectively. The abbreviations EN, LN and NEU above of the bars indicate El Niño, La Niña and neutral years, respectively.

frequency, position and intensity of the SALLJ activity during the austral summer.

\section{Interannual variability of SALLJ frequency}

The interannual variability of the SALLJ episodes detected in Santa Cruz during DJF from 1977 to 2004 period is shown in Fig. 2, where December represents the initial year (0) of the ENSO event and February the following year. The full, dashed and dotted lines in the figure represent the mean, one standard deviation above normal and one standard deviation below normal, respectively. In the EN events of $1976 / 77,1979 / 80,1987 / 88$ and 1997/98 it is observed abovenormal SALLJ frequency, i.e. number of jets is one standard deviation above-normal (17 plus 8) and the other events the frequencies are normal. For the LN events of 1984/85 and 1998/99, the number of jets was one standard deviation below-normal (17 minus 8), being normal for the others events.

Marengo et al. (2004) showed that statistically significant positive correlations among SALLJ frequency and SST anomalies are observed in the Pacific Ocean implying that a low percentage about $20 \%$ of the SALLJ variance can be explained by the SST anomalies in the Equatorial Pacific during austral summer. Although in the period used here the number of EN events (10) is double of the LN (5) and the sum of them is almost equivalent to the neutral years (13) (see Table 1), the SALLJ cases during the warm ENSO phase is greater than in the cold phase (Table 2). This analysis clearly indicates that there is a tendency for more jets during EN events independently of their number.

While there are still many aspects that may be further explored the present study will only be focused in how differ-
Table 2. Total number of observed SALLJ cases in Santa Cruz for EN, LN and neutral groups and the ratio between the SALLJ and the number of ENSO events during austral summer. The number of ENSO events is shown in the square bracket in the last column.

\begin{tabular}{lcc}
\hline ENSO events & $\begin{array}{c}\text { Total number } \\
\text { of SALLJ }\end{array}$ & $\begin{array}{c}\text { Ratio between number } \\
\text { of SALLJ and ENSO events }\end{array}$ \\
\hline El Niños & 218 & $22(10)$ \\
La Niñas & 57 & $11(5)$ \\
Neutral & 198 & $15(13)$ \\
\hline
\end{tabular}

ent large-scale patterns associated with warm and cold phase of ENSO over South America may modulate the interannual SALLJ variability.

\section{El Niño and La Niña signal in the variability of the SALLJ during austral summer}

Figure 3 displays the rainfall anomaly composites for the SALLJ maximum intensity at day 0 . For EN years significant positive anomalies are found in Uruguay, Northern Argentina, Paraguay, Southern Brazil, in mostly of the La Plata basin and isolated points around $20^{\circ} \mathrm{S}$ over Brazil (Fig. 3a). In Fig. $3 b$ for $L N$ years, the La Plata basin region shows a similar pattern to the EN composites; however the anomalies are more intense in this case. Berbery and Barros (2002) have already suggested that the large rainfall anomalies over La Plata region are not limited to EN events, and according to Fig. $3 b$ it also happens in $L N$ years when SALLJ occurs.

Figures 4 to 6 show the evolution of the atmospheric circulation features associated with the rainfall anomalies described in Fig. 3. The 200-hPa zonally asymmetric $\psi$ anomaly composite during $\mathrm{EN}$ and $\mathrm{LN}$ events from day -1 to +1 of SALLJ activity are shown in Fig. 4. The EN composites show a quasi-stationary wave pattern similar to the Pacific-South American 1 (PSA1) identified by Karoly (1989) and Mo and Paegle (2001): a wave train extending to southeast from the equatorial central Pacific turning to the northeast near the $60^{\circ} \mathrm{S}$ and reaching tropical latitudes over the Atlantic Ocean. Over southern South America near $35^{\circ} \mathrm{S}$ and adjacent ocean the cyclonic anomaly with the anticyclonic anomaly in the southern Brazil produce an enhancement of the SJ which generates a condition to increase rainfall over the region (Fig. 4a). This anomalous pattern is intensified on days 0 and +1 (Fig. $4 \mathrm{~b}$ and c, respectively) and shows the same phase when compared to the seasonal anomalies (Fig. 1a), though with higher amplitude. For the LN (Fig. 4d) composites the wave train observed shows opposite phase over the most part of the tropical latitudes. On the southern tip of South America an anomalous cyclonic circulation similar with that for EN composite is established but with no statistic significance. The anomalous wave pattern is 

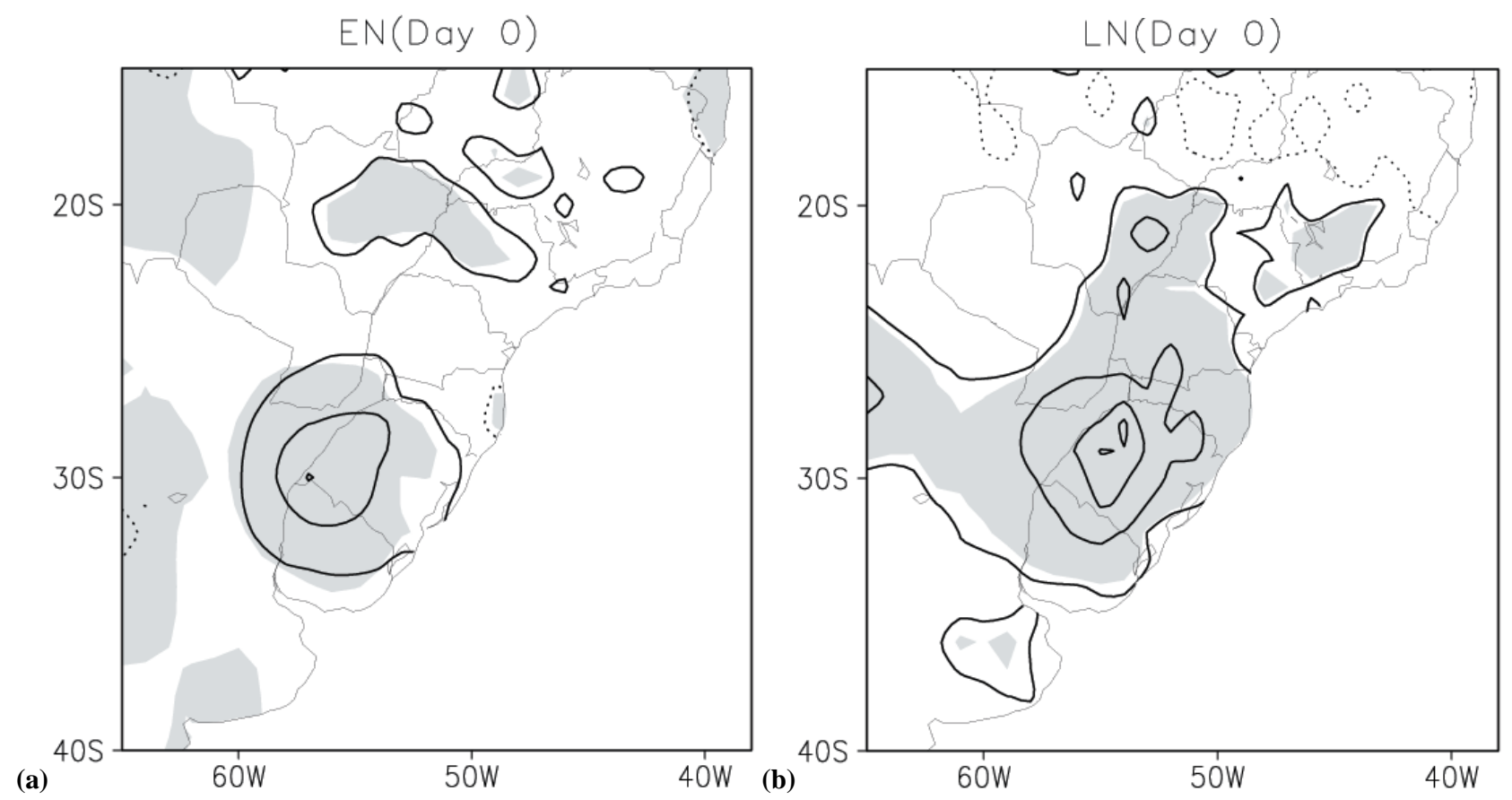

Fig. 3. Precipitation anomaly for DJF of SALLJ composites during their maximum intensity (day 0) for (a) EN and (b) LN years. Contour interval is $2 \mathrm{~mm} \mathrm{day}^{-1}$. Negative contours are dotted and the zero contours are omitted. Areas where the anomalies are statistically significant at the $95 \%$ level are shaded in gray.

intensified over the continent in the days 0 and +1 (Fig. 4 e and $\mathrm{f}$, respectively) having the same structure as observed in seasonal anomalies (Fig. 1d) but stronger.

From the 500-hPa $\Phi$ anomaly composite during EN and $\mathrm{LN}$ years for days $-1,0$ and +1 , we can see some important differences in the fields (Fig. 5). Although a negative geopotential height centered around $\left(50^{\circ} \mathrm{S} ; 70^{\circ} \mathrm{W}\right)$ is clearly observed in both composites at day 0 (Fig. 5a and d, respectively), being part of a wave train structure, their wavelength is quite different. In the EN composite the gradient between the positive values over the tropical SA and negative over the subtropics favors the intensification of the $\mathrm{SJ}$ around $30^{\circ} \mathrm{S}$ over the continent (Fig. 5a) which is maintained in the following days (Fig. 5b and c). It indicates more meridional wave propagation and resembles to the structure observed in Fig. $1 \mathrm{~b}$ but intensified. From day -1 to day +1 of the $\mathrm{LN}$ composites (Fig. 5d-f) a more zonally propagation pattern and larger wavelength is seen over the mid-latitudes when compared to the EN years. Negative values dominates over the SA related to the cyclonic center positioned in $50^{\circ} \mathrm{S}$; $70^{\circ} \mathrm{W}$ acting to produce a much weaker SJ over southeast South America when compared to the EN composites. This pattern resembles Fig. 1e with a shifted phase.

Figure 6 shows the $850 \mathrm{hPa}$ winds and SLP anomalies during EN and LN years from day -1 to +1 of SALLJ activity maximum. The high pressure over the Tropical Atlantic Ocean and tropical Brazil at day -1 for EN composites con- tributes to intensify the northeasterly trade winds over northern SA (Fig. 6a). These winds are channeled to the southeast SA (northern Argentina, Uruguay, South and part of southeast Brazil) along the east of the Andes Mountain. Negative SLP anomalies cross the Andes during this period causing an elongation of its maximum on the lee side. At day 0 (Fig. 6b), a high pressure anomaly favor the anticyclonic circulation over the central Brazil that helps to the maximum intensity of the SALLJ core with $9 \mathrm{~m} \mathrm{~s}^{-1}$ winds intensity. The low pressure mentioned acquire a cyclonic curvature over $40^{\circ} \mathrm{S} ; 55^{\circ} \mathrm{W}$ and when compared to the $500-\mathrm{hPa}$ $\Phi$ anomaly composite (Fig. 5b) indicates a westward inclination in the vertical and therefore the presence of a baroclinic structure. There is here a coupled among the SALLJ and the SJ shown in upper and mid-levels (Figs. $4 \mathrm{~b}$ and $5 \mathrm{~b}$ ). The presence of anomalous upper level SJ associated to the PSA1 wave-like may contribute to the formation and maintenance of the SALLJ trough mass adjustment by transversal circulations in the exit and entrance of the SJ. According to Uccellini and Johnson (1979) the flow accelerates in the jet entrance region of the SJ, the transverse ageostrophic flow generates a direct secondary circulation cell in the plane normal to the jet axis. The SALLJ located beneath the exit region of the upper tropospheric jet streak, was embedded within the lower branch of the indirect circulation cell. Convergence (divergence) regions in low levels, caused by divergence (convergence) mass pattern on equatorial (polar) 


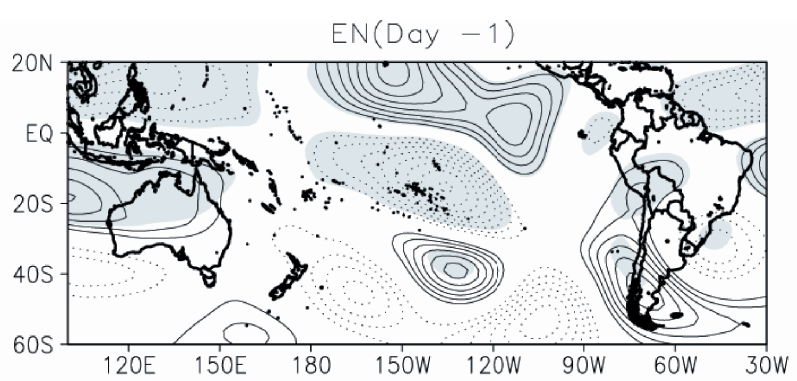

(a)

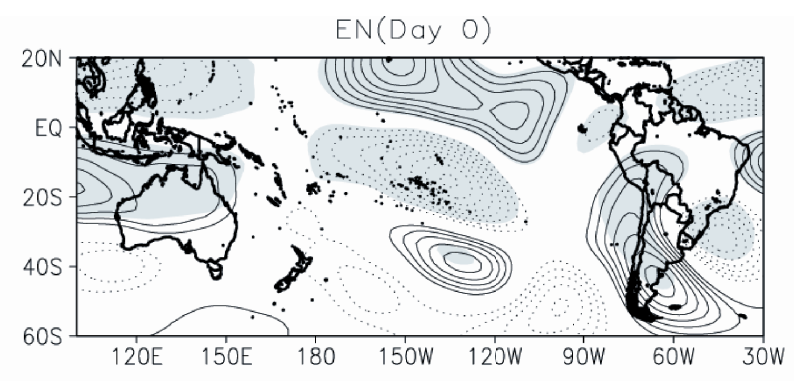

(b)

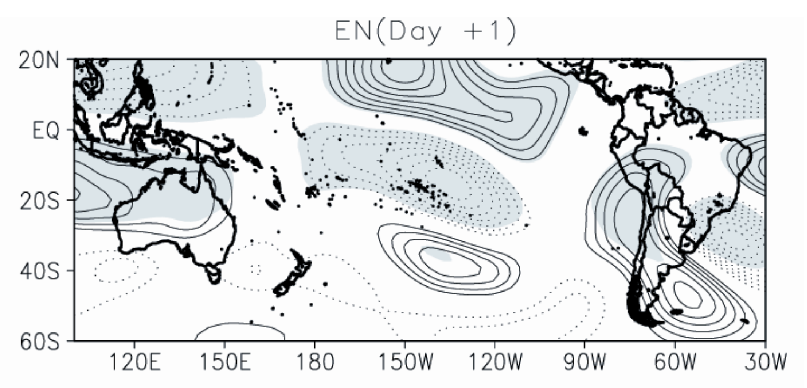

(c)

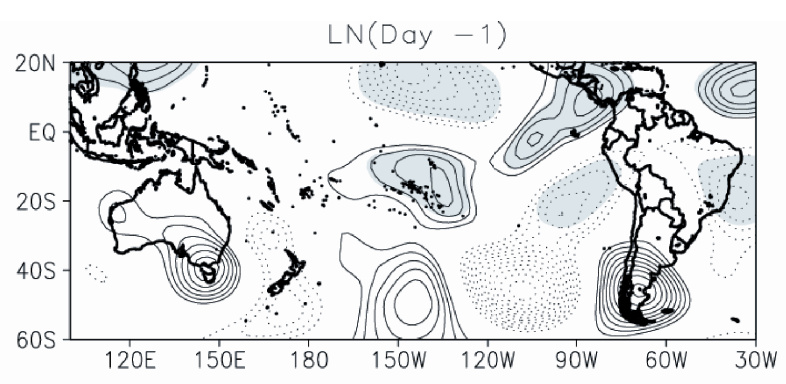

(d)

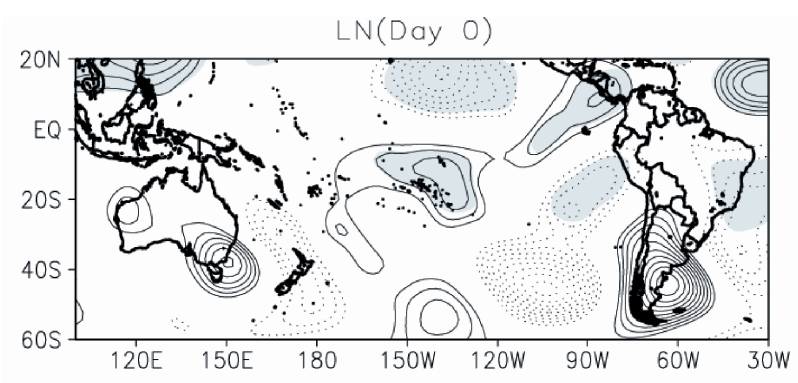

(e)

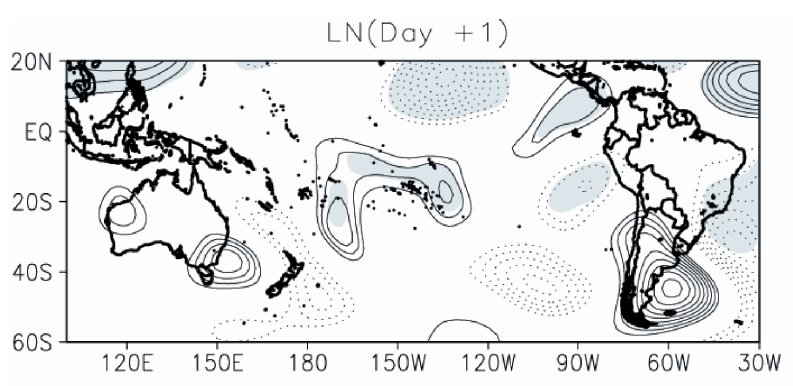

(f)

Fig. 4. $200 \mathrm{hPa}$ zonally asymmetric streamfunction anomaly for SALLJ composites. Left panels: EN years of (a) day -1 ; (b) day 0 and (c) day +1 of the maximum SALLJ intensity. Right panels similar to the left but for: LN years of (d) day -1 ; (e) day 0 and (f) day +1 . Contour interval is $1 \times 10^{6} \mathrm{~m}^{2} \mathrm{~s}^{-1}$. Negative contours are dotted and the zero contours are omitted. Areas where anomalies are statistically significant at the $95 \%$ level are shaded in gray.

side of the jet entrance and polar (equatorial) side of the jet exit produce negative (positive) tendency of SLP. The negative tendency of SLP favors more intense isallobaric wind component of the SALLJ. These conditions are favorable for the development of positive rainfall anomalies over La Plata Basin observed in Fig. 3a. In the following day, the anomalous anticyclonic pressure over the continent is maintained and the displacement of the cyclonic disturbance towards the South Atlantic Ocean coincides with the slight weakening of the SALLJ magnitude and its position is slight displaced to the north (Fig. 6c). The low level wind and SLP anomalies mainly observed in Fig. $6 \mathrm{~b}$ shows the same structure as compared to the Fig. 1c. However, in the first there is a more pronounced channeled southward wind of the northwesterly flow because the Bonner criterion 1 has been applied to wind data to select the SALLJ cases.

At day -1 for $\mathrm{LN}$ composites there is an inversion of the northeasterly trade winds over the continent due the predominance of low pressure over the tropics and in the most part of the western Tropical Atlantic Ocean (Fig. 6d). This is 

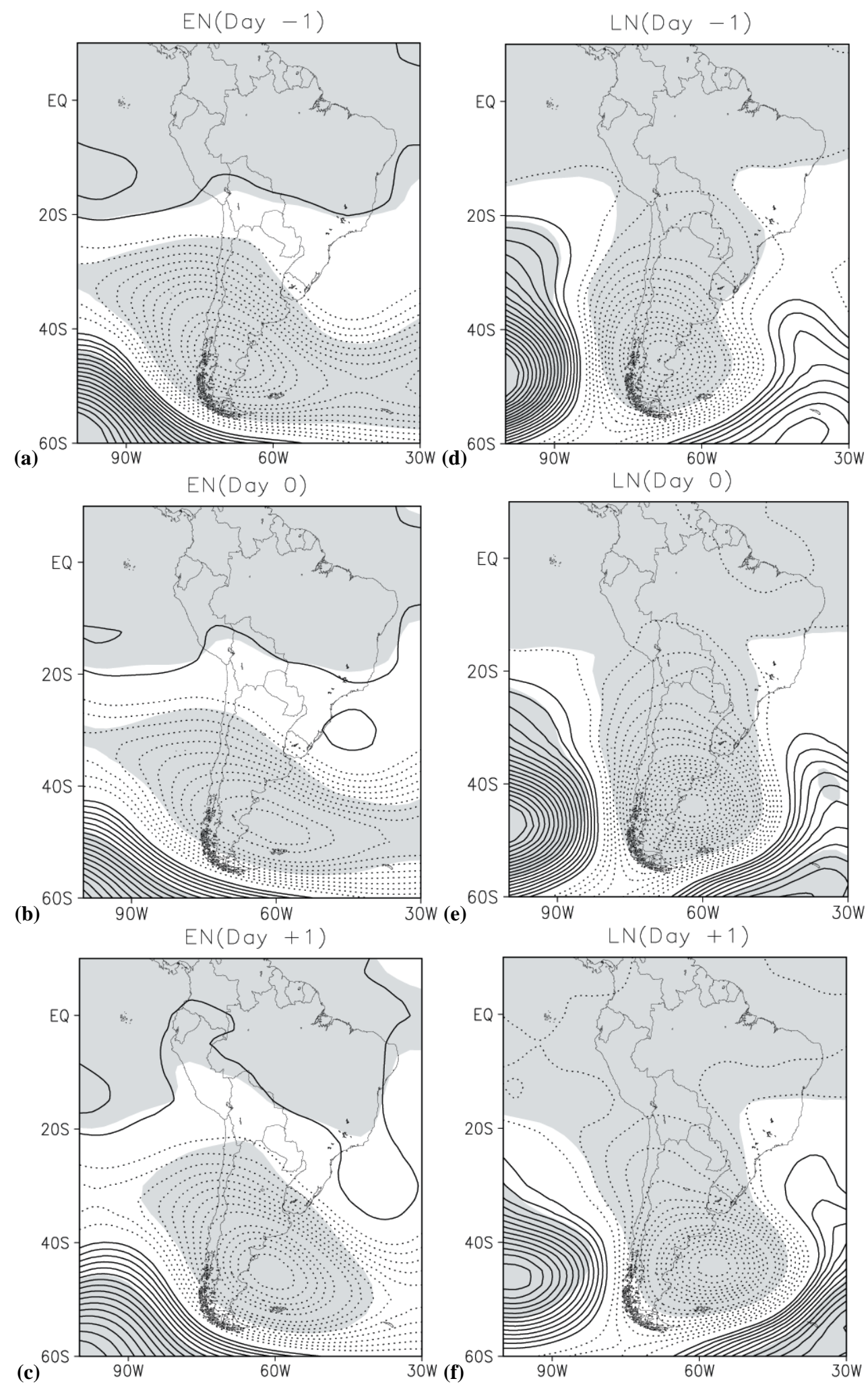

Fig. 5. Same as Fig. 4 but for the $500 \mathrm{hPa}$ geopotential height anomaly. Contour interval is $5 \mathrm{~m}$. Negative contours are dotted and the zero contours are omitted. Areas where anomalies are statistically significant at the $95 \%$ level are shaded in gray. 


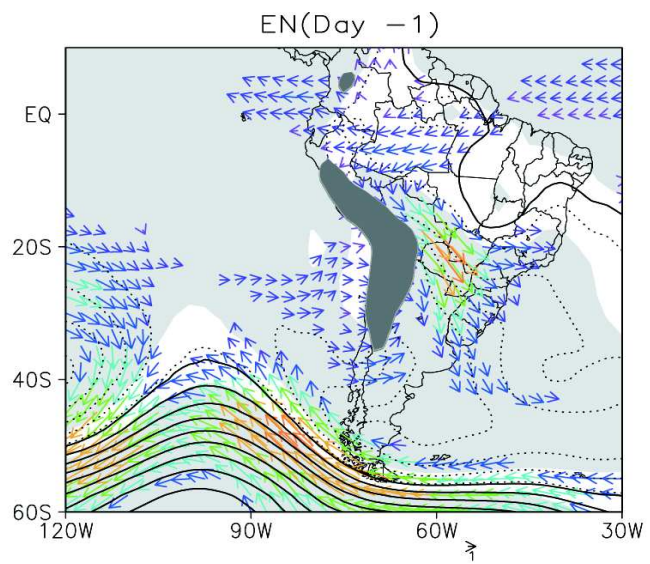

(a)

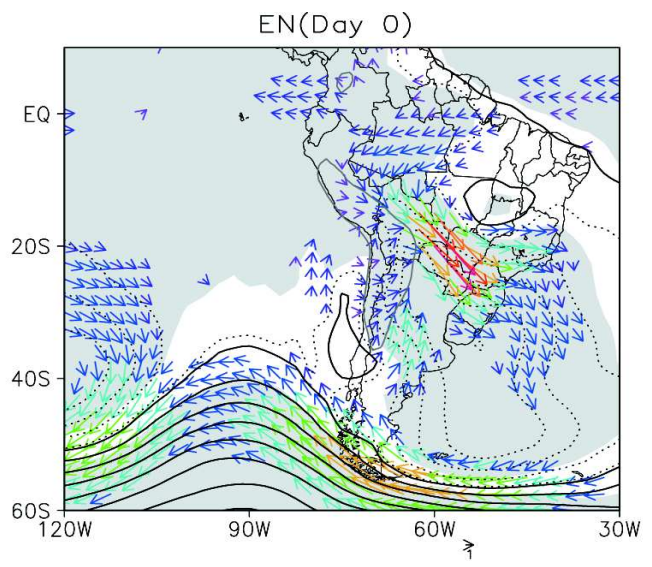

(b)

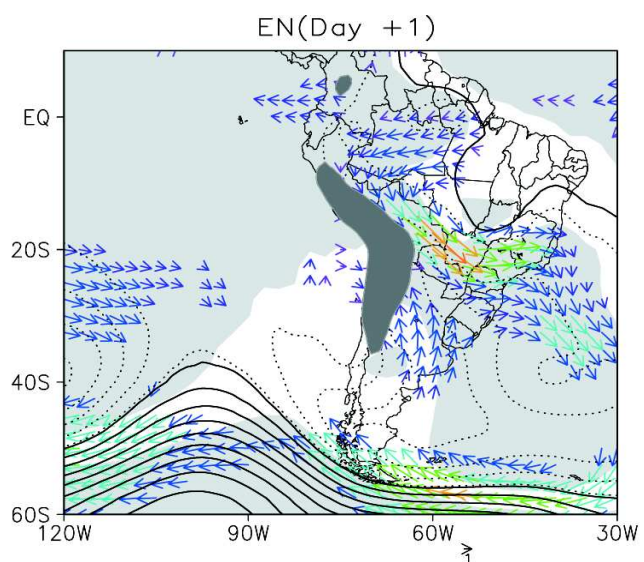

(c)

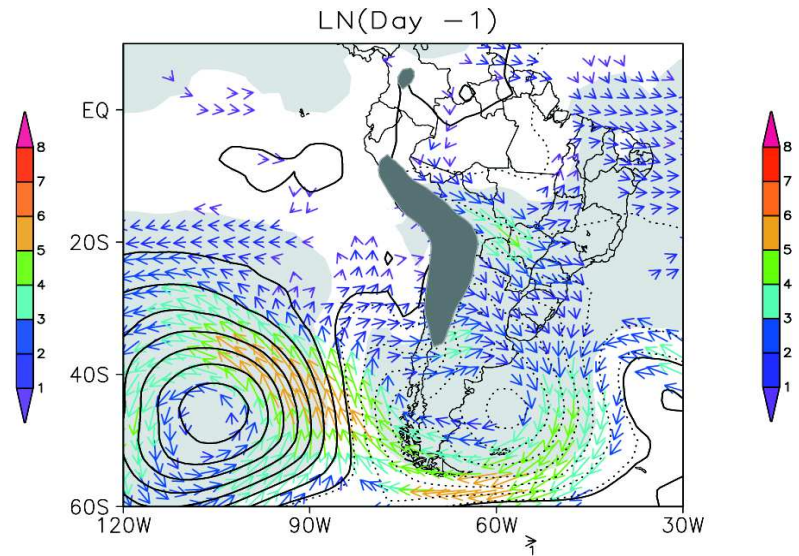

(d)

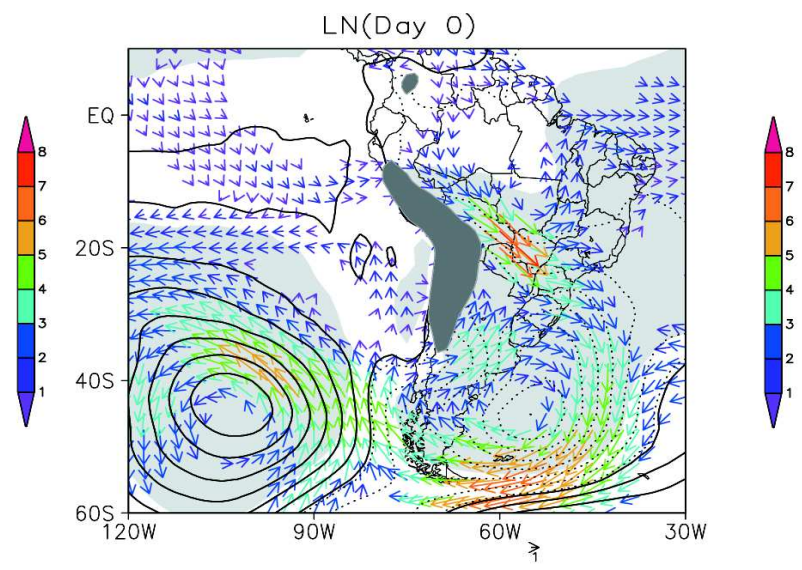

(e)

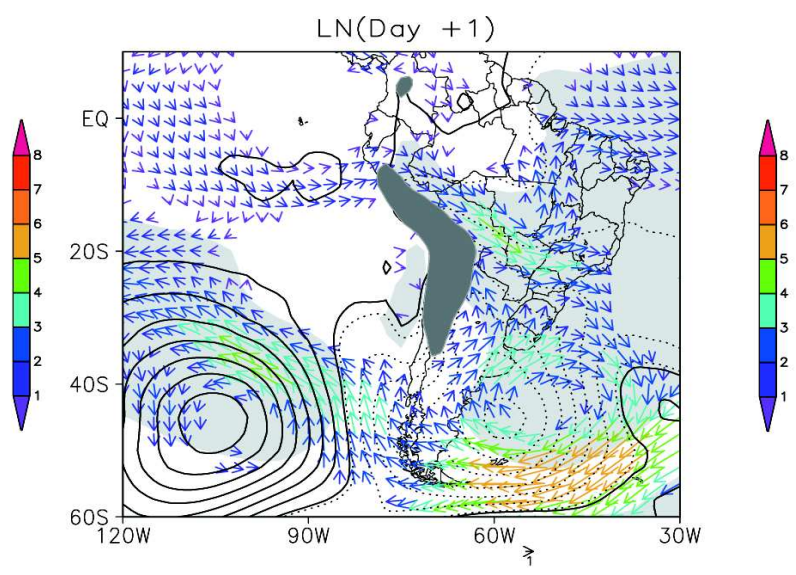

(f)

Fig. 6. Same as Fig. 4 but for the $850 \mathrm{hPa}$ wind and SLP anomalies. Contour interval is $1 \mathrm{hPa}$. Negative contours are dashed and the zero contours are omitted. A reference vector of $1 \mathrm{~m} \mathrm{~s}^{-1}$ is shown at the lower right-hand side of each panel. The vector wind plotted and areas where anomalies are statistically significant at the $95 \%$ level are shaded in gray. 
possibly associated to the zonally oriented high-low pressure configuration in mid-latitudes that configure a cyclonic transient centered at $45^{\circ} \mathrm{S} ; 60^{\circ} \mathrm{W}$. The wind magnitude on the core of SALLJ is up to $5 \mathrm{~m} \mathrm{~s}^{-1}$ and its exit is positioned over the central SA, not affecting the South of Brazil and Northern Argentina as observed in Fig. 6a. Despite of the importance of the Andes Mountain to channel the flow towards southeast of continent and the northern tropical Atlantic trade winds to trigger the whole process, Fig. 6d also suggests that the most important wind component (statistically significant) comes from the north Tropical Atlantic.

The zonally oriented high-low pressure configuration observed in mid-latitudes is intensified at day 0 when the SALLJ reaches around $7 \mathrm{~m} \mathrm{~s}^{-1}$ in the core (Fig. 6e). The stronger southwesterly flow over the southern sector of the continent due the gradient among the high-low pressure mentioned above maintain the SALLJ exit slightly positioned to the north when compared to Fig. 6b. These features are also very similar to those shown by Garreaud and Wallace (1998) and Mendes et al. (2007) related to the peaking at the time of extratropical cyclogeneses over SA during austral season. It creates a confluence region around $25^{\circ} \mathrm{S} ; 58^{\circ} \mathrm{W}$ that can contribute with advection of warm air from the north by the SALLJ and cold advection from the south due to the cyclone position near the east coast of Argentina. This configuration generates an increase in conditional instability and therefore enhanced precipitation over the region that can explain the more intense positive anomalies over La Plata basin observed in Fig. 3b. In the day after, the high-low pressure structure decays, the cyclone slightly moves to the east over the South Atlantic, the intensity of the SALLJ decreases and the southerly flow acquires a more meridional component (Fig. 6f). Compared to the EN composites, the SALLJ in this case is less intense (about $7 \mathrm{~m} \mathrm{~s}^{-1}$ in its core) and its exit is slightly positioned to the north due the absence of the high pressure and inversion of the trade winds. The configuration of southwesterly flux in mid-latitudes mentioned above was also observed in Fig. $6 \mathrm{~b}$ but weaker and with less statistic significance. The low level wind and SLP anomalies mainly observed at day 0 of $\mathrm{LN}$ years have a similar structure in mid-latitudes when compared to the Fig. 1f.

In general, it was observed that significant differences in frequency, amplitude and positioning of SALLJ depend on the ENSO phase. The frequency of normal to above normal in SALLJ cases during EN events and of normal to below normal during $\mathrm{LN}$ events can be explain by the differences in low level atmospheric circulation anomalies forced by the different high level wave pattern. This is agreement with results of Magaña and Ambrizzi (2005) that had already indicated that depending on the phase and trajectory followed by the wave generated on the tropical heating forcing during ENOS events the impact on the regional precipitation over the continent can be quite different. In the present study it was observed that this feature have impact on the daily evolution of the SALLJ follow by changes on the SLP anomaly over mid-latitudes. Also, the extratropical transients in SALLJ composites during LN years are more displaced to the south and more intense when compared to EN years. This is in accordance with Solman and Menéndez (2002) and Beu and Ambrizzi (2006) results who analyzed seasonal extratropical cyclones trajectories over the Southern Hemisphere during ENSO years.

\section{Summary and discussion}

The goal of this study was to investigate if EN and LN events can really affect the frequency, intensity, position and rainfall associated with the SALLJ cases during austral summer. Seasonal composites anomalies from EN and LN of atmospheric circulation variables and daily SALLJ composite anomalies were analyzed.

The differences on the phase and position of the quasistationary waves over the SA generated by the tropical heating source seem to affect the daily evolution of the SALLJ. With regard the ENSO-related circulations anomalies it was noted that during EN years the regional circulation anomalies over SA shows an intensification of the $\mathrm{SJ}$ around $30^{\circ} \mathrm{S}$ and the positive SLP anomalies over the western equatorial Atlantic and tropical SA helped to intensify the northeasterly trade winds over northern continent which were channeled by the Andes Mountain to the southeast region where negative SLP are found. It should be mentioned that a criterion was applied to identify what portion of this northwesterly flow east of the Andes is really related to the SALLJ circulation.

However, during LN years cyclonic anomalies prevailed at high level over the tropics associated to the cyclonic center over $40^{\circ} \mathrm{W}-30^{\circ} \mathrm{S}$ that contributes to the intensification of SJ though it is weaker than in EN years. The barotropic structured observed in this case also help to intensify the low level southerly winds over the subtropical SA. This favors the southerly transport of moist air to the east of the Andes and weakening the northwesterly flow east of the Andes.

The Bonner criterion 1 was applied to the NCEP reanalysis for the period 1977-2004 to identify the SALLJ episodes during austral summer period. It was found that the EN (LN) years tend to present normal to above-normal (below-normal) SALLJ frequency. The precipitation anomalies showed positive values over the La Plata Basin in both cases, but more intense during $\mathrm{LN}$ years. The daily evolution of the atmospheric circulation anomalies during the SALLJ maximum for EN and LN events were constructed and compared to the ENSO-related seasonal anomalies to explain the differences in the SALLJ frequency and rainfall anomalies associated.

In order to clarify the results found in the analysis, a conceptual diagram was constructed (Fig. 7) suggesting a possible physical mechanism to explain the modulation of the SALLJ by ENSO during austral summer. Figure 7 a for the 

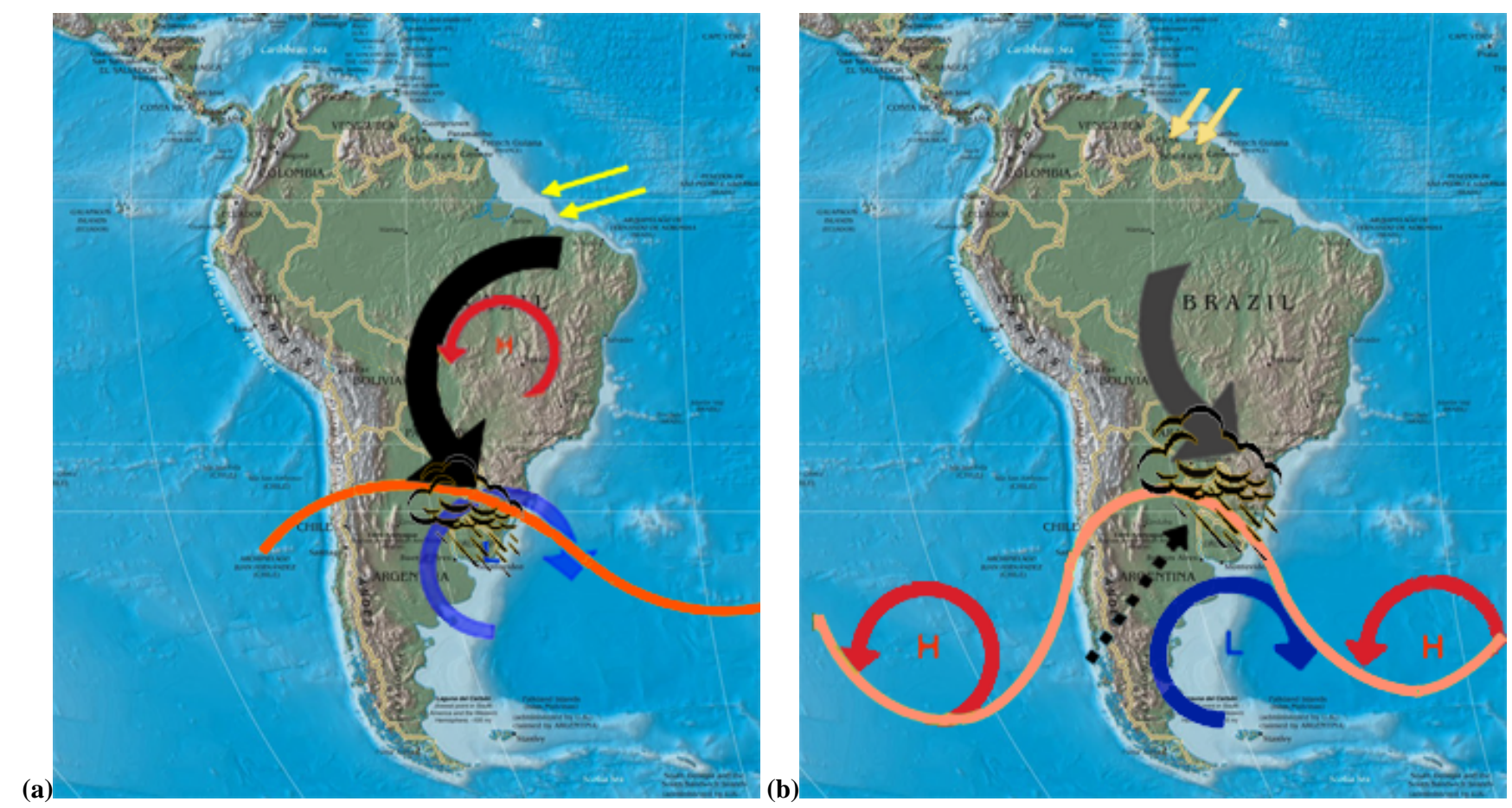

Fig. 7. Conceptual diagram on the physical mechanisms that may modulate the spatial and temporal variability of the SALLJ during the austral summer of (a) El Niño and (b) La Niña events. The yellow and black arrows indicate the trade winds and the SALLJ circulation that are more intense (darker arrow) in (a) than in (b). The $\mathrm{H}$ (red narrow) and the L (blue arrow) represents high and low pressures at $850 \mathrm{hPa}$. In (b) the dotted black arrow indicates the southerly flow associated with the high and low pressures at $850 \mathrm{hPa}$. The orange line shows the $\mathrm{SJ}$ at $200 \mathrm{hPa}$ where the dark color in (a) indicates a much stronger intensity than in (b). The cloud represents the main precipitation region.

SALLJ cases detected during EN years indicates that the northeasterly trade winds are intensified (yellow dark arrows), enter through the eastern equatorial part of the continent and are channeled by the Andes Mountain toward La Plata Basin due the anticyclonic anomalies over central Brazil (red dark arrow). The large baroclinicity of the basic flow associated with the intensification of the SJ (orange dark line) over the continent around $30^{\circ} \mathrm{S}$ is important to maintain the SALLJ (black dark arrow). Convergence (divergence) regions at low levels, caused by divergence (convergence) mass pattern on the equatorial (polar) side of the jet entrance and polar (equatorial) side of the jet exit produce negative (positive) SLP tendency. This negative tendency (blue clear arrow) increases the isallobaric wind component of the SALLJ. All these conditions contribute to the development of positive rainfall anomalies over La Plata Basin as observed in Fig. 3a and above-normal frequency of SALLJ episodes.

For the SALLJ cases detected during LN years (Fig. 7b) it was observed that the negative SLP anomalies over the tropical SA contributes to the inversion of the northeasterly trade winds into the continent and consequently SALLJ cases becomes weaker and less frequent than in EN years. There is a weak but significant contribution of the flow coming from the northern tropical Atlantic (yellow clear arrows) on the
SALLJ genesis. At mid-latitudes an equivalent barotropic environment modulates the SALLJ magnitude. A southerly flow anomaly (dotted black arrow) is generated as a result of the geostrophic balance between an anomalous southeast Pacific high (red dark arrow) and a cyclone over southeast South America (blue dark arrow). This configuration generates a cold air advection which encounters the warm northwesterly flow associated to the SALLJ (black clear arrow) which may explain the larger rainfall anomalies, particularly over Southern Brazil (Fig. 3b) when compared to the EN cases.

The interaction between the SALLJ and transient activity seem to be more pronounced during LN years, probably because the increase on the transient activity over midlatitude during this period which is in agreement with previous studies (Solman and Menéndez, 2002; Beu and Ambrizzi, 2006). This configuration helps to intensify the precipitation over the La Plata Basin though the subtropical jet is less intense when compared to the warm ENSO phase.

The regional atmospheric circulation observed in daily SALLJ anomalies composites during EN and LN years resembles that observed in the seasonal anomalies composites. This result suggests that the moisture transported by the SALLJ, besides the climatological flow due to the 
relationship among Amazon Basin - Andes Mountain Brazilian Plateau - La Plata Basin, appears to depend also on the large-scale patterns of the atmospheric circulation generated during ENSO. Of course, one should notice that in daily composites the northwesterly flow related to the SALLJ is more evident than that obtained from the seasonal anomalies composites because a specific criterion to select the events was applied. Future work is still needed to understand how different scale forcings modulate the SALLJ variability.

Acknowledgements. We thank to the editor and the constructive comments of the anonymous reviewers. We also thank to Brant Liebmann and Dave Allured for providing rainfall data and the Climate Prediction Center (CPC/NCEP/NWS) for providing the reanalysis. This work was supported by Fundação de Amparo à Pesquisa do Estado de São Paulo (FAPESP 01/13816-1 and 05/01804-0). TA acknowledges the partial support from the Inter American Institute for Global Change Research (IAI/CRN055), CNPq, CAPES and the EU CLARIS project.

Topical Editor F. D'Andrea thanks three anonymous referees for their help in evaluating this paper.

\section{References}

Beu, C. M. L. and Ambrizzi, T.: Interannual and interseasonal variability of Southern Hemisphere cyclone frequency (in Portuguese), Brazilian J. Meteorol., 21(1), 44-55, 2006.

Berbery, E. H. and Barros, V. R.: The hydrological cycle of the La Plata basin in South America, J. Hydrometerol., 3, 630-645, 2002.

Bonner, W. D.: Climatology of the Low Level Jet, Mon. Weather Rev., 96, 833-850, 1968.

Campetella, C. and Vera, C.: The influence of the Andes Mountains on the South American low-level flow, Geophys. Res. Lett., 29(17), 1826, doi:10.1029/2002GL015451, 2002.

Douglas, M. W., Peña, M., and Villarpando, R.: Special observations of the low level flow over eastern Bolivia during the 1999 atmospheric mesoscale campaign, in: Extended Abstracts of the 6th International Conference on Southern Hemisphere Meteorology and Oceanography. Santiago, Chile, 2000.

Garreaud, R. D. and Wallace, J. M.: Summertime incursions of midlatitude air into subtropical and tropical South America, Mon. Weather Rev., 126, 2713-2733, 1998.

Guedes, R. L. and Silva Dias, M. A. F.: The observed synoptic scale structure in the presence of mesoscale convective complexes over South America, in: 2nd Meeting of the Brazil-USA Cooperative Program on the Role of Convection in the Amazon Region, São José dos Campos, Brazil, 1985.

Harrison, D. E. and Larkin, N. K.: El Niño-Southern Oscillation sea surface temperature and wind anomalies, 1946-1993, Rev.Geophys, 36(3), 353-399, 1998.

Lau, K. M. and Zhou, H.: Anomalies of the South American summer monsoon associated with the 1997-99 El Niño-Southern Oscillation, Int. J. Climatol., 23, 529-539, 2003.

Liebmann, B., Kiladis, G. N., Marengo, J. A., Ambrizzi, T., and Glick, J. D.: Submonthly convective variability over South America and the south Atlantic convergence zone, J. Climate, 12, 1877-1891, 1999.
Liebmann, B., Kiladis, G. N., Vera, C. S., Saulo, A. C., and Carvalho, L. M. V.: Subseasonal variations of rainfall in South America in the vicinity of the low-level jet east of the Andes and comparison to those in the South Atlantic convergence zone, J. Climate, 17(19), 3829-3842, 2004.

Liebmann, B. and Allured, D.: Daily precipitation grids for South America, B. Am. Meteorol. Soc., 86, 1567-1570, 2005.

Kalnay, E., Kanamitsu, M., Kistler, R., Collins, W., Deaven, D., Gandin, L., Iredell, M., Saha, S., White, G., Woollen, J., Zhu, Y., Chelliah, M., Ebisuzaki, W., Higgins, W., Janoviak, J., Mo, K. C., Ropelewski, C., Wang, J., Leetmaa, A., Reynolds, R., Roy, J., and Joseph, D.: The NCEP/NCAR 40-year Reanalysis Project, B. Am. Meteorol. Soc., 77(3), 437-471, 1996.

Karoly, D. J.: Southern Hemisphere circulation features associated with El Niño - Southern Oscillation events, J. Climate, 2, 12391252, 1989.

Magaña, V. and Ambrizzi, T.: Dynamics of subtropical vertical motions over the Americas during El Niño boreal winters, Atmosfera, 18(4), 211-233, 2005.

Marengo, J. A., Douglas, M., and Silva Dias, P.: The South American low-level jet east of the Andes during the 1999 LBA-TRMM and LBA-WET AMC campaign, J. Geophys. Res., 107, 8079, doi:10.1029/2001JD001188, 2002.

Marengo, J. A., Soares, W. R., Saulo, C., and Nicolini, M.: Climatology of the Low-Level Jet east of the Andes as derived from the NCEP reanalyzes, J. Climate, 17, 2261-2280, 2004.

Mendes, D., Souza, E. P., Trigo, I. F., and Miranda, P. M. A.: On precursors of South American cyclogenesis, Tellus A, 59(1), 114-121, doi:10.1111/j.1600-0870.2006.00215.x, 2007.

Mo, K. C. and Paegle, J. N.: The Pacific-South American modes and their downstream effects, Int. J. Climatol., 21, 1211-1229, 2001.

Nicolini, M., Saulo, C., Torres, J. C., and Salio, P.: Strong South American low-level jet events characterization during warm season and implications for enhanced precipitation, Meteorologica, 27(1, 2), 59-69, 2002.

Nieto, F. R., Rickenbach, T. M., Herdies, D. L., and Carvalho, L. M. V.: Variability of South American convective cloud systems and tropospheric circulation during January-March 1998 and 1999, Mon. Weather Rev., 131, 961-973, 2003.

Nogués-Peagle, J. and Mo, K. C.: Alternating wet and dry conditions over South America during summer, Mon. Weather Rev., 125(2), 279-291, 1997.

Paegle, J.: A comparative review of South American low level jets, Meteorologica, 3, 73-82, 1998.

Saulo, A. C. and Nicolini, M.: The atmospheric conditions preceding the ocurrence of strong low level jets east of the Andes during January 1998, in: 6th International Conference on Southern Hemisphere Meteorology and Oceanography, Chile, 2000.

Saulo, C., Nicolini, M., and Chou, S. C.: Model characterization of the South American lowlevel flow during the 1997-98 springsummer season, Clim. Dynam., 16, 867-881, 2000.

Silva Dias, P. L.: The role of latent heat release in the dynamics of the LLJ's along the Andes, in: 6th International Conference on Southern Hemisphere Meteorology and Oceanography. Santiago, Chile, 2000.

Silva Dias, M., Silva Dias, P., Rutledge, S., Lima, M. A., Gomes, A., Antonio, M., Fisch, G., and Rocha, H.: Case study of multiple convective lines during the WET AMC/LBA and 
TRMM/Brazil, J. Geophys. Res., 107, 39.1-39.20, 2002.

Silva, G. A. M. and Ambrizzi, T.: Inter-El Niño variability and its impact on the South American low-level jet east of the Andes during austral summer - two case studies, Adv. Geosci., 6, 283287, 2006,

http://www.adv-geosci.net/6/283/2006/.

Solman, A. S. and Menéndez, C. G.: ENSO-Related Variability of the Southern Hemisphere Winter Storm Track over the Eastern Pacific-Atlantic Sector, J. Atmos. Sci., 59, 2128-2140, 2002.

Sugahara, S., Rocha, R. P., and Rodrigues, M. L.: Condições atmosféricas de grande escala associadas a jato de baixos níveis na América do Sul, in: VIII Brazilian Congress of Meteorology, 2, 573-577, 1994 (in Portuguese).
Uccellini, L. W. and Johnson, D. R.: The coupling of upper and lower tropospheric jet streaks and implications for the development of severe convective storms, Mon. Weather Rev., 107, 682703, 1979.

Vera, C., Higgins, W., Amador, J., Ambrizzi, T., Garreaud, R., Gochis, D., Gutzler, D., Lettenmaier, D., Marengo, J. A., Mechoso, C. R., Nogués-Paegle, J., Silva Dias, P. L., and Zhang, C.: Towards a unified view of the American Monsoon systems, J. Climate, 19, 4977-5000, 2006.

Vera, C., Vigliarolo, P. K., and Berbery, E. H.: Cold season synoptic scale waves over subtropical South America, Mon. Weather Rev., 130, 684-699, 2002.

Zhang, Y., Wallace J., and Battisti, D.: ENSO-like decade-tocentury scale variability: 1900-93, J. Climate, 10, 1004-1020, 1997. 


\section{APÊNDICE 2}

Cópia do trabalho Silva e Ambrizzi (2008) 


\title{
OSCILAÇÃO DECADAL DO PACÍFICO E VARIALIBIDADE DO JATO DE BAIXOS NÍVEIS A LESTE DOS ANDES DURANTE EVENTOS EL NIÑOS
}

\author{
Gyrlene Aparecida Mendes da Silva ${ }^{1}$ e Tércio Ambrizzi² \\ ${ }^{1,2}$ Instituto de Astronomia, Geofísica e Ciências Atmosféricas da Universidade de São Paulo. Rua do Matão, 1226 - \\ Cidade Universitária, São Paulo / SP - Brasil - 05508-900. gyrlene@ @odel.iag.usp.br; ambrizzi@ model.iag.usp.br
}

\begin{abstract}
RESUMO: Durante o verão austral foram detectados 98 casos de Jato de Baixos Níveis (JBN) em 6 eventos El Niños (EN) na fase fria da Oscilação Decadal do Pacífico (ODP(-)), e 223 casos em 10 eventos EN na fase quente $(\mathrm{ODP}(+))$. A anomalia mais intensa do Jato Subtropical em torno de $30^{\circ} \mathrm{S}$ a leste do continente e aceleração geostrófica dos ventos de norte na região subtropical contribuíram para casos de JBN mais intensos durante os eventos EN da ODP(-). Estes padrões anômalos estiveram associados a maior disponibilidade de água precipitável na região da Bacia do Prata, quando comparado com os casos da $\operatorname{ODP}(+)$.
\end{abstract}

ABSTRACT: During the austral summer 98 cases of SALLJ (South American Low Level Jet) were detected in 6 El Niños (EN) years on the PDO(-) (cold Pacific Decadal Oscillation phase), and 223 cases in 10 EN events on the $\mathrm{PDO}(+)$ (warm PDO phase). The most intense anomaly of the Subtropical Jet around $30^{\circ} \mathrm{S}$ on the eastward part of the continent and the geostrophic acceleration of the northern winds on the subtropics contributed to the most intense SALLJ cases during the EN events on the PDO(-). These anomalous pattern were associated to the most availability of precipitable water content on La Plata Basin region, when compared to the $\mathrm{PDO}(+)$.

PALAVRAS-CHAVE: Jato de Baixos Níveis a leste dos Andes, Oscilação Decadal do Pacífico, El Niño

\section{INTRODUÇÃO}

Durante as décadas de 1980 e 1990 estudos de casos como o de INZUNZA \& BERRI (1980) baseado em observações de radiossodagem sobre a América do Sul, identificaram uma região de ventos máximos próximo à superfície direcionada dos trópicos para médias latitudes a leste dos Andes. Esse escoamento foi denominado de Jato de Baixos Níveis a leste dos Andes, aqui chamado de JBN. O sistema aparece ao longo do ano, sendo o responsável pelo transporte de umidade do Atlântico Norte e Bacia Amazônica até o Sudeste/Sul do Brasil, Paraguai e Argentina. É durante o verão que esse transporte parece ser mais intenso (SILVA DIAS, 2000; MARENGO et al., 2004).

Entretanto existem poucos estudos a respeito da variabilidade interanual e interdecadal do JBN. NIETO FERREIRA et al. (2003) verificaram casos de JBN mais intensos e freqüentes durante o evento El Niño de 1997/98 quando comparado com o evento de La Niña de 1999/2000. MARENGO et al. (2004) sugerem ainda que $20 \%$ da variabilidade do JBN pode ser explicada pelas anomalias de temperatura de superfície do mar do oceano Pacífico Tropical; sobre o Atlântico as correlações foram mostraram-se bem mais fracas. SILVA (2005) verificou que durante o estágio de maturidade da fase quente do El NiñoOscilação Sul (ENOS) os episódios de JBN ocorreram em uma freqüência de normal a acima da normal climatológica. Já durante a fase fria o fenômeno ocorreu com frequiência de normal à abaixo da média. Em escala interdecadal, MARENGO et al. (2004) detectaram um aumento na freqüência do fenômeno a partir de meados da década de 70, associado à mudança de fase da Oscilação Decadal do Pacífico (ODP). Baseado nas incertezas que ainda existe sobre a variabilidade interanual e interdecadal do JBN, o presente estudo visa caracterizar as diferenças no comportamento dos casos de JBN detectados em anos de El Ninõs ocorridos em duas fases distintas da ODP.

\section{DADOS E METODOLOGIA}


As reanálises do NCEP (KALNAY et al., 1996) representam de maneira satisfatória condições atmosféricas de grande escala associadas ao JBN (MARENGO et al., 2004; SILVA \& AMBRIZZI, 2006 e referências). As variáveis meteorológicas foram selecionadas em horários sinóticos $(0000,0600,1200$ e 1800 UTC) para o período de verão austral de 1950 a 2000 com espaçamento de 2,5 de grade: conteúdo de água precipitável, altura geopotencial em $500 \mathrm{hPa}$, ventos zonal (u) e meridional (v) de 1000-200 hPa, Pressão ao Nível Médio do Mar (PNMM). Adicionalmente utilizou-se a variável função de corrente $(\psi)$ no nível sigma de 0.21 (correspondente a $200 \mathrm{hPa}$ ). Os eventos El Niños classificados por ZHOU et al. (2001) foram separados de acordo com as fases fria e quente da ODP (MANTUA et al., 1997) e a partir desta secção serão usadas as siglas ODP(-) e ODP(+) como referência as mesmas, respectivamente. A distribuição obtida de eventos El Niño foi: durante a ODP(-), 1952/53, 1957/58, 1958/59, 1963/64, 1969/70, 1972/73; durante a ODP(+), 1976/77, 1977/78, 1979/1980, 1982/83, 1987/88, 1990/91, 1991/92, 1992/93, 1994/95, 1997/98.

Os casos de JBN foram definidos de acordo com a metodologia de alguns estudos como os de MARENGO et al. (2004) e SILVA \& AMBRIZZI (2006). Desta forma assumiu-se que o núcleo do jato estaria posicionado na região de Santa Cruz na Bolívia $\left(17.75^{\circ} \mathrm{S} ; 63.06^{\circ} \mathrm{W}\right)$ no nível de $850 \mathrm{hPa}$. Apenas os casos onde a componente (v) era negativa foram selecionados. Aplicou-se o critério 1 de Bonner (BONNER, 1968) adaptado para a América do Sul nos campos de ventos (u,v) com base nas seguintes condições: a magnitude do vetor vento em torno de $850 \mathrm{hPa}$ deve ser maior ou igual a $12 \mathrm{~m} . \mathrm{s}^{-1}$ e deve apresentar cisalhamento vertical de pelo menos $6 \mathrm{~m} . \mathrm{s}^{-1}$ entre os níveis de $850-700 \mathrm{hPa}$.

Composições de anomalias das variáveis meteorológicas para análise dos padrões de circulação de verão nos dias de atuação de JBN em anos de El Niño para ambas as fases da ODP foram calculadas. As anomalias foram extraídas da climatologia dos anos neutros no Pacífico Equatorial nos 50 anos de dados selecionados. Os resultados a seguir mostrarão as diferenças entre as composições de anomalias da ODP(+) menos as da ODP(-). A significância estatística das anomalias foi obtida através do teste t-Student bi-caudal (HARRISON \& LARKIN, 1998) sendo aceitas com nível de confiabilidade de 95\%.

\section{RESULTADOS}

Do total de ocorrências de JBN detectados com a aplicação do critério 1 de Bonner, 98 casos ocorreram durante os 6 eventos El Niños selecionados na ODP(-), e 223 casos ocorreram durante os 10 eventos El Niños selecionados na ODP(+). As composições de anomalias das variáveis atmosféricas durante os dias de ocorrência de JBN para o verão austral de anos de El Niño na ODP(-) são ilustradas na Figura 1. A Figura 1a está relacionada ao conteúdo de água precipitável que é uma importante medida do teor de vapor d'água atmosférico, indicando a disponibilidade desse para se converter em precipitação. Anomalias positivas e significativas de água precipitável são observadas na parte sul das regiões Centro-oeste e Sudeste, e região Sul do Brasil, Bolívia, Paraguai, nordeste da Argentina e Uruguai indicando alto teor de umidade na coluna troposférica sobre essas regiões que compõem a Bacia do Prata. Sobre o centro-norte do Brasil predominam anomalias negativas estatisticamente significativas da variável.

A Figura $1 \mathrm{~b}$ referente ao campo de $\psi(200 \mathrm{hPa})$ com média zonal removida mostra as características de circulação em altos níveis associada ao padrão anômalo da Figura 1a. É possível observar um intenso trem de ondas de Rossby emanando do Pacífico Equatorial Central em direção aos extratrópicos em resposta à fonte de calor anômala tropical associada aos eventos El Niños. Esse trem é referenciado como PacíficoAmérica do Sul (sigla em inglês, PSA; MO, 2000) e ao chegar à América do Sul via extratrópicos altera o clima sobre o continente. Associado ao padrão de onda PSA, sobre a parte sul das regiões Centro-oeste e Sudeste, e região Sul do Brasil, nordeste da Argentina e Uruguai, configura-se um centro anticiclônico e a sudoeste desse uma anomalia ciclônica. O padrão favorece a intensificação do Jato Subtropical (JST) em torno de $30^{\circ} \mathrm{S}$ a leste do continente e oceano adjacente. Sobre o setor tropical oeste da América do Sul, a circulação ciclônica anômala indica que pode ocorrer um enfraquecimento da circulação de Alta da Bolívia em dias de JBN durante os verões de anos de El Niños na fase fria da ODP. De fato, um enfraquecimento da circulação de Alta da Bolívia pode estar associado às anomalias negativas de água precipitável observadas na Figura 1a. Em $500 \mathrm{hPa}$ a configuração zonalmente simétrica de altura geopotencial com anomalias positivas sobre trópicos do continente e negativas centradas em $50^{\circ} \mathrm{S} ; 60^{\circ} \mathrm{W}$, favorece a intensificação dos ventos de oeste sobre $30^{\circ} \mathrm{S}$ a leste do continente e Atlântico Sudoeste (Figura 1c).

A Figura 1d ilustra a composição de anomalia do vento em $850 \mathrm{hPa}$ e PNMM. É possível notar a predominância de uma alta pressão anômala sobre o centro-leste do Brasil entre $20^{\circ} \mathrm{S}$ e $5^{\circ} \mathrm{N}$ e oceano adjacente associada à circulação ciclônica em $200 \mathrm{hPa}$ sobre o Brasil central observada na Figura $1 \mathrm{~b}$. O padrão é semelhante ao encontrado por DRUMOND \& AMBRIZZI (2005), porém deslocado de fase. Os 
autores sugerem que o mesmo está associado à redução na atividade convectiva da ZCAS e aumento da precipitação na região Sul do Brasil, o que é consistente com o padrão de conteúdo água precipitável observado na Figura 1a. A leste dos Andes uma baixa pressão anômala devido ao ciclone transiente, centrado em $50^{\circ} \mathrm{S} ; 50^{\circ} \mathrm{W}$ sobre o Atlântico Sudoeste é observada. A característica de alongamento na escala meridional do sistema de baixa pressão ao cruzar os Andes foi observada por GAN \& RAO (1994), indicando um padrão de ciclogênese a sotavento dos Andes. O intenso gradiente de pressão leste-oeste entre os sistemas anômalos de alta e baixa pressão citados anteriormente favorece o giro anticiclônico e aceleração geostrófica dos ventos de norte na região subtropical. O escoamento associado ao JBN anômalo adquire um alongamento desde a Amazônia até o Sul do Brasil e nordeste da Argentina, alcançando uma velocidade de aproximadamente $8 \mathrm{~m} \cdot \mathrm{s}^{-1}$ no seu eixo. A intensificação do JST em torno de $30^{\circ} \mathrm{S}$ a leste do continente citada anteriormente gera circulações secundárias indiretas na região de saída do escoamento contribuindo para aceleração do JBN, mecanismo este exemplificado em UCCELLINI \& JOHNSON (1979). Assim, ao atuarem conjuntamente esses sistemas atmosféricos anômalos proporcionaram o aumento do conteúdo de água precipitável na região da Bacia do Prata, como foi verificado na Figura 1a. O perfil vertical do vento meridional mostra que o JBN anômalo possui forte componente (v) negativa até níveis altos da troposfera e com intensidade máxima em $850 \mathrm{hPa}$ (Figura 1e).

A Figura 2 ilustra as diferenças entre as composições de anomalias atmosféricas entre os casos de JBN identificados em anos de El Niño na ODP(+) (Figura não mostrada) menos os casos da ODP(-) (Figura 1). Na Figura 2a sobre o centro-norte do Brasil são observadas diferenças significativas e positivas de água precipitável indicando que na $\mathrm{ODP}(+)$ as anomalias são positivas ao contrário do que foi observado ODP(-) (Figura 1a). Sobre a região da Bacia do Prata diferenças significativas e negativas são encontradas devido ao predomínio de anomalias positivas em ambas as fases, entretanto, na ODP(-) estas foram mais intensas. A Figura $2 \mathrm{~b}$ mostra que as diferenças encontradas com relação à propagação do trem de ondas em altos níveis podem ter influência na modulação dos casos de JBN detectados. Um anticiclone anômalo sobre os trópicos a oeste da América do Sul é decorrente de circulações opostas sobre a região. No sudeste do continente sul americano a anomalia positiva centrada em $30^{\circ} \mathrm{S} ; 40^{\circ} \mathrm{W}$ sugere que na ODP(-) há presença de uma circulação anticlônica mais intensa sobre a região do que na $\operatorname{ODP}(+)$. Adicionalmente, a anomalia negativa sobre o cone sul sugere que na ODP(-) existe uma circulação ciclônica mais intensa sobre a região quando comparado com a ODP(+). Conseqüentemente o escoamento de oeste, associado ao JST, mostrou-se mais intenso em $30^{\circ} \mathrm{S}$ a leste do continente e Atlântico Sudoeste nos casos de JBN ocorridos nos eventos El Niños durante a ODP(-). Essas diferenças são refletidas também na Figura 2c com o intenso gradiente de altura geopotencial em níveis médios sobre essa região.

Em baixos níveis (Figura 2d) destacam-se as diferenças no campo dos alísios sobre a região do Atlântico Equatorial em direção ao continente. Uma baixa pressão seguida de circulação ciclônica sobre centro-leste do Brasil entre $0^{\circ}$ e $20^{\circ} \mathrm{S}$ devido a padrões de PNMM opostos entre as duas fases da oscilação decadal é observada. Diferenças positivas de PNMM sobre o Paraguai, nordeste da Argentina e Sul do Brasil sugerem que houve uma maior queda de pressão devido ao ciclone transiente citado na Figura 1d relativo a ODP(-) ao cruzar os Andes, quando comparado com o sistema da ODP(+). Conseqüentemente houve favorecimento de casos de JBN mais intensos na ODP(-). O vetor vento no sentido sudeste-noroeste reforça a observação sugerindo significantes diferenças na intensidade dos jatos em baixos níveis entre as fases da ODP, entretanto poucas diferenças em relação ao posicionamento do sistema foram encontradas. Coerentemente as diferenças positivas no perfil de vento (v) em torno de $55^{\circ} \mathrm{W}$ mostram que nos eventos da ODP(-), essa componente é foi mais intensa.

\section{COMENTÁRIOS FINAIS}

Uma maior frequiência de casos de JBN foi encontrada durante os verões de anos de El Niño ocorridos na fase quente da ODP em relação à fase fria, tendo 223 e 98 casos, respectivamente. Entretanto, estas freqüências foram aproximadamente proporcionais às quantidades de eventos El Niños selecionados em cada fase, tendo sido 10 eventos na $\mathrm{ODP}(+)$ e 6 eventos na $\mathrm{ODP}(-)$. Foram encontradas diferenças estatisticamente significativas no campo de anomalia de conteúdo de água precipitável referente aos casos de JBN identificados em anos de El Niño relativo a ODP(+) menos os da ODP(-). Durante a ODP(-) anomalias negativas predominaram sobre a região centro-norte sendo esse padrão oposto ao encontrado na $\operatorname{ODP}(+)$. Sobre a região da Bacia do Prata predominaram anomalias positivas em ambas as fases, porém mais intensas na ODP(-). Não foi observada mudança significativa em relação ao posicionamento do JBN de uma fase para outra. De maneira geral o sistema deslocou-se desde a Amazônia até o Sul do Brasil e nordeste da Argentina. 
Entretanto foi durante a ODP(-) que os casos detectados mostraram-se mais intensos associados a diferentes padrões de circulação atmosférica em altos níveis sobre a parte tropical do continente. Nos subtrópicos a anomalia ciclônica em associação a um anticiclone em altos e médios níveis favoreceu a intensificação do JST em torno de $30^{\circ} \mathrm{S}$ em ambas fases da oscilação. Entretanto o gradiente mais intenso entre esses sistemas ocorreu durante os casos da ODP(-) em torno de $30^{\circ} \mathrm{S}$ a leste do continente e Atlântico Sudoeste o que favoreceu a intensificação dos ventos de oeste em altos níveis sobre a região. Um intenso gradiente de pressão em baixos níveis entre uma alta pressão anômala sobre o centro-leste do Brasil e um ciclone transiente à leste do Andes, favoreceu a aceleração geostrófica dos ventos de norte sobre os subtrópicos. $\mathrm{O}$ acoplamento entre esses sistemas atmosféricos e a intensificação dos ventos de oeste em altos níveis citado anteriormente podem ter fornecido suporte dinâmico para os casos de JBN terem sido mais intensos durante El Niños na ODP(-) quando comparado com os casos da ODP(+). Como conseqüência houve um maior aumento do conteúdo de água precipitável na região da Bacia do Prata o que se mostrou independente da disponibilidade de água precipitável sobre a região Amazônica.

AGRADECIMENTOS: Os autores agradecem à FAPESP (05/01804-0) pelo apoio financeiro da pesquisa. TA agradece também ao auxílio do CNPq e CAPES.

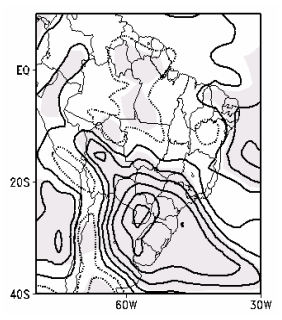

(a)

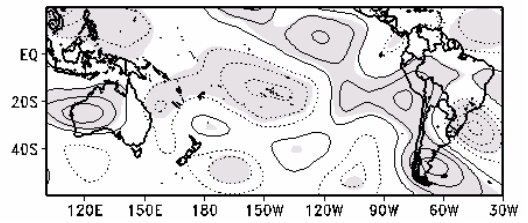

(b)

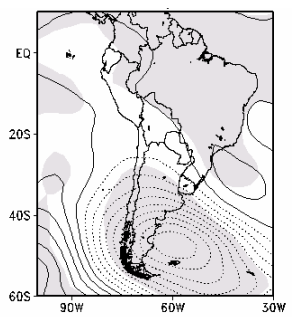

(c)
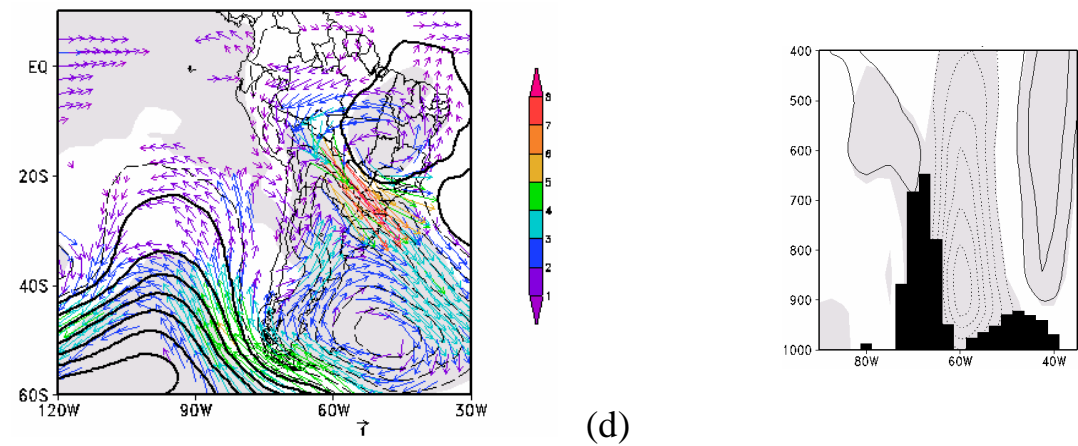

(e)

(d)

Figura 1: Composições de anomalias para os casos de JBN detectados em anos de EN durante a ODP(-):

(a) conteúdo de água precipitável; (b) $\psi(200 \mathrm{hPa}$ ) com média zonal removida; (c) altura geopotencial em 500 $\mathrm{hPa}$; (d) vento em $850 \mathrm{hPa}$ e PNMM; (e) perfil vertical do vento (v) em Santa Cruz. Isolinhas a cada 1 kg.m ${ }^{-2}$; $2 \mathrm{~m}^{2} . \mathrm{s}^{-1} ; 10 \mathrm{~m}, 1 \mathrm{hPa}$, respectivamente; e vetor vento a cada e $1 \mathrm{~m} \cdot \mathrm{s}^{-1}$. Anomalias de vento são plotadas ao nível de significância de 95\%. Para as demais variáveis as anomalias estatisticamente significativas ao nível de $95 \%$ estão sombreadas.

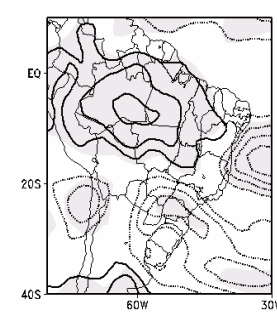

(a)

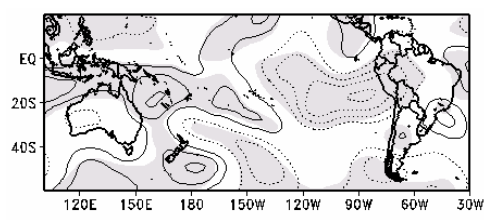

(b)

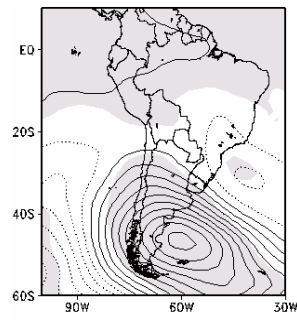

(c) 

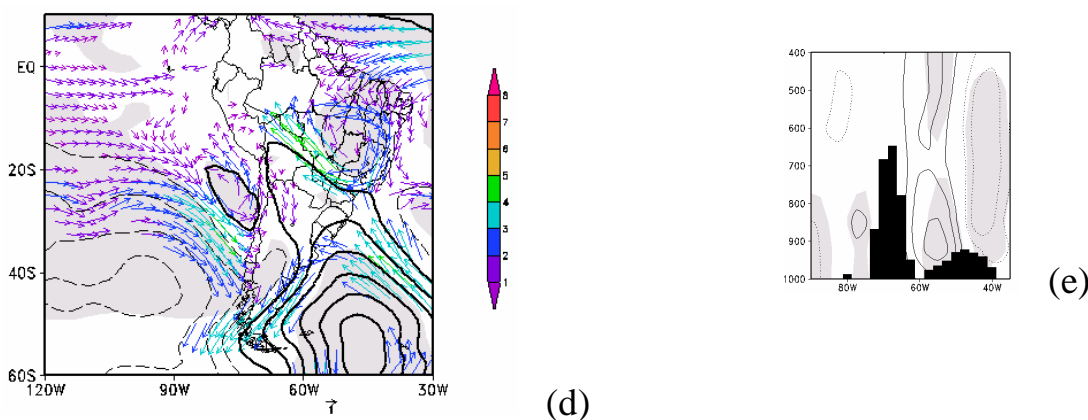

(d)

Figura 2: Diferença entre as composições de anomalias dos casos de JBN detectados em anos de El Niño durante a fase quente da ODP menos os casos da fase fria. Seqüência das figuras e significância estatística assim como na Figura 1.

\section{REFERÊNCIAS BIBLIOGRÁFICAS}

BONNER, W.D. Climatology of the Low Level Jet. Monthly Weather Review, 96, 833-50, 1968.

DRUMOND, A.R.M.; AMBRIZZI, T. The role of SST on the South American Atmospheric Circulation during January, February And March 2001. Climate Dynamics, 24, 781-791, 2005.

GAN, M.A.; RAO, V.B. The influence of the Andes Cordillera on transient disturbances. Monthly Weather Review, 122, 1141-1157, 1994.

HARRISON, D.E; LARKIN, N.K. El Niño-Southern Oscillation sea surface temperature and wind anomalies, 1946-1993. Review of Geophysics, 36(3), 353-399, 1998.

INZUNZA, B.J.; BERRI, G.J. Campo de Movimiento y transporte de humedad asociado en la baja tropos fera en el norte de Argentina. Meteorologica, 17, 17-25, 1980.

KALNAY, E.; KANAMITSU, M.; KISTLER, R.; COLLINS, W.; DEAVEN, D.; GANDIN, L.; IREDELL M.; SAHA, S.; WHITE, G.; WOOLLEN, J.; ZHU, Y.; CHELLIAH, M.; EBISUZAKI, W.; HIGGINS, W.; JANOVIAK, J.; MO, K.C.; ROPELEWSKI, C.; WANG, J.; LEETMAA, A.; REYNOLDS, R.; ROY, J.; JOSEPH, D. The NCEP/NCAR 40-year Reanalysis Project. Bulletin of the American Meteorological Society, 77(3), 437-471, 1996.

MANTUA, N.J.; HAREM, S.R.; ZHANG, Y.; WALLACE, J.M.; FRANCIS, R.C. A Pacific interdecadal climate oscillation with impacts on salmon production. Bull. Amer. Meteor. Soc., 78, 1069-1079, 1997.

MARENGO, J.A.; SOARES, W.R.; SAULO, C.; NICOLINI, M. Climatology of the Low-Level Jet east of the Andes as derived from the NCEP reanalyses. Journal of Climate, 17, 2261-2280, 2004.

MO, K.C. Relationships between low-frequency variability in the Southern Hemisphere and sea surface temperature anomalies. J. Climate, 13, 3599-3610, 2000.

NIETO FERREIRA, R.; RICKENBACH, T. M.; HERDIES DL, CARVALHO LMV. Variability of South American convective cloud systems and tropospheric circulation during January-March 1998 and 1999. Monthly Weather Review, 131, 961-973, 2003.

SILVA DIAS M.; SILVA DIAS P.; RUTLEDGE, S.; LIMA, M.A.; GOMES, A.; ANTONIO, M.; FISCH, G.; ROCHA, H. Case study of multiple convective lines during the WET AMC/LBA and TRMM/Brazil. Journal of Geophysical Research, 107, 39.1 - 39.20, 2002. 
SILVA, G.A.M. Variabilidade inter-El Niños e seu impacto no jato de baixos níveis a leste dos Andes durante o verão austral. São Paulo, 2005. 84p. Dissertação de Mestrado do Instituto Astronomia, Geofísica e Ciências Atmosféricas da Universidade de São Paulo.

SILVA, G.A.M.; AMBRIZZI, T. Inter-El Niño variability and its impact on the South American low-level jet east of the Andes during austral summer - two case studies. Advances in Geosciences, 6, 283-287, 2006. SRef-ID: 1680-7359/adgeo/2006-6-283

UCCELLINI, L. W.; JOHNSON, D. R. The coupling of upper and lower tropospheric jet streams and implications for the development of severe convective storms. Monthly Weather Review, v. 107, p. 682-703, 1979.

Zhou, Y.P.; Higgins R.W.; Kim H-K. Relationships between El Niño- Southern Oscillation and the Arctic Oscillation: A Climate- Weather Link. NCEP/Climate Prediction Center Atlas 8, 2001. Disponível em: <http://www.cpc.ncep.noaa.gov/products/outreach/atlas.html>. Acesso em: 9 fev. 2005. 